Aus dem Institut für Molekularbiologie

(Prof. Dr. rer. nat. B. Schwappach-Pignataro)

im Zentrum Biochemie und Molekulare Zellbiologie

der Medizinischen Fakultät der Universität Göttingen

\title{
Identifizierung von neuen Komponenten oder Cargoes der COPI-Vesikelhüll- Maschinerie
}

\author{
INAUGURAL-DISSERTATION \\ zur Erlangung des Doktorgrades \\ für Zahnmedizin \\ der Medizinischen Fakultät der \\ Georg-August-Universität zu Göttingen
}

vorgelegt von

Julia Franz (geb. Grundmeier)

aus

Gütersloh

Göttingen 2020 

Dekan:

\section{Betreuungsausschuss}

Betreuer/in

Ko-Betreuer/in:

\section{Prüfungskommission}

Referent/in:

Ko-Referent/in:

Drittreferent/in:
Prof. Dr. med. W. Brück

Prof. Dr. rer. nat. B. Schwappach

Prof. Dr. rer. nat. M. Thumm

Prof. Dr. rer. nat. B. Schwappach

Datum der mündlichen Prüfung: 
Hiermit erkläre ich, die Dissertation mit dem Titel "Identifizierung von neuen Komponenten oder Cargoes der COPI-Vesikelhüll-Maschinerie" eigenständig angefertigt und keine anderen als die von mir angegebenen Quellen und Hilfsmittel verwendet zu haben.

Göttingen, den 


\section{Inhaltsverzeichnis}

\begin{tabular}{ll|l} 
Abbildungsverzeichnis & III
\end{tabular}

$\begin{array}{lll}\text { Tabellenverzeichnis } & \text { IV }\end{array}$

$\begin{array}{lll}\text { Abkürzungsverzeichnis } & \text { V }\end{array}$

1 Einleitung 1

1.1 Kompartimente der eukaryontischen Zelle 1

1.1.1 Zytoplasma 2

1.1.2 Endosom 2

1.1.3 Endoplasmatisches Retikulum 2

1.1.4 Golgi-Apparat 3

1.1.5 Mitochondrium 3

1.1.6 Zellkern 3

1.1.7 Vakuole 4

1.1.8 Zellwand 4

1.1.9 Zytoskelett 4

1.2 Intrazellulärer Transport 4

1.2.1 Hüllvesikelproteine 5

1.3 COPI 6

1.3.1 Struktur 6

1.3.2 Funktion 8

1.4 Autophagie 8

1.5 Saccharomyces cerevisiae als Modellsystem 10

1.5.1 Mikroskopie von Hefezellen mit Hilfe einer SWAT-GFP-Bibliothek 12

1.6 Auswirkungen von Mutationen des COPI-Proteins aus biologischer und medizinischer Sicht 12

$1.7 \quad$ Fragestellung dieser Arbeit 13

2 Material und Methoden $\quad 15$

$\begin{array}{lll}2.1 & \text { Material } & 15\end{array}$

$\begin{array}{lll}\text { 2.1.1 Standardmedien und -puffer } & 15\end{array}$

2.1.2 Kits und andere Materialien 18

$\begin{array}{lll}2.1 .3 \text { Geräte } & 19\end{array}$

$\begin{array}{lll}2.1 .4 & \text { Enzyme } & 19\end{array}$

2.1.5 Antikörper 20

2.1.6 Hefestämme 21

2.1.7 Primer und Plasmide $\quad 21$

2.2 Methoden 23

2.2.1 DNA-Techniken 23

2.2.2 Biochemische Techniken 28 
$\begin{array}{lll}\text { 2.2.3 Experimente mit S. cerevisiae } & 30\end{array}$

3 Ergebnisse $\quad 34$

3.1 Herstellung eines Knockout-Stammes und einer isogenetischen Kontrolle 34

3.2 Auswabl eines Knockout-Stammes und einer isogenetischen Kontrolle 35

3.3 Untersuchung der Hitzesensibilität 38

3.4 SGA der SWAT-GFP Bibliothek mit dem Knockout-Stamm und der isogenetischen Kontrolle 41

3.5 Mikroskopie des SGAs 42

3.6 Untersuchung der Treffer 43

4 Diskussion $\quad 52$

$\begin{array}{llr}5 & \text { Zusammenfassung } & 68\end{array}$

$6 \quad$ Literaturverzeichnis $\quad \mathbf{7 0}$

6.1 Beiträge in Sammelwerken, Handbüchern, Lebrbüchern, Monographien und Zeitschriftenbeiträgen 70

$\begin{array}{ll}6.2 & \text { Internetquellen } \\ \end{array}$ 


\section{Abbildungsverzeichnis}

Abbildung 1: Schematische Darstellung der Zellkompartimente einer Hefezelle

Abbildung 2: Schematische Darstellung eines membranassoziierten Coatomers

Abbildung 3: Schematische Darstellung der JPred-Sekundärstrukturvorhersagen der $\delta$-COP-

Untereinheit

Abbildung 4: Schematische Darstellung der Herstellung eines Knockout-Stammes und einer isogenetischen Kontrolle

Abbildung 5: Western Blot der Knockout Stämme und der isogenetischen Kontrollen .36

Abbildung 6: Wachstumstest verschiedener Knockout Stämme und isogenetischer Kontrollen ....37

Abbildung 7: Wachstums-Analyse nach Überexpression der relevanten Ret2-Variante durch Plasmid-Transformation in die isogenetische Kontrolle bzw. den Knockout.

Abbildung 8: Western Blots nach Überexpression der relevanten Ret2-Variante durch PlasmidTransformation in die isogenetische Kontrolle bzw. den Knockout.....

Abbildung 9: SGA-Ablaufplan für Ret2LD2 $\alpha$ und Ret2Clonat zur Kreuzung mit der SWAT GFPBibliothek

Abbildung 10: Mikroskopie-Bilder der Proteine Fun14, Ubx3 und Get3 .......................................44

Abbildung 11: Mikroskopie-Bilder der Proteine Apm3, Atg8 und Emp 24.....................................45

Abbildung 12: Mikroskopie-Bilder der Proteine Ygr016w, Hrr25 und Mpd1 ...................................46

Abbildung 13: Western-Blot-Analyse von Ganzzell-Proteinextrakten der vorläufigen TrefferStämme mit den GFP-Fusionsproteinen von Fun14, Ubx3, Get3 und Apm3

Abbildung 14: Western Blot der vorläufigen Treffer-Stämme mit den GFP-Fusionsproteinen von Atg8 und Emp24

Abbildung 15: Western Blot der vorläufigen Treffer-Stämme mit den GFP-Fusionsproteinen von Ygr016w, Hrr25, Mpd1 und Jem1

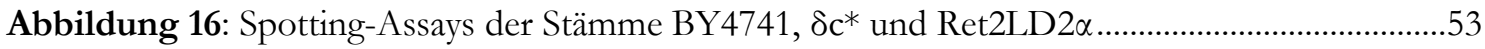

Abbildung 17: Finale Treffer und die Koregulation durch Transkriptionsregulatoren 


\section{Tabellenverzeichnis}

Tabelle 1: COPI-Untereinheiten des Homo sapiens und der S.cerevisiae (Gaynor et al. 1998) .......11

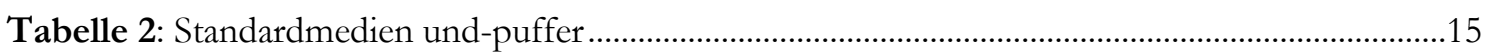

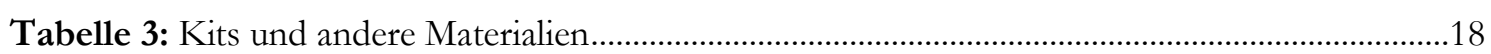

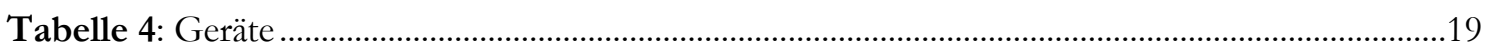

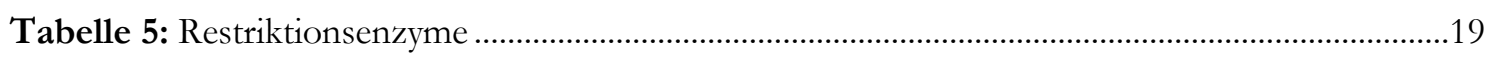

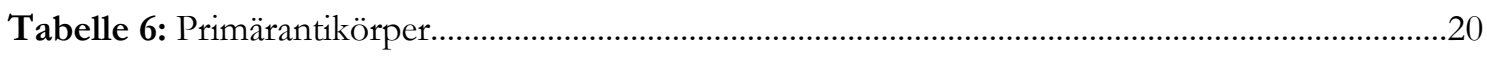

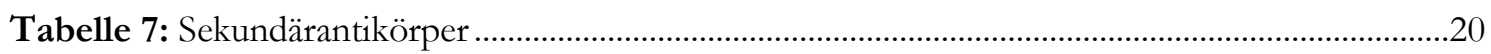

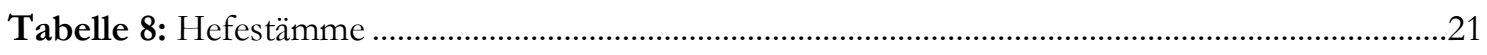

Tabelle 9: Primer zur Herstellung des Konstrukts .......................................................................21

Tabelle 10: Primer zur Vermehrung der Rekombinationskassette.........................................................22

Tabelle 11: Primer zum Einbringen der Klonat-Kassette nach dem Ret2-Stop-Codon ...................22

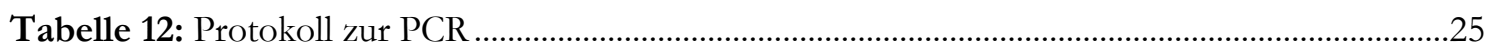

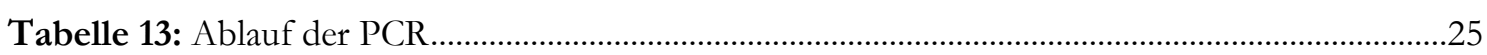

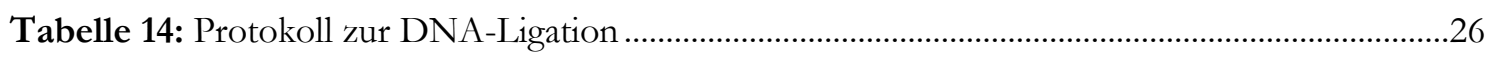

Tabelle 15: Protokoll zum zeitlichen Ablauf der Ligation...................................................................26

Tabelle 16: Protokoll zur Herstellung von Trenn- und Sammelgel .....................................................29

Tabelle 17: Die verwendeten Restriktionsenzyme und ihre jeweilige Erkennungssequenz...............34

Tabelle 18: Vorläufige Trefferliste der High-Throughput-Fluoreszenz-Mikroskopie ........................47

Tabelle 19: Finale Trefferliste der High-Throughput- Fluoreszenz-Mikroskopie................................55

Tabelle 20: Liste aller finalen Treffer, die untereinander eine genetische/physikalische Beziehung aufweisen

Tabelle 21: Liste der Proteine, die mit mehreren Treffern aus Tabelle 19 interagieren und in einer Beziehung zu COPI stehen

Tabelle 22: Liste der Proteine die mit mehreren Treffern aus Tabelle 19 interagieren und in einer Beziehung zur Autophagie stehen.... 


\section{Abkürzungsverzeichnis}

\begin{tabular}{|c|c|}
\hline$\alpha-\mathrm{COP}$ & Alpha-COP \\
\hline $\mathrm{ADP}$ & Adenosine Diphosphate \\
\hline ATP & Adenosine Triphosphate \\
\hline Arf1 & Adenosyl-Ribosylierungs-Faktor 1 \\
\hline$\beta-\mathrm{COP}$ & Beta-COP \\
\hline$\beta^{6}-\mathrm{COP}$ & Beta'-COP \\
\hline Bp & Basenpaar(e) \\
\hline BSA & Bovines Serumalbumin \\
\hline C- & Carboxy- \\
\hline CRP & C-reaktives Protein \\
\hline CVT & Cytoplasm-to-Vacuole Targeting \\
\hline ddNTP & Didesoxynukleosidtriphosphat \\
\hline$\delta-\mathrm{COP}$ & Delta-COP \\
\hline DNA & Desoxyribonukleinsäure \\
\hline DTT & Dithiothreitol \\
\hline$\varepsilon-\mathrm{COP}$ & Epsilon-COP \\
\hline EDTA & Ethylendiamintetraacetat \\
\hline ELISA & Enzyme-linked Immunosorbent Assay \\
\hline ER & Endoplasmatisches Retikulum \\
\hline$\gamma$-COP & Gamma-COP \\
\hline GAP & GTPase Activating Protein \\
\hline GEF & Guanine Nucleotide Exchange Factor \\
\hline GFP & Green Fluorescent Protein \\
\hline$\mu-\mathrm{HD}$ & Mu-Homologie-Domäne \\
\hline Nur17 & Neurological-17-Maus \\
\hline PI3K & Phosphatidylinositol-3-phosphat-Kinase \\
\hline RNA & Ribonukleinsäure \\
\hline rRNA & Ribosomale Ribonukleinsäure \\
\hline S. cerevisiae & Saccharomyces cerevisiae \\
\hline SGA & Synthetic Genetic Array \\
\hline SNARE & Soluble NSF Attachment Protein Receptor \\
\hline SWAT & Swap-Tag \\
\hline $\mathrm{tRNA}$ & Transfer-Ribonukleinsäure \\
\hline$\zeta-\mathrm{COP}$ & Zeta-COP \\
\hline
\end{tabular}




\section{$1 \quad$ Einleitung}

\subsection{Kompartimente der eukaryontischen Zelle}

Die eukaryontische Zelle umfasst eine Größe von 10-100 $\mu \mathrm{m}$ und setzt sich aus den einzelnen Organellen, die als voneinander abgegrenzte Kompartimente fungieren, zusammen. Die einzelnen Kompartimente werden unterschiedlichen Anforderungen und Rahmenbedingungen gerecht und können so diverse Prozesse in dichter räumlicher Nähe erfüllen. Da Entstehungs- und Wirkungsort von Proteinen und Lipiden häufig nicht übereinstimmen, ist ein stetiger Austausch der Kompartimente untereinander essentiell.

Abbildung 1 zeigt den Aufbau und die Aufteilung einer eukaryontischen Zelle mit ihren Kompartimenten.

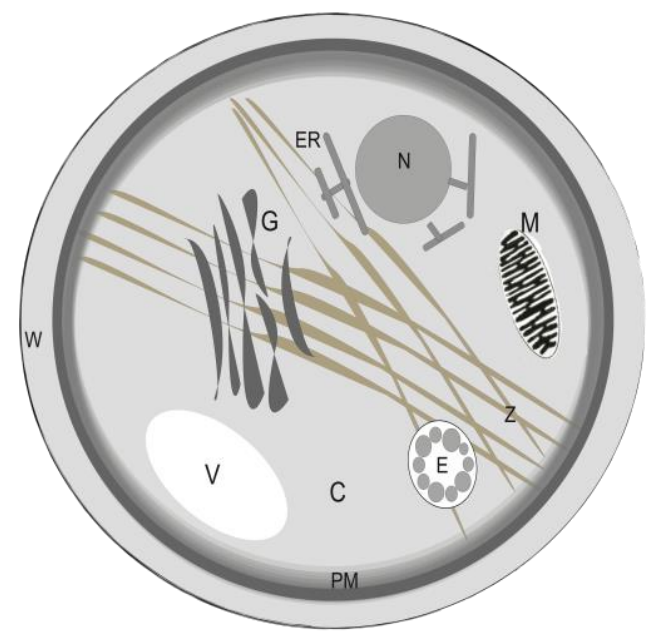

C: Cytosol

E: Endosom

ER: endoplasmatisches Retikulum

G: Golgi-Apparat

M: Mitochondrium

$\mathrm{N}$ : Zellkern

V: Vakuole

W: Zellwand

PM: Plasmamembran

Z: Zytoskelett

Abbildung 1: Schematische Darstellung der Zellkompartimente einer Hefezelle Eine Hefezelle ist ca. 6-12 $\mu \mathrm{m}$ lang und ca. 4-8 $\mu \mathrm{m}$ dick.

Wie anhand von Abbildung $1 \mathrm{zu}$ erkennen ist, sind die einzelnen Kompartimente von einer Membran umgeben. Die auf diese Weise erzeugte selektiv durchlässige Struktur ist entscheidend für eine effiziente Trennung einer Zelle oder Organelle von ihrer Umgebung. Membranen bestehen aus verschiedenen Arten von Molekülen. Hierzu zählen u.a. Phospholipide, integrale Membranproteine, periphere Proteine, Glykoproteine und 
Glycolipide (Buselmaier 2012). Die Verteilung dieser unterschiedlichen Komponenten erfolgt nicht zufällig, sondern gezielt, um bestimmte Mengen der Komponenten sicherzustellen. Dies macht einen selektiven Transport bzw. die selektive Zurückhaltung von Proteinen oder Lipiden notwendig.

Nachfolgend sollen die Einzelbestandteile der eukaryontischen Zelle näher erläutert werden.

\subsubsection{Zytoplasma}

Das Zytoplasma ist der Inhalt einer Zelle innerhalb der Plasmamembran und umgibt in eukaryontischen Zellen den Nukleus. Es dient als eine Art dreidimensionales Gitter, welches die anderen festen Strukturen verbindet und unterstützt. Hier findet ein Großteil der Proteinsynthese statt (Lechowski 2014). Das Zytosol (der lösliche Teil des Zytoplasmas außerhalb der Organellen) besteht hauptsächlich aus Wasser und vielen niedermolekularen Verbindungen (Buselmaier 2012).

\subsubsection{Endosom}

Endosomen sind dynamische Membransysteme, die am Transport innerhalb der Zelle beteiligt sind. Sie erhalten endozytäre Zellmembranmoleküle und sortieren sie zum Abbau oder zur Rückführung an die Zelloberfläche. Sie erhalten ebenfalls neu synthetisierte Proteine, die für vakuoläre Kompartimente bestimmt sind. Bei bestimmten Zelltypen können endosomale multivesikuläre Körper exozytisch mit der Zelloberfläche verschmelzen. Diese freigesetzten Vesikel werden Exosomen genannt (Buselmaier 2012).

\subsubsection{Endoplasmatisches Retikulum}

Das endoplasmatische Retikulum (ER) ist ein aus Membrantubuli, Vesikeln und abgeflachten Zisternen bestehendes Netzwerk. Man unterscheidet zwischen einem glatten und dem rauen ER. Während ersteres frei von Ribosomen ist, zeichnet sich letzteres durch die Besetzung mit Ribosomen aus. Das ER hat viele allgemeine Funktionen, u. a. die Modifikation und die Faltung von Proteinen sowie deren Transport und Sekretion (Buselmaier 2012). 


\subsubsection{Golgi-Apparat}

Der sogenannte Golgi-Apparat besteht aus mehreren abgeflachten Zisternenmembranen und gleichartigen Vesikeln, die meist eng zueinander angeordnet sind. Es entsteht eine stapelartige Struktur. Der Golgi-Apparat ist nicht symmetrisch aufgebaut. Er besitzt stattdessen eine cis-Seite (Bildungsseite) und eine trans-Seite (Sekretionsseite) (Buselmaier 2012).

Der Golgi-Apparat empfängt die gesamte Ausgabe von denovo synthetisierten, sekretorischen Polypeptiden aus dem ER an der Bildungsseite. Er dient dazu, sie mit Hilfe von Vesikeln posttranslational zu verarbeiten und $\mathrm{zu}$ sortieren, sodass die modifizierten Proteine auf unterschiedliche Transportvesikel verteilt werden, mit denen sie von der Sekretionsseite zu ihren Bestimmungsorten (Plasmamembran, sekretorische Vesikel oder Lysosomen) gebracht werden. Somit besitzt der Golgi-Apparat eine dynamische Struktur, die mit anderen Organellen in Verbindung steht (Boujard et al. 2014).

\subsubsection{Mitochondrium}

Das Mitochondrium ist eine halbautonome, sich selbst reproduzierende Organelle, die im Zytoplasma der meisten eukaryontischen Zellen vorkommt. Jedes Mitochondrium ist von einer doppelten Begrenzungsmembran umgeben. Proteine, die ins Innere des Mitochondriums gelangen wollen, passieren die innere und äußere Membran mit Hilfe von Translocons (Lechowski 2014).

In den Mitochondrien findet die oxidative Phosphorylierung statt, die zur Bildung von ATP führt. Die Größe und Kodierungskapazität der mitochondrialen Desoxyribonukleinsäure (DNA) variiert in unterschiedlichen Organismen beträchtlich und kodiert für Ribosomale-Ribonukleinsäure (rRNAs), Transfer-Ribonukleinsäure (tRNAs) und wenige essentielle mitochondriale Proteine (Buselmaier 2012).

\subsubsection{Zellkern}

Im Zellkern findet die DNA-Transkription, -Replikation und RNA-Reifung statt. Die Hülle des Zellkerns besteht aus zwei Lipidschichten. Diese innere und äußere Kernmembran grenzen den sogenannten perinukleären Raum ab, welcher mit dem Lumen 
des ER verbunden ist. Der Austausch zwischen Zellkern und Cytoplasma erfolgt durch Kernporen, welche aus mehr als 30 Proteinen bestehen (Lechowski 2014).

\subsubsection{Vakuole}

Die Vakuole - verwandt dem Lysosom von tierischen Zellen - ist von einer einfachen Membran umgeben. Sie speichert kleine Moleküle oder Ionen und baut verschiedene Zellbestandteile ab. Der für den Abbau notwendige saure $\mathrm{pH}$-Wert wird durch Protonenpumpen innerhalb der Membran erreicht (Lechowski 2014).

\subsubsection{Zellwand}

Bei der Zellwand handelt es sich um eine komplexe Schicht, die die Zelle umgibt. Sie spielt eine entscheidende Rolle für die Zellform, -stabilität und -entwicklung sowie für den Schutz vor Umweltgefahren (Buselmaier 2012).

\subsubsection{Zytoskelett}

Beim Zytoskelett handelt es sich um eine dynamische dreidimensionale Struktur, die das Zytoplasma von Zellen füllt. Es dient der Zytokinese und der Organisation der Organellen oder organellenähnlichen Strukturen innerhalb der Zelle (Buselmaier 2012).

\subsection{Intrazellulärer Transport}

Kompartimentierung ermöglicht das gleichzeitige Ablaufen von unterschiedlichsten Stoffwechsel- und Signal-Prozessen sowie die Energie-Transduktion. Weiterhin erfordert die Organisation in Kompartimente den Transport von Proteinen. Ein gezielter Transport von Proteinen in die bzw. aus den jeweiligen Zellkompartimenten und damit durch die jeweils begrenzende Membran hindurch, findet in den meisten Fällen nicht spontan statt. Stattdessen ermöglichen Transportsysteme, welche ebenfalls aus Proteinen bestehen, den Ein- und Austritt von Stoffen aus den Zellorganellen (Wickner und Schekman 2005). 


\subsubsection{Hüllvesikelproteine}

Der Transport der meisten Proteine und Membranlipide zwischen den Organellen erfolgt in von Proteinen umhüllten Vesikeln. Der Transport via Hüllvesikel wird heute als wichtigste Art des intrazellulären Stoffaustauschs angesehen. Für die Verformung und Krümmung der Membran ist dabei die Hüllprotein Polymerisation verantwortlich.

Hüllvesikel wurden erstmals im Jahr 1975 von Palade und seinen Co-Autoren in Säugetierzellen erwähnt (Palade 1975). In den darauffolgenden Studien wurden drei Typen beschichteter Vesikelproteine - detailliert hinsichtlich ihrer strukturellen Komponenten und Funktionen charakterisiert: Clathrin-verpackte Vesikel vermitteln im späten sekretorischen Weg den Transport zwischen Golgi-Apparat, Endosomen und der Plasmamembran (Robinson 2004). COPI und COPII ermöglichen hingegen den Transport zwischen ER und Golgi-Apparat. COPII ist dabei für den anterograden (ER zu Golgi) und COPI für den retrograden Transport (Golgi zu ER) verantwortlich. Zusätzlich dient das Protein COPI auch dem internen Transport zwischen den Golgi-Zisternen (Rothman, 1994; Schekman und Orci, 1996; Schmid, 1997).

Bei den Hüllvesikelproteinen handelt es sich um eine molekulare Maschinerie mit zwei zentralen Aufgaben. Zum einen dient sie der Vesikelbildung und zum anderen der aktiven Auswahl von Proteinen und Lipidfrachten (Springer et al. 1999). Weiterhin spielt sie für die Aufrechterhaltung der Identität der Organellen eine wichtige Rolle, da sie eine Vermischung der Komponenten verhindert (Kirchhausen 2000).

Die beschriebenen Proteine Clathrin, COPI und COPII weisen einige Gemeinsamkeiten auf. Zu diesen gehört bspw. die einheitliche Vesikelbildung, welche in drei Phasen verläuft: $\mathrm{Zu}$ Beginn findet die Abschnürung des betreffenden Membranabschnitts statt. Diese sogenannte Vesikelknospung ist von Proteinfaktoren abhängig: Zur Ausbildung der Vesikelhülle erfolgt die Rekrutierung der Hüllproteine über GTPasen. Diese werden wiederum durch GEF-Proteine (Guanine nucleotide exchange factor) reguliert.

Darauf folgt die Einleitung des Vorgangs der Hüllenablösung, welche aus einer GTPHydrolyse über GTPasen resultiert. Die Regulierung der GTPasen erfolgt dabei durch GAP (GTPase activating protein). Als Folge der Hydrolyse von GTP wird die GTPase aus der Membran ausgeschlossen, was schließlich zu einer vollständigen Ablösung des Vesikels von seiner Hülle führt. 
Im letzten Schritt kommt es durch Ankerfaktoren, die an die GTPasen der Rab-Familie gebunden sind, zur Anlagerung an die Membran des Zielkompartiments und zur SNARE (Soluble NSF attachement protein receptor) vermittelten Fusion (Boujard et al. 2014).

\subsection{COPI}

COPI, das Hüllvesikelprotein, auf dem der Fokus der vorliegenden Dissertation liegt, wurde zwar vor COPII entdeckt, ist in der Vergangenheit jedoch strukturell längst nicht so umfangreich untersucht worden wie COPII und Clathrin.

Hüllproteinkomplexe bewirken die Bildung eines COPI-Vesikels. Die Rekrutierung dieser Coatomer-Proteine erfolgt durch Arf1, welches an GTP bindet und zur Ras-Superfamilie der GTPasen gehört (Donaldson et al. 1992; Palmer et al. 1993; Gillingham und Munro 2007; Lechowski 2014). Solange Arf1 an GDP gebunden ist, verbleibt es im Cytosol. Durch die Bindung an GTP verändert es jedoch seine Konformation und seine nun freiliegende Glycin-myristoylierten N-terminale amphiphatische Helix interagiert mit der Membran, sodass es schließlich zur Anlagerung an die Membran kommt. GEFs aktivieren Arf1 und der Einfluss von GAPs führt zu einer Deaktivierung von Arf1 (Franco et al. 1996; Liu et al. 2009). GBF1 befindet sich im Golgi-Apparat und unterstützt als GEF die Bindung von GTP an Arf1. Arf1 ist in der Lage Membranen zu verformen. Daher wurde in Studien bereits vermutet, dass das Zusammenspiel von Hüllprotein-Polymerisation und Arf1-Bindung Krümmungen der Membran verursacht (Krauss et al. 2008). ArfGAP1, der Antagonist von ArfGEF1, ist ebenfalls im Golgi-Apparat lokalisiert und hemmt die Aktivierung von Arf1 (Chardin et al. 1996).

Nachfolgend wird auf die Struktur von COPI eingegangen.

\subsubsection{Struktur}

Coatomer, der heptamere Proteinkomplex der 75-100 nm großen COPI-Vesikel (Malhotra et al. 1989) besteht aus sieben Untereinheiten: alpha-, beta-, beta'-, gamma-, delta-, epsilonund zeta-COP (Waters et al. 1991). Diese sind in der nachfolgenden Abbildung visualisiert. 


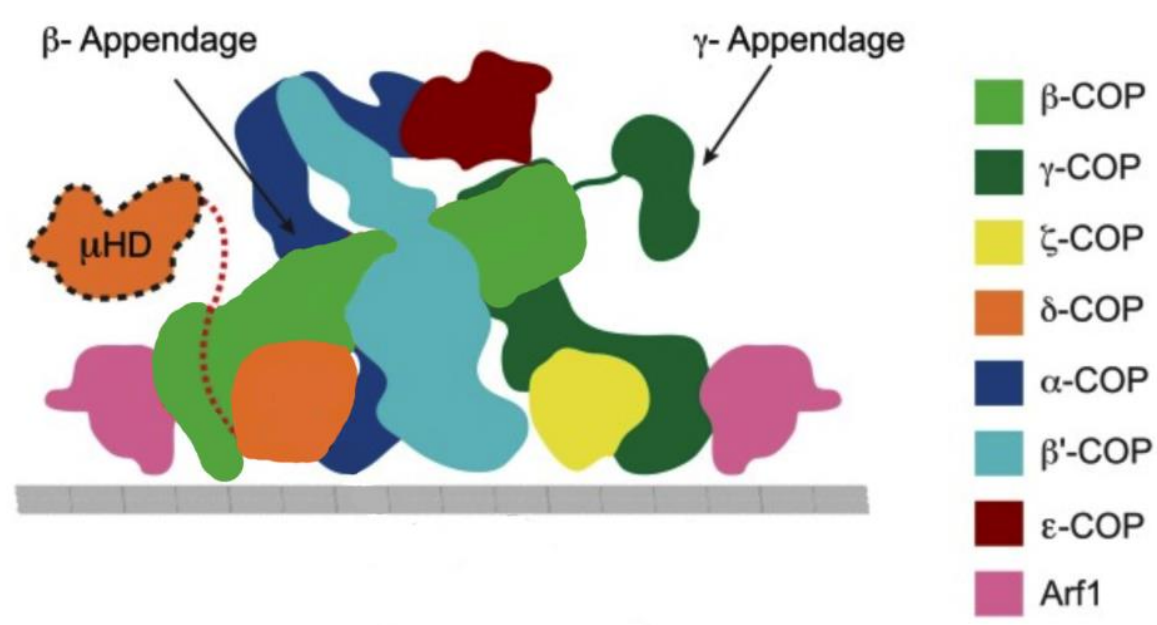

Abbildung 2: Schematische Darstellung eines membranassoziierten Coatomers.

Es werden alle 7 Untereinheiten von COPI (alpha-, beta-, beta'-, gamma-, delta-, epsilon-, zetaCOP) gezeigt. Zusätzlich ist Arf1 und die zu delta-COP gehörige $\mu$-Homologie dargestellt. (Mit Genehmigung des Proc. Natl. Acad. Sci. U S A-Verlags abgewandelt (Arakel et al. 2016))

Alpha- und beta'-COP bilden zusammen eine Art Brücke aus und befinden sich mit ihren Propellerdomänen an der Außenseite von COPI. Zusammen mit beta- und gamma-COP gehören sie zu den großen Untereinheiten. An den Enden der beiden letztgenannten Bestandteile fungiert Arf als Bindungstransmitter. Innerhalb von beta- und gamma-COP befinden sich zudem die beiden kleinen Untereinheiten delta- und zeta-COP, die jeweils eine Longin-Domäne enthalten. Dabei handelt es sich um eine Domäne mit einer charakteristischen Kombination von einer Helix, fünf beta-Faltblättern und zwei weiteren alpha-Helices, die in etlichen Proteinen mit Zusammenhang zu Transportvesikeln vorkommt. Zusätzlich existiert in delta-COP eine C-terminale $\mu$-Homologie Domäne $(\mu$ HD), die über einen Linker an die Helix des delta-COP gebunden ist (Arakel et al. 2016)

Besonders ist die dynamische und flexible Struktur von COPI. Im Vergleich zu COPII und Clathrin formt COPI recht unregelmäßige Käfige und die Rekrutierung erfolgt „en bloc“ (Hara-Kuge et al. 1994). Trotz der Homologie von vier Untereinheiten von COPI zum Clathrin-Adaptor-Komplex ist COPI deutlicher gespreizt und außer epsilon-COP besitzen alle Untereinheiten des Heptamers Kontakt zur Membran. Nach aktuellem Kenntnisstand wird davon ausgegangen, dass der C-Terminus von alpha-COP und die $\mu$-HomologieDomäne in delta-COP an der Coatomer-Triaden-Bildung beteiligt sind. 
COPI lässt sich in folgende Subkomplexe untergliedern: Der B-Komplex, auch als Käfig bekannt, umfasst alpha-, beta'- und epsilon-COP. Lange Zeit wurde davon ausgegangen, dass der B-Komplex, in Analogie zu Clathrin-beschichteten Vesikeln, ein käfigformender Subkomplex ist. Diese Annahme musste jedoch überdacht werden, seitdem bekannt ist, dass alpha- und beta'-COP mit dem zweiten Subkomplex F interagieren, die Membran direkt berühren und keine regelmäßigen Käfige um das Vesikel ausbilden. Der Subkomplex F, auch als Adapter-Komplex bezeichenet, ist ein Tetramer aus beta-, gamma-, delta- und zeta-COP.

\subsubsection{Funktion}

Wie bereits zuvor erwähnt, ist COPI für den retrograden Transport vom cis- GolgiApparat zum ER sowie für den Intra-Golgi Transport zuständig. Unter dem Transport innerhalb des Golgi-Apparats versteht man den Weg vom trans-Golgi zum medianen Golgi und vom medianen Golgi zum cis-Golgi (Lechowski 2014).

Somit spielt COPI eine essentielle Rolle dabei, dass sich Chaperone und Enzyme an ihrem Bestimmungsort befinden. Untersuchungen mit Brefeldin A (Hemmstoff eines GEFProteins) zeigten, dass der Golgi-Apparat durch eine starke Hemmung der COPI-Aktivität verschwindet. Nachdem Brefeldin A abgesetzt wurde, konnten die GEF Proteine die Vesikelbildung jedoch wieder einleiten. Somit fand keine Hemmung von COPI mehr statt und es konnte beobachtet werden, wie sich der Golgi-Apparat wieder aufbaute (Boujard et al. 2014).

\subsection{Autophagie}

Die Autophagie bezeichnet einen in allen Eukaryonten hoch konservierten Prozess. Er dient der Beseitigung überflüssiger Zellbestandteile und alter Organellen. Intrazelluläres Material wird zum Abbau und zur Rückgewinnung verwertbaren Materials zum Lysosom (in Saccharomyces cerevisiae Vakuole) transportiert (Lynch-Day und Klionsky 2010).

Die Autophagie spielt u.a. eine Rolle bei der zellulären Reaktion auf Stress, bei der Entwicklung (Levine und Klionsky 2004), der Tumorsuppression (Gozuacik und Kimchi 2004) und der Resistenz gegen Krankheitserreger (Nakagawa et al. 2004).

Grundsätzlich lässt sich zwischen Makro-, Mikroautophagie, sowie der Chaperonvermittelten Autophagie unterscheiden (Levine und Klionsky 2004). 
Die Mikroautophagie wird durch eine Invagination der Lysosom-Membran um die abzubauenden Bestandteile initiiert. Im Folgenden kommt es zu einer röhrenartigen Verlängerung der Invagination, an dessen Ende ein Vesikel abgeschnürt wird. Dieser wird schließlich gemeinsam mit seinem Inhalt im Lysosom degradiert (Li et al. 2012).

Bei der Chaperon-vermittelten Autophagie, welche bisher nur in höheren Säugetieren charakterisiert wurde, wird ein abzubauendes Protein vom Chaperon erkannt und als Proteinkomplex zum Lysosom geleitet. Durch das sogenannte Lysosomal-Membranassoziierte Protein 2a (LAMP-2A) gelangt der Komplex in das Lysosom um in ihm anschließend abgebaut zu werden (Cuervo und Wong 2014).

Die Induktion der Makroautophagie wird bei Saccharomyces cerevisiae (S. cerevisiae) über die Aktivierung des Atg1-Komplexes ausgelöst und bedarf etlicher Atg-Proteine. Im menschlichen Organismus spricht man von einem ULK-Komplex. Die Induktionsphase kann durch die Protein-Kinase Tor gehemmt werden (Boujard et al. 2014).

In der zweiten Phase kommt es durch die Bildung einer isolierenden Membran zum Einschluss der abzubauenden zytoplasmatische Komponenten. Es entsteht ein sogenanntes Phagophor. Sowohl Proteine, als auch Lipide sind an diesem Prozess beteiligt. Durch die Rekrutierung von Atg-Proteinen an die Stelle der prä-autophagosomalen Strukturen (PAS) kommt es zur Einleitung des Vesikeleinschlusses (Boujard et al. 2014).

Der nächste Schritt beinhaltet die Ausdehnung des Vesikels zu einem Autophagosom, welches von einer Doppelmembran umgeben ist. Die Bildung von Phosphatidylinositol-3phosphat (PI3P) durch die Phosphatidylinositol-3-phosphat-Kinase (PI3K) ist hierbei essentiell. PI3K interagiert mit Atg6 und befindet sich meist an der Membran des transGolgis. Der Komplex aus Atg6 und PI3K ermöglicht die Konjugation von Atg12 an Atg5. Im Weiteren folgt die Konjugation des Proteins Atg5 mit einer PhosphatidylethanolaminGruppe von Atg8 (Boujard et al. 2014).

Im letzten Schritt entsteht durch Fusion der äußeren Autophagosom-Membran mit dem Lysosom das Autophagolysosom. Während dieses Schrittes kommt es zum Abbau der inneren Membran des ehemaligen Autophagosoms und die im Inneren befindlichen Bestandteile werden von den Enzymen des Lysosoms hydrolysiert (Kroemer et al. 2010).

Die Makroautophagie kann sowohl in nichtselektiver als auch in selektiver Weise auftreten. Die nichtselektive Variante tritt z. B. unter Nährstoff- oder Energiemangelbedingungen auf, das Autophagosom bindet zufällig einen Teil des Zytoplasmas und die Abbauprodukte dienen als Nährstoffquellen. Bei der selektiven Autophagie umhüllt das Autophagosom schädliche Materialien wie Proteinaggregate, beschädigte Mitochondrien (=Mitophagie), invasive Bakterien oder überschüssige Peroxisomen (=Pexophagie) zur Eliminierung (Lynch-Day und Klionsky 2010). Letztere Variante hat in den vergangenen Jahren aufgrund ihrer direkten Relevanz für Erkrankungen des Menschen Aufmerksamkeit erregt 
(Deretic und Levine 2009; Johansen und Lamark 2011; Mizushima und Komatsu 2011; Weidberg et al. 2011).

In bestehende Studien mit dem Modellorganismus S. cerevisiae konnten bisher 41 mit Autophagie in Verbindung stehende Proteine dargestellt werden, es handelt sich um AtgProteine. 15 von ihnen sind entscheidend bei der Bildung der autophagosomalen Membran und werden daher als die Kernmaschinerie angesehen. Einige der übrigen Atg-Proteine sind für die Regulierung der Kernmaschinerie verantwortlich und bestimmen die Ziele der autophagosomalen Sequestrierung bei der selektiven Autophagie (Tanaka et al. 2014).

In der Bäckerhefe existiert der „Cytoplasm-to-Vacuole Targeting“ (Cvt-Weg) als ein selektiver Autophagie bezogener Signalweg, der den Transport von Enzymen vermittelt, die im Vakuolarlumen wirken (Lynch-Day und Klionsky 2010). Auf dem Cvt-Weg sammelt sich die vakuoläre Aminopeptidase Ape1 im Zytoplasma unter Bildung einer aggregatartigen Struktur, die vom Rezeptorprotein Atg19 erkannt wird (Kim et al. 1997; Scott et al. 2001). Atg19 bindet u.a. die Aspartylaminopeptidase Ape4 und die $\alpha$ Mannosidase Ams1, wodurch diese in die Anordnung eingebaut werden (Shintani et al. 2002; Yuga et al. 2011). Anschließend rekrutiert Atg19 das Adapterprotein Atg11, welches eine Verbindung zwischen der Anordnung und der Vakuolarmembran schafft und die AtgKernproteine rekrutiert, um die Membranbildung zu initiieren (Shintani et al. 2002; Tanaka et al. 2014).

\subsection{Saccharomyces cerevisiae als Modellsystem}

Bereits in der Vergangenheit kam S. cerevisiae als genetisch manipulierbares Modellsystem in wissenschaftlichen Studien zum Einsatz. Mit Hilfe von genetischen, biologischen und zellulären Methoden wurden intrazelluläre Transportmechanismen von Hüllvesikeln untersucht. Sobald ein Hefegen charakterisiert wurde, ist es unter praktischen Gesichtspunkten häufig vorteilhaft, das menschliche Äquivalent zu ermitteln und dessen Rolle zunächst in der heterologen Umgebung Hefe zu untersuchen, als die sofortige Charakterisierung in Säugerzellen anzustreben. Durch die hohe Konservierung zwischen den intrazellulären Transport-Vorgängen des menschlichen Organismus und denen der $S$. cerevisiae lassen sich die gewonnenen Erkenntnisse gut übertragen (Boujard et al. 2014) - bis hin zur Untersuchung von krankheitsverursachenden Mutationen mit Hilfe der funktionellen Komplementation.

Da die Bäckerhefe einige Vorteile im Laboralltag liefert, bietet sich ihre Verwendung auch für den Rahmen dieser Arbeit an: 
Durch die geringe Verdopplungszeit ergibt sich ein schnelles Wachstum, die Konstruktion von mutanten Organismen ist vergleichsweise einfach, das Genom ist gut charakterisiert und zudem leicht zu manipulieren. Auch die aufzuwendenden Kosten für die Forschung mit Bäckerhefe sind als günstig einzustufen. Weiterhin erlauben die erforderlichen Sicherheitsmaßnahmen für den Umgang mit $S$. cerevisiae das Arbeiten in S1-Laboren (Sherman 2002).

Wie bereits erwähnt, besteht ein weiterer, wesentlicher Vorteil in der einfachen Übertragbarkeit der Erkenntnisse. In nachfolgender Tabelle werden daher die Äquivalente der menschlichen COPI-Untereinheiten für die S. cerevisiae aufgeführt:

Tabelle 1: COPI-Untereinheiten des Homo sapiens und der S.cerevisiae (Gaynor et al. 1998)

\begin{tabular}{|c|c|}
\hline $\begin{array}{c}\text { Homo Sapiens } \\
(\text { Mensch) }\end{array}$ & $\begin{array}{c}\text { S. cerevisiae } \\
\text { (Bäckerhefe) }\end{array}$ \\
\hline$\alpha$-COP & RET1 \\
\hline$\beta-$ COP & SEC26 \\
\hline$\beta^{\prime}-\mathrm{COP}$ & SEC27 \\
\hline$\gamma$-COP & SEC21 \\
\hline$\delta$-COP & RET2 \\
\hline$\epsilon-$ COP & SEC28 \\
\hline$\zeta$-COP & RET3 \\
\hline
\end{tabular}

Weiterhin bietet der Modellorganismus S. cerevisiae systematische Sammlungen von Stämmen oder ganzen Bibliotheken, in denen jedes Gen auf ähnliche Weise modifiziert wurde, um somit umfassende genomische Studien zu ermöglichen (Giaever et al. 2002; Huh et al. 2003; Tarassov et al. 2008; Botstein und Fink 2011)

Jüngste Forschungsergebnisse ermöglichen eine einfache, schnelle und kostengünstige Herstellung solcher Bibliotheken mit Hilfe einer Methode namens SWAp-Tags (SWAT) (Khmelinskii et al. 2011; Yofe et al. 2016). Eine sogenannte SWAT-Bibliothek besteht aus einem systematischen Array von Akzeptor-Genfusionen, die es möglich machen, die Ursprungsbibliothek in eine veränderte Bibliothek $\mathrm{zu}$ konvertieren. Hierfür wird das Akzeptormodul durch eine neue Genomsequenz ersetzt. Dieser Austausch erfolgt durch 
die Kreuzung der Ursprungsbibliothek mit dem gewünschten Donorstamm (Yofe et al. 2016).

\subsubsection{Mikroskopie von Hefezellen mit Hilfe einer SWAT-GFP-Bibliothek}

Die Mikroskopie mit Hilfe von fluoreszenten Proteinen ist eine sensitive Methode. Markierte Moleküle werden hierbei als Lichtpunkte vor einem schwarzen Hintergrund sichtbar. Bei der klassischen Mikroskopie findet hingegen eine Farbveränderung vor einem bereits angefärbten Hintergrund statt (Lechowski 2014).

Grundsätzlich besteht sowohl die Möglichkeit der Markierung über Fluorophor-gekoppelte Antikörper, als auch über die genetische Kopplung eines fluoreszierenden Proteins (z. B. green fluorescent protein) an das jeweilige Zielprotein. Es kann somit einerseits die Lokalisation von Proteinen, als auch die von Zellorganellen bestimmt werden. Das in dieser Arbeit verwendete, als Biomarker fungierende green fluorescent protein (GFP) stammt ursprünglich aus der Qualle Aequorea victoria (Lechowski 2014).

Dank der vollständigen Genombibliothek, welche aus 5500 Stämmen besteht, die das SWAT NOP1-Promotor-GFP-Modul tragen (Meurer et al. 2017), ist es möglich, große Datenmengen an Mikroskopie-Bildern zu generieren und auszuwerten.

\subsection{Auswirkungen von Mutationen des COPI-Proteins aus biologischer und medizinischer Sicht}

Beeinträchtigungen des intrazellulären Transports wurden in der Pathogenese von verschiedenen neurodegenerativen Erkrankungen, wie der Alzheimer-Krankheit (Annaert und De Strooper 2002) und der Parkinson-Krankheit (Cooper et al. 2006) beobachtet.

Die Bedeutung des intrazellulären Transports für die ordnungsgemäße Funktion und Aufrechterhaltung neuronaler Zellen ist somit klar ersichtlich. Das genaue Zusammenspiel zwischen den Mechanismen, welche die neurodegenerativen Erkrankungen verursachen, ist jedoch häufig nicht vollständig nachvollziehbar. Insbesondere der Wissensstand bzgl. der Auswirkungen von Mutationen der COPI- Untereinheiten weist einige Lücken auf.

Die essentielle Bedeutung von COPI für eukaryontisches Leben ist unter Fachexperten unumstritten. Selbst kleinere Veränderungen innerhalb des Proteins können zu schweren Erkrankungen führen. Mutationen, welche die Funktionalität einzelner COPI- 
Untereinheiten beeinträchtigen, wurden als Ursache seltener, menschlicher Erbkrankheiten ermittelt. Unter anderem konnten autoimmunbedingte Lungenerkrankungen mit einer Mutation in der alpha-COP-Untereinheit in Verbindung gebracht werden (Watkin et al. 2015). Es konnte weiterhin gezeigt werden, dass eine Mutation im delta-COP-Gen zu Entwicklungsstörungen, mit denen ebenfalls eine veränderte Skelettbildung und eine eingeschränkte Gehirnentwicklung einhergingen, führte (Izumi et al. 2016).

Die „neurological 17“ (nur17) Maus besitzen eine N-Ethyl-N-Nitrosourea (ENU)induzierte Mutation. Die Mutantenmäuse zeigten als Phänotyp sowohl eine Veränderung der Fellfarbe als auch eine Ataxie, was auf eine Purkinje-Zelldegeneration im Kleinhirn zurückgeführt werden konnte. Bereits Jeans et al. beschrieben im Jahr 2007 im Rahmen eines Mausversuchs die Ursache von Ataxie in einer Störung des vesikulären Transportwegs (Jeans et al., 2007). Durch positionelles Klonieren der nur17-Maus fand man zudem heraus, dass eine T-zu-C-Missense-Mutation im zehnten Exon des Archain 1Gens vorlag. Da dieses für die delta-Untereinheit des COPI-Komplexes codiert, lag eine Störung des intrazellulären Transports vor. Als Beleg für die These, dass die Arcn1Mutation für die Phänotypen in Nur17-Mäusen verantwortlich war, dienten weitere Versuchsergebnisse. Zum Beispiel konnte die transgene Expression von Wildtyp-Archain 1 (delta-COP) die Nur17-Phänotypen retten, sodass keine Neurodegeneration mehr auftrat (Xu et al. 2010).

\subsection{Fragestellung dieser Arbeit}

Wie unter dem vorangegangenen Gliederungspunkt beschrieben, beeinflussen Mutationen in Genen, die für verschiedene COPI-Untereinheiten kodieren, den intrazellulären Transport und können damit zu neurodegenerativen Erkrankungen führen. Somit würde eine weitere biochemische und zellbiologische Charakterisierung der Vesikelhülle COPI auch das Verständnis bzgl. solcher Krankheitsbilder voranbringen.

Jüngste Studien zeigten, dass $S$. cerevisiae trotz der Deletion der $\mu$-Homologie Domäne des delta-COP lebensfähig ist. Auch die Tatsache, dass eine bestimmte Hefespezies namens Schizosaccharomyces pombe nur ein RET2-homologes Gen besitzt, welches für eine verkürzte Variante der $\delta$-COP-Untereinheit kodiert, der die C-terminale $\mu$-Homologie Domäne völlig fehlt, unterstreicht diese Aussage (Arakel et al. 2016). Angesichts der publizierten Theorie, dass die Beteiligung der $\mu$-Homologie Domäne von delta-COP an der Triadenverbindung 
innerhalb der Vesikelhülle beiträgt (Dodonova et al. 2015), ist deren Fehlen jedoch sehr erstaunlich. Die nachfolgende Abbildung 3, die von Dr. Eric Arakel zur Verfügung gestellt wurde, zeigt schematisch die Sekundärstrukturvorhersagen für delta-COP. Dargestellt sind die entsprechenden Proteine von Saccharomyces cerevisiae, Schirosaccharomyces pombe und Homo sapiens. Mit Hilfe der Darstellung wird das Fehlen der $\mu$-Homologie Domäne in $S$. pombe veranschaulicht.

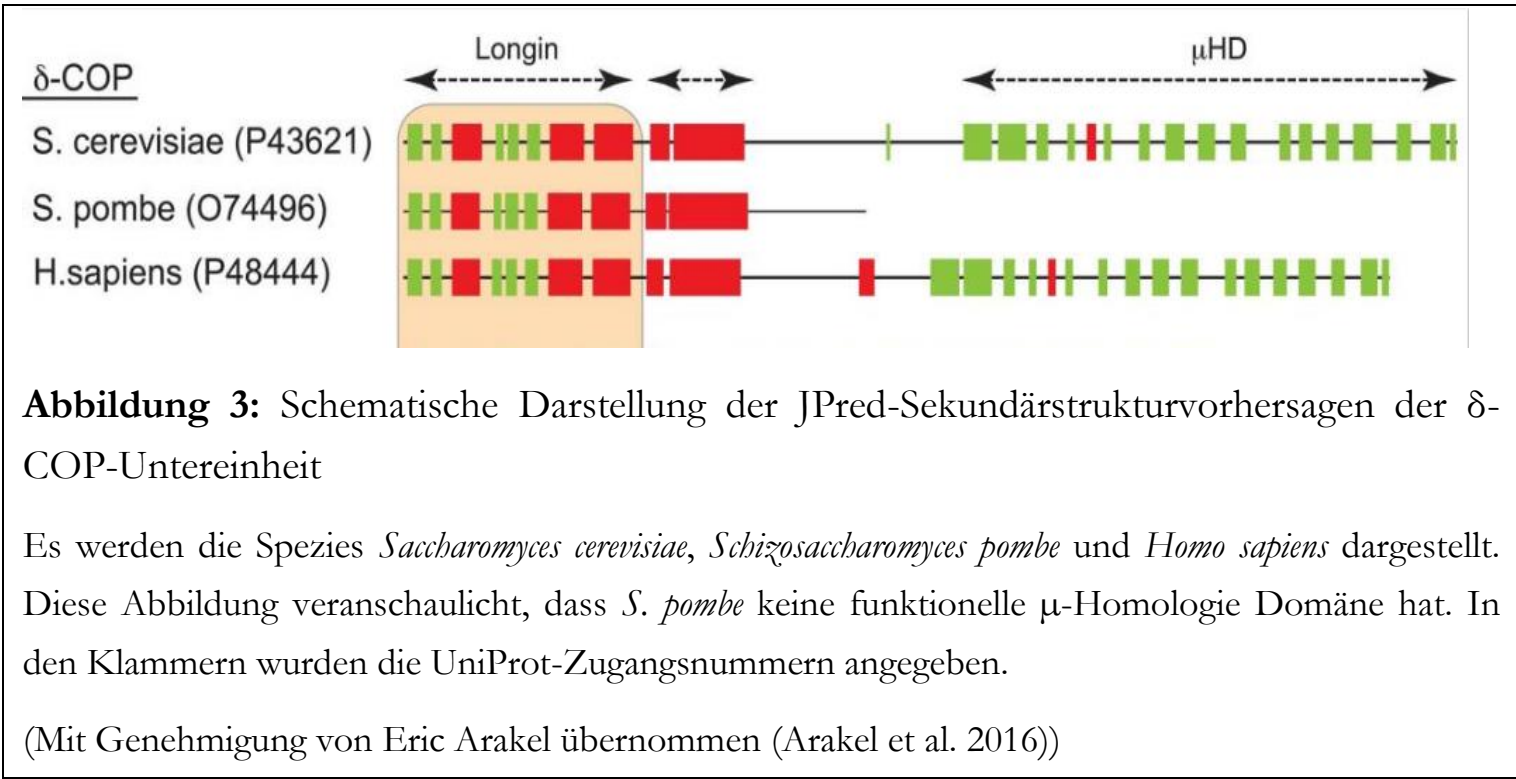

Um die grundsätzliche Rolle und die aktuellen Forschungserkenntnisse der $\mu$-Homologie der delta-COP-Untereinheit in eukaryontischen Systemen genauer zu verstehen, sollte ein high-content GFP-basiertes Lokalisations-Screening durchgeführt werden. Dabei wurde die Lokalisation einer an Cargoes und Maschinerie-Komponenten des vesikulären Transports angereicherten Untermenge des Hefeproteoms mit Hilfe automatisierter Mikroskopie und manueller Bildanalyse in einem Stamm mit delta-COP mit und ohne $\mu$-HomologieDomäne verglichen. Zur weiteren Charakterisierung von identifizierten GFPFusionsproteinen, deren Lokalisation von der $\mu$-Homologie-Domäne abhängt, wurden Western Blots angefertigt, da mit dieser Methode die betroffenen GFP-Fusionsproteine anhand ihres Molekulargewichts verifiziert werden können. 


\section{Material und Methoden}

\subsection{Material}

\subsubsection{Standardmedien und -puffer}

Tabelle 2: Standardmedien und-puffer

\begin{tabular}{|c|c|c|}
\hline Bezeichnung & Konzentration & Inhalt \\
\hline Acrylamid & $30 \%(w / v)$ & $\begin{array}{l}\text { Acrylamide } 4 \mathrm{~K} 292,2 \mathrm{~g} / 1 \text {, bisacrylamide } \\
4 \mathrm{~K} 7,8 \mathrm{~g} / 1\end{array}$ \\
\hline Ampicillin Stocklösung & $100 \mathrm{mg} / \mathrm{ml}$ & $\begin{array}{l}\text { Ampicillin-Natriumsalz in } \mathrm{H}_{2} \mathrm{O} \text {, steril } \\
\text { filtriert, Lagerung bei }-20^{\circ} \mathrm{C}\end{array}$ \\
\hline Ammoniumpersulfat $10 \%$ & $10 \%(w / v)$ & Ammoniumpersulfat-Pulver \\
\hline Bakterien-Agar (LB-Agar) & $15 \mathrm{~g} / 1$ & Agar in LB-Medium, autoklavieren \\
\hline \multirow[t]{3}{*}{$\begin{array}{l}\text { Blocking-Lösung für Western } \\
\text { Blot }\end{array}$} & $1 \mathrm{x}$ & TBS in $\mathrm{H}_{2} \mathrm{O}$ \\
\hline & $5 \%(\mathrm{w} / \mathrm{v})$ & Milchpulver \\
\hline & $0,02 \%(\mathrm{v} / \mathrm{v})$ & IGEPAL \\
\hline ClonNat-Stocklösung & $100 \mathrm{mg} / \mathrm{ml}$ & $\begin{array}{l}\text { Clon-Natriumsalz in } \mathrm{H}_{2} \mathrm{O} \text {, steril } \\
\text { filtriert, Lagerung bei }-20^{\circ} \mathrm{C}\end{array}$ \\
\hline \multirow[t]{2}{*}{ DNA-Ladepuffer 6fach } & $30 \%(v / v)$ & Glycerol \\
\hline & $0,2 \%(\mathrm{w} / \mathrm{v})$ & Bromphenolblau \\
\hline \multirow[t]{2}{*}{ Glukose $40 \%$} & $200 \mathrm{~g}(\mathrm{w} / \mathrm{v})$ & Glukose \\
\hline & $500 \mathrm{ml}$ & $\mathrm{H}_{2} \mathrm{O}$ \\
\hline Hefeagar & $40 \mathrm{~g} / \mathrm{l}$ & $\begin{array}{l}\text { Bactoagar für Hefe in } \mathrm{H}_{2} \mathrm{O} \text { oder } \\
\text { YPAD, autoklavieren }\end{array}$ \\
\hline \multirow[t]{5}{*}{ Hefemedium YPAD } & $10 \mathrm{~g} / 1$ & Hefeextrakt \\
\hline & $20 \mathrm{~g} / 1$ & Peptonwasserstoff \\
\hline & $40 \mathrm{mg} / 1$ & Adeninsulfat \\
\hline & $20 \mathrm{~g} / 1$ & Glukose \\
\hline & & mit $\mathrm{H} 2 \mathrm{O}$ zu 1L auffüllen, autoklavieren \\
\hline
\end{tabular}




\begin{tabular}{|c|c|c|}
\hline Bezeichnung & Konzentration & Inhalt \\
\hline \multirow[t]{9}{*}{ Hefemedium selektiv } & $6,7 \mathrm{~g} / 1$ & Hefestickstoffbasis \\
\hline & $0,57 \mathrm{~g} / 1$ & Aminosäurengemisch (je nach Bedarf) \\
\hline & $20 \mathrm{~g} / 1$ & Glukose \\
\hline & $20 \mathrm{mg} / 1$ & $\begin{array}{l}\text { L-Arginin, L-Methionin, L-Histidin, } \\
\text { L-Uracil }\end{array}$ \\
\hline & $30 \mathrm{mg} / 1$ & L-Lysin, L-Tyrosin \\
\hline & $40 \mathrm{mg} / 1$ & Adeninhemisulfat \\
\hline & $50 \mathrm{mg} / 1$ & L-Phenylalanin, L-Tryptophan \\
\hline & $100 \mathrm{mg} / \mathrm{l}$ & L-Aspartat, L-Glutamat, L-Leucin \\
\hline & & In $\mathrm{H}_{2} \mathrm{O}$, steril filtriert \\
\hline \multirow[t]{2}{*}{ Hefeplatten } & $50 \%(\mathrm{v} / \mathrm{v})$ & Hefeagar, autoklaviert \\
\hline & $50 \%(\mathrm{v} / \mathrm{v})$ & Hefemedium, steril filtriert \\
\hline \multirow[t]{4}{*}{ LB-Medium für Bakterien } & $15 \mathrm{~g} / 1$ & Trypton \\
\hline & $5 \mathrm{~g} / 1$ & Hefeextrakt \\
\hline & $5 \mathrm{~g} / \mathrm{l}$ & $\mathrm{NaCl}$ \\
\hline & & mit $\mathrm{H}_{2} \mathrm{O}$ zu 1L auffüllen, autoklavieren \\
\hline Lithium Acetat 10fach (1M) & $102 \mathrm{~g} / \mathrm{l}$ & $\begin{array}{l}\text { Lithium Acetat } \\
\text { mit } \mathrm{H}_{2} \mathrm{O} \text { zu } 1 \mathrm{~L} \text { auffüllen, steril filtriert }\end{array}$ \\
\hline \multirow[t]{3}{*}{ Lithium Acetat-Mix } & $1 \mathrm{x}$ & $10 \times \mathrm{TE}$ pH 7,5 \\
\hline & $1 \mathrm{x}$ & 10 x Lithium Acetat pH 7,5 \\
\hline & $8 x$ & $\mathrm{H}_{2} \mathrm{O}$ \\
\hline \multirow{4}{*}{$\begin{array}{l}\text { PBS (phosphate buffered } \\
\text { saline) } 1 \mathrm{x}\end{array}$} & $140 \mathrm{mM}$ & $\mathrm{NaCl}$ \\
\hline & $3 \mathrm{mM}$ & $\mathrm{KCl}$ \\
\hline & $8 \mathrm{mM}$ & $\mathrm{Na}_{2} \mathrm{HPO}_{4}$ \\
\hline & & mit $\mathrm{H}_{2} \mathrm{O}$ zu $1 \mathrm{~L}$ auffüllen \\
\hline PEG-Stocklösung (50 \%) & $500 \mathrm{~g} / 1$ & $\begin{array}{l}\text { PEG (Polyethylglycol) } 4000 \text { in } \mathrm{H}_{2} \mathrm{O} \text {, } \\
\text { steril filtriert }\end{array}$ \\
\hline \multirow[t]{4}{*}{ Ponceau-S-Stocklösung $10 \mathrm{x}$} & $20 \mathrm{~g} / \mathrm{l}$ & Ponceau-S \\
\hline & $300 \mathrm{~g} / 1$ & Trichloressigsäure \\
\hline & $300 \mathrm{~g} / \mathrm{l}$ & Schwefelsalicylsäure \\
\hline & & in $\mathrm{H}_{2} \mathrm{O}$, steril filtriert \\
\hline
\end{tabular}




\begin{tabular}{|c|c|c|}
\hline Bezeichnung & Konzentration & Inhalt \\
\hline \multirow[t]{5}{*}{ SDS-Ladepuffer Proteingel $5 \mathrm{x}$} & $250 \mathrm{mM}$ & Tris-HCL pH 6,8 \\
\hline & $5 \%(w / v)$ & SDS $10 \%$ \\
\hline & $0.5 \%(\mathrm{w} / \mathrm{v})$ & Bromphenolblau \\
\hline & $50 \%(\mathrm{v} / \mathrm{v})$ & Glycerol \\
\hline & $250 \mathrm{mM}$ & DTT (Dithiotreitol) \\
\hline \multirow[t]{4}{*}{ SDS-Laufpuffer Proteingel $5 \mathrm{x}$} & $250 \mathrm{mM}$ & Glycin $\mathrm{pH} 8,3$ \\
\hline & $125 \mathrm{mM}$ & Tris \\
\hline & $0,1 \%(\mathrm{v} / \mathrm{v})$ & $10 \%$ SDS \\
\hline & & mit $\mathrm{H}_{2} \mathrm{O}$ zu $1 \mathrm{~L}$ auffüllen \\
\hline \multirow{8}{*}{$\begin{array}{l}\text { SOC-Medium für } \\
\text { Bakterien }\end{array}$} & $20 \mathrm{~g} / 1$ & Tryptone \\
\hline & & \\
\hline & $5 \mathrm{~g} / 1$ & Hefeextrakt \\
\hline & $0,5 \mathrm{~g} / 1$ & $\mathrm{NaCl}$ \\
\hline & $2,5 \mathrm{mM}$ & $\mathrm{KCl}$ \\
\hline & & $\mathrm{H}_{2} \mathrm{O}$ nach dem Autoklavieren \\
\hline & $10 \mathrm{mM}$ & $\mathrm{MgCl}_{2}$ \\
\hline & $20 \mathrm{mM}$ & Glukose \\
\hline SDS $10 \%$ & $100 \mathrm{~g} / 1$ & Natriumdodecylsulfat \\
\hline \multirow[t]{6}{*}{ T4-Ligase-Puffer } & $50 \mathrm{mM}$ & Tris-HCL pH 7,6 \\
\hline & $10 \mathrm{mM}$ & $\mathrm{MgCl}_{2}$ \\
\hline & $1 \mathrm{mM}$ & ATP \\
\hline & $1 \mathrm{mM}$ & DTT \\
\hline & $50 \mathrm{mg} / \mathrm{ml}$ & PEG-8000 \\
\hline & & $\mathrm{H}_{2} \mathrm{O}$, Aliquots bei $-20{ }^{\circ} \mathrm{C}$ lagern \\
\hline \multirow{3}{*}{$\begin{array}{l}\text { TAE-Puffer (DNA-Gel- } \\
\text { Laufpuffer) } 20 \mathrm{x}\end{array}$} & $800 \mathrm{mM}$ & Tris- $\mathrm{HCl} \mathrm{pH} 7,5$ \\
\hline & $200 \mathrm{mM}$ & Natrium-Acetat \\
\hline & $20 \mathrm{mM}$ & EDTA pH 8,0 \\
\hline \multirow[t]{4}{*}{ TBS $10 \mathrm{x}$} & $240 \mathrm{mM}$ & Tris $\mathrm{pH} 7,4(\mathrm{HCl})$ \\
\hline & $1,36 \mathrm{M}$ & $\mathrm{NaCl}$ \\
\hline & $30 \mathrm{mM}$ & $\mathrm{KCl}$ \\
\hline & & mit $\mathrm{H}_{2} \mathrm{O}$ zu $1 \mathrm{~L}$ auffüllen \\
\hline
\end{tabular}




\begin{tabular}{|l|l|l|}
\hline Bezeichnung & Konzentration & Inhalt \\
\hline TBS-Tween 20 & $0,02 \%(\mathrm{v} / \mathrm{v})$ & Tween-20 \\
\hline TE $10 \mathrm{x}$ & $1 \mathrm{x}$ & TBS \\
\hline & $100 \mathrm{mM}$ & Tris- $\mathrm{HCl} \mathrm{pH} 7,5$ \\
\hline & $10 \mathrm{mM}$ & EDTA \\
\hline $\begin{array}{l}\text { TEMED } \\
\text { Tetramethylethylendiamin) }\end{array}$ & & $\mathrm{pH} 7,5$ mit $\mathrm{HCl}$ \\
\hline Transferpuffer 10 $\mathrm{x}$ & $390 \mathrm{mM}$ & $\mathrm{C}_{6} \mathrm{H}_{16} \mathrm{~N}_{2}$ \\
\hline & $480 \mathrm{mM}$ & Glycin \\
\hline & $3,7 \mathrm{~g} / \mathrm{l}$ & SDS $\mathrm{pH} 8,3$ \\
\hline & & $+20 \%(\mathrm{v} / \mathrm{v})$ Methanol in 1 x Puffer \\
\hline Trichloressigsäure (TCA) & $50 \%(\mathrm{w} / \mathrm{v})$ & Trichloressigsäurepulver \\
\hline
\end{tabular}

\subsubsection{Kits und andere Materialien}

Tabelle 3: Kits und andere Materialien

\begin{tabular}{|l|l|}
\hline Kit & Hersteller und Katalognummer \\
\hline Hybond $^{\mathrm{TM}}-\mathrm{ECL}^{\mathrm{TM}}$ Nitrocellulosemembran & $\begin{array}{l}\text { Amersham Bioscience } \\
\text { (Katalognummer RPN3032d) }\end{array}$ \\
\hline Page Ruler Prestained Protein Ladder & $\begin{array}{l}\text { Thermo Scientific } \\
\text { (Katalognummer 26616) }\end{array}$ \\
\hline Page Ruler Plus Prestained Protein Ladder & $\begin{array}{l}\text { Thermo Scientific } \\
\text { (Katalognummer 26619) }\end{array}$ \\
\hline YeaStar & $\begin{array}{l}\text { Zymo Research } \\
\text { (Katalognummer D2002) }\end{array}$ \\
\hline
\end{tabular}




\subsubsection{Geräte}

Tabelle 4: Geräte

\begin{tabular}{|l|l|l|}
\hline Gerät & Name & Hersteller \\
\hline $\begin{array}{l}\text { Agarosegelelektrophorese } \\
\text { Apperatur }\end{array}$ & PowerPac Basic & BioRad \\
\hline Elektroporator & Gene Pulser & BioRad \\
\hline Imaging Machine & IM02 & Acquifer \\
\hline Liquid Handling-Robotor & Bravo & Agilent Technology \\
\hline Membrandetektion & Odyssey & Licor \\
\hline Nano-Drop & NanoDrop2000c & ThermoScientific \\
\hline Pinning-Robotor & Rotor HDA & Singer \\
\hline Spektralphotometer & BioMate5 & ThermoScientific \\
\hline $\begin{array}{l}\text { SDS-Gelelktrophorese- } \\
\text { Apperatur }\end{array}$ & $\begin{array}{l}\text { Multiple Gel Caster, Mighty } \\
\text { Small 250 }\end{array}$ & Hoefer \\
\hline Tisch-Zentrifuge & Centrifuge 5418 R & Eppendorf \\
\hline Western Blot-Apperatur & Mighty Small Transfer & Amersham Biosciences \\
\hline
\end{tabular}

\subsubsection{Enzyme}

Tabelle 5: Restriktionsenzyme

\begin{tabular}{|l|l|}
\hline Restriktionsenzym & Hersteller: \\
\hline BamHI (Bacillus amyloliquefaciens) & Fermentas \\
\hline EcoRI (Escherichia coli) & Fermentas \\
\hline XhoI (Xanthomonas holcicola) & Fermentas \\
\hline
\end{tabular}

Verwendete Polymerase: Expand ${ }^{\mathrm{TM}}$ High Fidelity PCR polymerase. 


\subsubsection{Antikörper}

Tabelle 6: Primärantikörper

\begin{tabular}{|l|l|l|l|l|}
\hline Name & Erzeugt in & Katalognummer & Verdünnung & Herkunft \\
\hline -Coat1 & Kaninchen & & $1: 1000$ & H. D. Schmitt \\
\hline -GFP & Kaninchen & TP401 & $1: 1000$ & $\begin{array}{l}\text { Torrey Pines biolabs } \\
\text { (von Acris bestellt) }\end{array}$ \\
\hline$\alpha$-HIS & Maus & 34660 & $1: 1000$ & Qiagen \\
\hline$\alpha$-PGK1 & Maus & 459250 & $1: 1000$ & $\begin{array}{l}\text { Thermo Fisher } \\
\text { Scientific }\end{array}$ \\
\hline$\alpha$-RET2 & Kaninchen & & $1: 1000$ & H. D. Schmitt \\
\hline
\end{tabular}

Tabelle 7: Sekundärantikörper

\begin{tabular}{|l|l|l|l|}
\hline Name & Katalognummer & Verhältnis & Herkunft \\
\hline $\begin{array}{l}\text { IRD 680LT } \\
\text { Donkey anti-Mouse } \\
\text { IgG (H+L) }\end{array}$ & $926-68072$ & $1: 5000$ & $\begin{array}{l}\text { LI-COR } \\
\text { Biosciences }\end{array}$ \\
\hline $\begin{array}{l}\text { IRD 800CW } \\
\text { Donkey anti-Rabbit } \\
\text { IgG (H+L) }\end{array}$ & $926-32213$ & $1: 5000$ & $\begin{array}{l}\text { LI-COR } \\
\text { Biosciences }\end{array}$ \\
\hline
\end{tabular}




\subsubsection{Hefestämme}

Tabelle 8: Hefestämme

\begin{tabular}{|c|c|c|}
\hline Name & Genotyp & Herkunft \\
\hline BY4741 & $\begin{array}{l}M A T a ; \text { his } 3 \Delta 1 ; \text { leu } 2 \Delta 0, \operatorname{met} 15 \Delta 0 ; \\
\text { ura } 3 \Delta 0\end{array}$ & Euroscarf \\
\hline Ret2Clonat & $\begin{array}{l}\text { MATa his } 3 \Delta 1, \text { leu2 } \Delta 0, \\
\text { lys2+/lys }+, \text { met15 } \Delta 0, \text { ura3 } \Delta 0, \\
\text { can1::STE2pr-spHIS5, } \\
\text { yp1::STE3pr-LEU2 Ret } \\
2 \alpha:: \text { Clonat }\end{array}$ & $\begin{array}{l}\text { mit Hilfe von Dr. } \\
\text { Arakel in dieser } \\
\text { Dissertation hergestellt }\end{array}$ \\
\hline $\operatorname{Ret} 2 \mathrm{LD} 2 \alpha$ & $\begin{array}{l}\text { MATa his } 3 \Delta 1, \text { leu } 2 \Delta 0, \\
\text { lys2+/lys+, met15 } \Delta 0, \text { ura } 300, \\
\text { can1::STE2pr-spHIS5, } \\
\text { bp } 1:: \text { STE3pr-LEU2 Ret2 Longin } \\
\text { Domain } 2 \alpha:: \text { Clonat }\end{array}$ & $\begin{array}{l}\text { mit Hilfe von Dr. } \\
\text { Arakel in dieser } \\
\text { Dissertation hergestellt }\end{array}$ \\
\hline
\end{tabular}

\subsubsection{Primer und Plasmide}

Tabelle 9: Primer zur Herstellung des Konstrukts

\begin{tabular}{|l|l|}
\hline Primer & Sequenz \\
\hline Ret2_BamF & CGCGGATCCATGGTGGTTTTGGCTGC \\
\hline Ret2-Longin-H6-RP- & $\begin{array}{l}\text { EcoR1CCGGAATTCCGGtcagtgatggtgatggtgatgCCCGTGTT } \\
\text { TCCTTTCATGTTCTTT }\end{array}$ \\
\hline $\begin{array}{l}\text { EcoR1- } \\
\text { PAG25TEFp_FP }\end{array}$ & $\begin{array}{l}\text { CCGGAATTCCGGGGGTTAATTAAGGCGCGCCAGAT } \\
\text { CTGTTTA }\end{array}$ \\
\hline Xho1-PAG25term_RP & $\begin{array}{l}\text { CCGCTCGAGCGGCGAGCTCGTTTTCGACACTGGAT } \\
\text { GGCGGCG }\end{array}$ \\
\hline
\end{tabular}


Tabelle 10: Primer zur Vermehrung der Rekombinationskassette

\begin{tabular}{|l|l|}
\hline Primer & Sequenz \\
\hline Ret2Flank-Pr1_FP & $\begin{array}{l}\text { TAGATCATATTAGAATACCTATAGCTCCATCAAAAGAA } \\
\text { ATACACAATGGTGGTT'TTGGCTGCTTCTATCACTACG }\end{array}$ \\
\hline Ret2Flank-Pr2_FP & $\begin{array}{l}\text { TGTTGACACCTCAAGAACAAGGGCAATTAGCCTCAGC } \\
\text { GTCGAATATAGATCATATTAGAATACCTATAGCTCCAT }\end{array}$ \\
\hline Ret2Flank-Pr1_RP & $\begin{array}{l}\text { AGTTTGTGTATATAACTTAAGTATTTTATATGTGAATG } \\
\text { TAACGTAGCGGCGAGCTCGTTTTCGACACTGGATGGC }\end{array}$ \\
\hline Ret2Flank-Pr2_RP & $\begin{array}{l}\text { TATATAGAAGGACGAAAGAAAAGATACCTCGAT'TTTTA } \\
\text { TTTATTTAGTTTGTGTATATAACTTAAGTATTTTATA }\end{array}$ \\
\hline
\end{tabular}

Tabelle 11: Primer zum Einbringen der Klonat-Kassette nach dem Ret2-Stop-Codon

\begin{tabular}{|c|c|}
\hline Primer & Sequenz \\
\hline Ret2-3'-Clonat-FP1 & $\begin{array}{l}\text { AAATCGAGGTATCT'T'TCTT'TCGTCCT'TCTATATATATA } \\
\text { GTTTAAAATTCCGGGGGTTAATTAAGGCGCGCCAGA }\end{array}$ \\
\hline Ret2-3'-Clonat-FP2 & $\begin{array}{l}\text { TCACATATAAAATACTTAAGTTATATACACAAACTAAAT } \\
\text { AAATAAAAATCGAGGTATCTTTTCTTTCGTCCTTCT }\end{array}$ \\
\hline Ret2-3'-Clonat-RP1 & $\begin{array}{l}\text { TGACGGGTAACCCTAAAAGGAAAAATAATAAAGAATA } \\
\text { AGAGTAAGCGAGCTCGTTTTCGACACTGGATGGCGGC } \\
\text { G }\end{array}$ \\
\hline Ret2-3'-Clonat-RP2 & $\begin{array}{l}\text { GCAAATTCTAAACCAAGAAGCTGGAACATCTTTAATAA } \\
\text { AAAGGATTGACGGGTAACCCTAAAAGGAAAAATAATA }\end{array}$ \\
\hline
\end{tabular}




\subsection{Methoden}

\subsubsection{DNA-Techniken}

\subsubsection{Restriktionsverdau von DNA-Molekülen}

Beim Restriktionsverdau handelt es sich um eine Methodik zum Schneiden von DNA an bestimmten DNA-Sequenzen durch die Verwendung von Restriktionsenzymen. Dazu werden Restriktionsendonukleasen eingesetzt, welche das Zerschneiden des DNADoppelstranges katalysieren. Diese „Schnitte“ erfolgen an bekannten Stellen (Palindromen). Im Anschluss daran können die geschnittenen Sequenzen in einem Agarosegel der Größe nach aufgetrennt und aufgereinigt werden.

Restriktionsenzym-Verdauungen werden durchgeführt, indem 2-3 $\mu \mathrm{g}$ DNA mit einer geeigneten Menge an Restriktionsenzymen (1-5 Einheiten) in ihrem jeweiligen Puffer und bei der empfohlenen Idealtemperatur für die spezifisch verwendeten Enzyme inkubiert werden (Herstellerangaben sind zu beachten).

Das Volumen der Reaktion hängt von der Konzentration und Größe der zu verdauenden DNA ab. Entsprechend des Verwendungszweckes wird das Reaktionsgemisch entweder 60 Minuten (Klonierung) oder 90 Minuten (Testverdauung) inkubiert. Um eine VektorSelbstligation zu verhindern, wurde das Reaktionsgemisch nach 60 Minuten mit einer Einheit alkalischer Phosphatase (CIAP) aus dem Kälberdarm vermengt. Alkalische Phosphatase katalysiert die Entfernung von 5'-Phosphatgruppen aus der DNA. DNAFragmente, denen die 5'-Phosphoryl-Termini fehlen, können sich nicht selbstligieren. Diese Eigenschaft wurde sich zunutze gemacht, um den Vektorhintergrund während des Klonens zu verringern. Die DNA wurde nur für einen kurzen Zeitraum ( 10 Minuten) bei $37{ }^{\circ} \mathrm{C}$ mit CIAP inkubiert. Der Prozess des Restriktionsverdaus bzw. der Phosphatasebehandlung wurde durch Überführen des Reaktionsgemisches auf $4{ }^{\circ} \mathrm{C}$ oder $-20{ }^{\circ} \mathrm{C}$ gestoppt. Ergänzend wurde DNA-Beladungspuffer zu dem Reaktionsgemisch gegeben, um die Produkte durch Agarose-Gelelektrophorese aufzutrennen.

\subsubsection{Agarose-Gelelektrophorese}

Mit Hilfe der Agarose-Gelelektrophorese lassen sich Nukleinsäure-Stränge (RNA oder DNA) anhand von unterschiedlichen Laufverhalten-auftrennen, was dazu dient, ihre Größe und Masse durch einen Vergleich mit DNA-Strängen bekannter Größe zu bestimmen.

Die Agarose-Gelelektrophorese wird angewendet, um das Fortschreiten eines Restriktionsenzymverdaus zu stoppen. Weiterhin dient sie dazu, die Ausbeute und Reinheit der DNA-Reinigung oder einer PCR-Reaktion zu bestimmen. Ebenso zählt die Trennung der DNA-Fragmente auf der Basis ihrer Größe, um sie später vom Gel zu reinigen, zu den Verwendungsmöglichkeiten der Agarose-Gelelektrophorese. 
Die DNA-Proben werden mit einem Beladungspuffer gemischt, der einen Farbstoff enthält, um die Vorderseite zu markieren. Anschließend werden diese in die Probenvertiefungen geladen. Die Gele werden 45 Minuten lang bei konstanter Spannung (100 bis 200 Volt) einer Elektrophorese unterzogen. Größenmarker werden zusammen mit den DNA-Proben einer Co-Elektrophorese ausgesetzt, um die Größe der aufgelösten Fragmente zu bestimmen. Die Gele werden mit Ethidiumbromid, das in der Gelmatrix enthalten war, gegossen, um die Sichtbarmachung der DNA-Fragmente unter UV-Licht (302 bis 366 Newtonmeter) zu ermöglichen. Alternativ werden die Gele mit Safeview (einem Farbstoff, der Ethidiumbromid - ein toxisches mutagenes Reagens - ersetzt) mit einer Fluoreszenzemission von rund 490 Newtonmetern gegossen. Der Prozentsatz der Gele liegt zwischen 0,8 Prozent und 2 Prozent, abhängig von der Größe der aufgelösten Fragmente: Je größer das DNA-Fragment ist, desto geringer ist der Prozentsatz des anzufertigenden Agarosegels.

\subsubsection{Polymerase-Ketten-Reaktion}

Mit Hilfe der Polymerasen-Ketten-Reaktion (nachfolgend PCR) ist es möglich, einen DNA-Abschnitt in vitro in großen Mengen zu vervielfältigen. Für die PCR werden die zu vervielfältigende Matrizen-DNA, die spezifischen Primer - welche an die Ausgangs-DNA binden -, Desoxynukleotide sowie eine thermostabile Polymerase zusammengegeben. Insgesamt werden im Rahmen der PCR 20 bis 40 Zyklen durchlaufen. Jeder Zyklus besteht dabei aus drei Schritten: Zunächst erfolgt die Denaturierung, die der Auftrennung der doppelsträngigen DNA dient und bei ca. $95{ }^{\circ} \mathrm{C}$ stattfindet. Als zweites folgt die Phase der Anlagerung. Während dieser wird die Temperatur wieder gesenkt und es lagern sich die beiden Primer an ihre komplementären Sequenzen in der Matrizen-DNA an. Als letzter Schritt findet die Elongation statt. Bei dieser kommt es zu einem erneuten Temperaturanstieg auf ca. $75^{\circ} \mathrm{C}$. Hierbei nutzt die thermostabile DNA-Polymerase die angelagerten Primer als Startpunkt und baut die vorhandenen Desoxynukleotide komplementär zur Matrizen-DNA ein.

Der erste und zweite Zyklus unterscheidet sich leicht von den darauffolgenden Zyklen. Bei den entstehenden Produkten am Anfang einer PCR handelt es sich um zu lange Amplifikate. Dies lässt sich auf eine Synthese des neuen Strangs über die Bindestelle des komplementären Primers hinaus zurückführen. Aus diesem Grund erhält man die gewünschte Länge erst ab dem dritten Zyklus (Molekularbiologische Methoden 2.0).

Der PCR-Reaktionsansatz erfolgt gemäß den Angaben von Tabelle 12. 
Tabelle 12: Protokoll zur PCR

\begin{tabular}{|l|l|}
\hline Plasmid-DNA/genomische DNA & $0.5-5 \mathrm{ng} / 25-200 \mathrm{ng}$ \\
\hline 5x Phusion HF Puffer/10x Roche Buffer & $6 \mu \mathrm{l} / 3 \mu \mathrm{l}$ \\
\hline dNTP-Mix & $2,4 \mu \mathrm{l}$ \\
\hline Primer F & $1,2 \mu \mathrm{l}$ \\
\hline Primer R & $1,2 \mu \mathrm{l}$ \\
\hline Phusion HF Polymerase/Roche Polymerase & $0.6 \mu \mathrm{l} / 0.3 \mu \mathrm{L}$ \\
\hline Steriles H2O & auf $30 \mu \mathrm{L}$ auffüllen \\
\hline Plasmid DNA/genomische DNA & $0.5-5 \mathrm{ng} / 25-200 \mathrm{ng}$ \\
\hline
\end{tabular}

Die PCR erfolgt in den innerhalb der nachfolgenden Tabelle aufgeführten Teilschritten:

Tabelle 13: Ablauf der PCR

\begin{tabular}{|l|l|l|}
\hline Schritt & Temperatur & Dauer \\
\hline 1 & $94^{\circ} \mathrm{C}\left(96^{\circ} \mathrm{C}\right.$ bei Verwendung von genomischer DNA & $5 \mathrm{~min}$ \\
\hline 2 & $94^{\circ} \mathrm{C}$ & $1 \mathrm{~min}$ \\
\hline 3 & $50-65^{\circ} \mathrm{C}$ (Primer-Schmelztemperatur überprüfen & $1 \mathrm{~min}$ \\
\hline 4 & $72^{\circ} \mathrm{C}$ & $1 \mathrm{~min}$ \\
\hline 5 & $72^{\circ} \mathrm{C}$ & $5 \mathrm{~min}$ \\
\hline 6 & $4^{\circ} \mathrm{C}$ & $\infty$ \\
\hline
\end{tabular}

Die Schritte 2 bis 4 werden dabei 24 bis 34 Mal wiederholt

\subsubsection{Aufreinigung von DNA aus Agarosegelen}

Nach der Elektrophorese wird der Bereich des Gels, der die isolierten DNA-Fragmente enthält, herausgeschnitten, gewogen und es wird das gemäß den Anweisungen des Kits (High Pure PCR Product Purification Kit, Roche) vorgeschriebene Volumen an DNABindungspuffer-hinzugegeben. Die Gelmatrix wird anschließend bei $55{ }^{\circ} \mathrm{C}$ geschmolzen und auf eine Reinigungssäule (die eine Siliciumdioxid Matrix enthält) aufgetragen. Nach der vorgeschriebenen Anzahl von Wäschen, um alle verbleibenden Verunreinigungen zu entfernen, wird die gereinigte DNA mit Puffern geringer Salzelution eluiert. 


\subsubsection{DNA-Ligation}

Die DNA-Ligation dient der Verknüpfung zweier DNA-Fragmente zu einer Einheit. Ein 30-Mikroliter-Ansatz beinhaltet 6 Mikroliter linearisierten Vektor, 4 Mikroliter linearisiertes Insert, 0,5 Mikroliter T4-DNA-Ligase (Fermentase), 3 Mikroliter 10fach T4-Puffer und 16,5 Mikroliter steriles Wasser zum Auffüllen. Zur Bestimmung des Hintergrunds (z. B. unvollständig geschnittener Vektor) sollte eine Kontrolle angesetzt werden. Diese wird auf die gleiche Weise wie die Ligation hergestellt. Allerdings wird hierbei die Insertmenge durch steriles Wasser ersetzt. Die angesetzte Lösung wird für 16 Stunden konstant bei einer Temperatur von $18{ }^{\circ} \mathrm{C}$ gehalten, anschließend für 10 Minuten auf $65{ }^{\circ} \mathrm{C}$ erhitzt und schließlich bei $4{ }^{\circ} \mathrm{C}$ aufbewahrt.

Tabelle 14: Protokoll zur DNA-Ligation

\begin{tabular}{|l|l|l|}
\hline & Ligation & Kontrolle \\
\hline Vektor & $6 \mu \mathrm{l}$ & $6 \mu \mathrm{l}$ \\
\hline Insert & $4 \mu \mathrm{l}$ & - \\
\hline 10fach T4 Puffer & $3 \mu \mathrm{l}$ & $3 \mu \mathrm{l}$ \\
\hline Steriles Wasser & $16,5 \mu \mathrm{l}$ & $20,5 \mu \mathrm{l}$ \\
\hline T4-Ligase & $0,5 \mu \mathrm{l}$ & $0,5 \mu \mathrm{l}$ \\
\hline Volumen gesamt & $30 \mu \mathrm{l}$ & $30 \mu \mathrm{l}$ \\
\hline
\end{tabular}

Die Ligation erfolgt in den innerhalb der nachfolgenden Tabelle aufgeführten Schritten:

Tabelle 15: Protokoll zum zeitlichen Ablauf der Ligation

\begin{tabular}{|l|l|}
\hline $18^{\circ} \mathrm{C}$ & 16 Stunden \\
\hline $65^{\circ} \mathrm{C}$ & 10 Minuten \\
\hline $4^{\circ} \mathrm{C}$ & $\infty$ \\
\hline
\end{tabular}

\subsubsection{Elektroporation}

Elektroporation dient dem Einbringen von Plasmid-DNA in Bakterienzellen. Zunächst wird der DNA der Eintritt ermöglicht, indem die Membran des E. coli-Bakteriums vorübergehend permeabel wird. Durch eine selektive Agarplatte (z. B. mit Antibiotikum) werden nur Bakterienzellen positiv selektioniert, die ein Plasmid aufgenommen haben. Im Anschluss an das ausreichende Wachstum der Kolonie kann mit Hilfe einer sogenannten Minipräparation Plasmid-DNA gewonnen werden. 
Die allgemeinen Grundeinstellungen des Elektroporators liegen bei 400 Ohm und 25 Mikrofarad. Nach dem Einschalten muss die Voltzahl auf 2,5 erhöht werden; dies entspricht dem Maximum.

Zunächst wird 1 Milliliter SOC in den Pasteur, anschließend die DNA in jeweils 50 Mikroliter-Aliquots pipettiert. Die zu pipettierende Menge DNA liegt bei einer Ligation bei ca. 1,5 Mikroliter einer 50 Mikroliter-Reaktion. Bei geplanter Retransformation wird 1 Mikroliter einer 1:1000- bis 1:100000-Verdünnung verwendet. Im nächsten Schritt erfolgt die blasenfreie Befüllung der Elektroporationsküvette mit allen zuvor genannten Bestandteilen. Anschließend wird die Küvette in den Elektroporator gestellt und dieser wird gestartet. Die Zeitkonstante sollte zwischen 6 und 10 liegen. Sollte sie niedriger sein, ist auch die Transformationseffizienz geringer. Die Resuspendierung mit 1 Milliliter SOC in Kulturröhrchen sollte direkt im Anschluss vorgenommen werden. Danach erfolgt für 30 bis 60 Minuten eine Inkubation der Zellen bei $37^{\circ} \mathrm{C}$. Im letzten Schritt werden zwischen 100 und 500 Mikroliter der Lösung auf eine selektive Platte gegeben und über Nacht bei 37 ${ }^{\circ} \mathrm{C}$ inkubiert.

\subsubsection{Isolierung von Plasmid-DNA}

Die Isolierung von Plasmid-DNA aus Bakterienzellen wird als sogenannte Minipräparation bezeichnet. Nachdem die Zellkolonien auf dem Selektivmedium ausreichend gewachsen sind, werden sie in ein Flüssigmedium geimpft und bei $37^{\circ} \mathrm{C}$ für 24 Stunden inkubiert.

Mit Hilfe der Plasmid-DNA wird die Minipräparation mit dem „Nucleo Spin®Plasmid Mini-Kit“ von Machery-Nagel nach Herstellerprotokoll durchgeführt.

\subsubsection{Bestimmung der DNA-Konzentration}

Mit Hilfe des „NanoDrop“-Geräts der Firma ThermoScientific wurde die Extinktion der DNA-Proben angezeigt. Durch die Verwendung des Lambert-Beer'schen Gesetzes konnte die DNA-Konzentration (c) der Proben ermittelt werden:

$$
E_{\lambda}=\log _{10}\left(\frac{I_{0}}{I_{1}}\right)=\varepsilon_{\lambda} \cdot c \cdot d
$$

(E: Extinktion; I1: Intensität des transmittierten Lichtes; I0: Intensität des einfallenden Lichtes; c: Stoffmengenkonzentration der absorbierenden Substanz, $\varepsilon_{\lambda}$ : dekadischer Extinktionskoeffizient, d: Schichtdicke der Küvette) 


\subsubsection{DNA-Sequenzierung}

Die DNA-Sequenzierung erfolgte durch die Firma GATC Biotech AG (Konstanz, HRB 381757) nach der Technik von Sanger (Sanger und Coulson 1975).

\subsubsection{Biochemische Techniken}

\subsubsection{Zelldichte bei Hefezellen}

Mit Hilfe des Spektralphotometers wird die Zelldichte der Hefezellkulturen gemessen. Die optische Dichte (OD) gibt die Dichte von Zellen in einem flüssigen Medium an, die bei 600 Newtonmetern gemessen wurde (OD600). Dabei wird die von der Schichtdicke unabhängige Extinktion angegeben.

\subsubsection{Alkalische Natriumhydroxid-Lyse von Zellen}

Um die Proteine für weitere Experimente aus den S. cerevisiae extrahieren zu können, muss die Zelle lysiert werden. Eine alkalische Lösung dient hierbei dem Aufbrechen der Zellmembran. Diese Natriumhydroxid-Lyse erfolgt für alle Proben, die auf ein SDS-Gel aufgetragen werden sollen.

Zunächst werden die aufzutragenden Zellen während der exponentiellen Wachstumsphase bei $13000 \mathrm{Upm}$ zentrifugiert und dann in 200 Mikrolitern $100 \mathrm{mM} \mathrm{NaOH}$ resuspendiert. Nach zehnminütiger Inkubation bei Raumtemperatur werden sie erneut pelletiert und entsprechend der Zelldichte in variablen Volumina von $1 \times$ SDS-Ladepuffer resuspendiert. Danach wird die Suspension fünf Minuten auf $95{ }^{\circ} \mathrm{C}$ erhitzt und dann pelletiert. Der sich daraus ergebende Überstand wird als Proteinlysat verwendet.

\subsubsection{SDS-Polyacrylamid-Gelelektrophorese}

Die Natriumdodecylsulfat-Polyacrylamid-Gelelektrophorese (SDS-PAGE) dient der Auftrennung von Proteinen nach Größe und Ladung in einem elektrischen Feld. Die zuvor alkalisch lysierten und durch SDS-Ladepuffer-Resuspension negativ geladenen und mit DTT (Dithiotreitol) versetzen Proteine wandern durch das Anlegen einer Spannung zum positiven Pol - der Anode. Generell wandern kleinere Proteine schneller und leichter durch das Gel als größere.

Die verschiedenen Proteine besitzen eine individuelle Netto-Eigenladung. Deshalb ist das anionische Tensid SDS notwendig, um die Proteine zu beschichten und ihnen eine negative Ladung zu geben. Das Reduktionsmittel DTT (Dithiotreitol) dient hingegen der Auflösung von Disulfidbrücken. Das anschließende Probensieden ermöglicht eine Denaturierung und 
eine überwiegend lineare Konformation des Proteins, sodass das Laufverhalten der jeweiligen Proteine nur noch von ihrem molekularen Gewicht abhängt.

Das System der SDS-PAGE besteht hauptsächlich aus drei Komponenten: dem Trennund Sammelgel sowie dem Elektrodenpuffer. Für diese Arbeit wurden Sammelgele mit einer $\quad 5 \%$-igen Konzentration und Trenngele überwiegend mit einer $12 \%$-igen Konzentration verwendet.

Tabelle 16: Protokoll zur Herstellung von Trenn- und Sammelgel

\begin{tabular}{|l|l|l|}
\hline & $\begin{array}{l}\text { Sammelgel } 5 \% \text { in } \mathrm{ml} \\
\text { Mengenangaben für 2 } \\
\text { Gele }\end{array}$ & $\begin{array}{l}\text { Trenngel 12 \% in ml } \\
\text { Gengenangaben für 2 }\end{array}$ \\
\hline $\mathrm{H} 2 \mathrm{O}$ & 5,5 & 3,3 \\
\hline Acrylamide mix $(30 \%)$ & 1,3 & 4,0 \\
\hline 1.5 M Tris (pH 8,8) & - & 2,5 \\
\hline 1.0 M Tris (pH 6,8) & 1,0 & - \\
\hline SDS (10\%) & 0,08 & 0,1 \\
\hline Ammonium persulfate $(10 \%)$ & 0,08 & 0,1 \\
\hline TEMED & 0,008 & 0,004 \\
\hline
\end{tabular}

Die für die Gelherstellung zu verwendenden Glasplatten werden vor jedem Gebrauch gewaschen und mit Ethanol gereinigt. Im Anschluss werden als erstes 3,5 Milliliter des Trenngels zwischen die Glasplatten gegossen und an der Oberkante mit $100 \%$ Isopropanol abgedeckt, um eine gerade Kante zu erhalten. Nach ca. 45 Minuten ist eine vollständige Polymerisation des Trenngels zu erwarten. Das Isopropanol muss abgegossen und vollständig entfernt werden, sodass die Kammer mit ca. 1 Milliliter Sammelgel aufgefüllt und ein Kamm für die Taschen eigesetzt werden kann. Nachdem auch das Sammelgel vollständig polymerisiert ist, kann der Kamm für die Taschen vorsichtig entfernt werden und es kann - mit Hilfe der Gele - der Zusammenbau der Kammer erfolgen. Je nach Taschengröße werden bis zu 15 Mikroliter der Probe in die Tasche eingebracht. Als Längenstandard kommt der Page Ruler Prestained von ThermoScientific zur Anwendung. Während sich die Proteine im Sammelgel befinden, liegt der Strom bei 15 Milliampere pro Gel. Nachdem die Moleküle das Trenngel erreichen, wird der Strom auf 30 Milliampere pro Gel erhöht. Bei Ankunft der Marker am unteren Gelrand wird der Stromfluss schließlich gestoppt. 


\subsubsection{Western Blot und Antikörper-Detektion}

Die Antikörper-Detektion ist eine Methode zum Nachweis spezifischer Proteine, die auf der Erkennung eines Epitops durch einen Antikörper basiert. Somit wird die Analyse der im SDS-PAGE-Gel aufgetrennten Proteine durch eine spezielle Visualisierung ermöglicht. Nach Absolvierung der SDS-PAGE wird das Gel in Transferpuffer gelegt. Mit Hilfe einer Art „Transfer-Sandwich“ - bestehend aus Filterpapier, Nitrocellulose-Membran, Gel und einer weiteren Schicht Filterpapier - erfolgt die Übertragung von Gel auf die Nitrocellulose-Membran. Die Herstellung des Transfer-Sandwichs erfolgte gemäß Herstellerangaben. Die Übertragung dauerte innerhalb der im Rahmen dieser Dissertation durchgeführten Versuche 80 Minuten bei Einstellungen von 60 Volt und 0,5 Ampere.

Nach der Übertragung sind die aufgetrennten Proteine für den Antikörpernachweis zugänglich: Die Membranen werden für 5 Minuten mit Ponceau-S-Lösung gefärbt. Dies dient dem Nachweis einer korrekten Übertragung der Proteine auf die Membran, da sich Ponceau-S unspezifisch an jedes Protein bindet. Im nächsten Schritt wird die Membran in Milchpuffer eingelegt, damit alle nicht von Proteinen besetzten Flächen blockiert werden. Anschließend wird die blockierte Membran mit dem primären Antikörper, welcher in Milch gelöst wird, über Nacht bei $4{ }^{\circ} \mathrm{C}$ inkubiert. Dieser Antikörper bindet sich spezifisch an das nachzuweisende Protein. Am folgenden Tag wird die Membran dreimal fünf Minuten lang mit 1xPBS-T gewaschen. Im letzten Schritt wird die Membran mit dem sekundären Antikörper eine Stunde lang bei Raumtemperatur in Milch inkubiert, dann erneut dreimal in 1xPBS-T gewaschen und schließlich im Licor Odyssey gescannt.

\subsubsection{Experimente mit $S$. cerevisiae}

\subsubsection{Transformation von Hefezellen}

Damit manipulierte DNA in Hefezellen eingebracht werden kann, muss eine Transformation durchgeführt werden. Zunächst erfolgt eine Inkubation des Stamms in 4 Millilitern Flüssigmedium für 24 Stunden bei $30^{\circ} \mathrm{C}$.

Die flüssige Kultur wird bei 2000 Upm für 5 Minuten abzentrifugiert und anschließend in 1 Milliliter sterilem Wasser gewaschen. Das entnommene Pellet wurde im Rahmen der Versuche in 200 Mikrolitern Lithium-Acetat-Mix resuspendiert und mit 0,5 bis 1,0 Mikrogramm DNA und 18 Mikrolitern Carrier-DNA vermengt und gevortext. Anschließend wurden 1,2 Milliliter PEG-Lösung hinzugegeben. Es erfolgte zunächst eine Inkubation für 45 Minuten bei Raumtemperatur und für weitere 15 Minuten bei $42{ }^{\circ} \mathrm{C}$. Nach erneutem Abzentrifugieren wurde das Zell-Pellet mit 100 Millilitern sterilem Wasser resuspendiert und auf selektiven Platten ausgestrichen. Abschließend folgt die Inkubation dieser Platten bei $30^{\circ} \mathrm{C}$ für ca. 48 Stunden. 


\subsubsection{Wachstumstest}

Die zu untersuchenden Zellkulturen werden über Nacht in 3 Millilitern YPAD inkubiert. Am nächsten Tag werden 900 Mikroliter steriles Wasser (H2O), zusammen mit 100 Mikrolitern der Zellkultur, in eine Küvette gegeben und die OD (optische Dichte) wird bestimmt. Mit Hilfe der folgenden Formel wird die Zellkultur entsprechend ihrer gemessenen $\mathrm{OD}$ mit $\mathrm{H} 2 \mathrm{O}$ verdünnt:

$$
O D_{600}(\text { unverdünnt }) \times \text { Volumen }=O D_{600}(\text { verdü } n n t) \times 1000 \mathrm{ml}
$$

Anschließend werden die bereits verdünnten Zellkulturen dreimal jeweils im Verhältnis 1:8 weiter verdünnt. So entsteht eine Verdünnungsreihe mit insgesamt vier Verdünnungsstufen.

2.2.3.3 Kreuzung der GFP-getaggten Bibliothek mit den zu untersuchenden ret2 Mutanten

Für die Hefe S. cerevisiae wurde eine Methode, die „SGA-Analyse“ (Synthetic Genetic Array) entwickelt, welche die Möglichkeit bietet, eine systematische Konstruktion von Doppelmutanten zu erstellen und eine globale Analyse von genetischen Wechselwirkungen ermöglicht. In einem SGA-Screening wird eine sogenannte Query-Mutation mit einem geordneten Array von ungefähr 5000 lebensfähigen Gen-Deletionsmutanten gekreuzt, sodass die Nachkommen, welche die Mutationen aufweisen, hinsichtlich ihrer Veränderungen bewertet werden können. Dieser Ansatz kann auch mit Hefearrays, die Modifikationen wie eine GFP-Fusion enthalten, durchgeführt werden. Im Rahmen dieser Arbeit erfolgte die Verwendung einer Hefebibliothek, deren einzelnen Proteine eine GFPMarkierung trugen, sodass eine Fluoreszenzmikroskopie zur Lokalisationsbestimmung des jeweiligen Proteins im jeweils zu untersuchenden genetischen Hintergrund möglich war. Dieser Array-basierte Ansatz automatisiert die genetische Analyse von Hefen im Allgemeinen und kann leicht für eine Reihe unterschiedlicher genetischer Screenings angepasst werden.

Für die SGA-Analyse ist zunächst ein Aufbau erforderlich, bei dem die BibliotheksStämme und die Knockout- oder modifizierten Stämme generiert werden. Anschließend umfasst das Verfahren mehrere Replikationsschritte, die manuell oder robotergesteuert durchgeführt werden können. Für das SGA dieser Arbeit wurde der Rotor HDA der Firma Singer Instruments verwendet; der Ablauf orientierte sich an den Herstellerempfehlungen. 
SGA-Ablauf:

Der im Folgenden beschriebene Ablauf wurde sowohl für die isogenetische Kontrolle als auch für den Knockout Stamm durchgeführt. Beide wurden als modifizierter Stamm beschrieben (s. Tabelle 8).

1. Herstellung der Quellenplatten des modifizierten Stamms und der GFP-Bibliothek

Der modifizierte Stamm wurde über Nacht in $5 \mathrm{ml}$ YEPD hochgezogen.

Die flüssige Kultur wurde auf eine YEPD-Platte gegossen und mit einem Replikator auf eine frische YEPD-Platte übertragen. In dem darauffolgenden Schritt diente diese Platte als Quelle zur Paarung mit der bekannten GFP-Bibliothek. Das zu verwendende Format betrug 384 Kolonien pro Platte. Das Fixieren des modifizierten Stamms in einem 384-Format auf einer Agarplatte wurde wie vom Hersteller empfohlen durchgeführt. Die Kolonien wuchsen für zwei Tage lang bei $30^{\circ} \mathrm{C}$.

Die GFP-Bibliothek wurde auf frisches YEPD-G418-Medium im 384 KolonienFormat kopiert, sodass die Formate der zu kreuzenden Stämme übereinstimmten. Eine Inkubation von einem Tag bei $30{ }^{\circ} \mathrm{C}$ wurde durchgeführt.

2. Kreuzung des modifizierten Stamms auf der 384 Kolonien-Platte mit der GFP-Platte im 384 Kolonien-Format (diploide Selektion):

Als erstes wurde die gewachsene Platte mit den 384 Kolonien des modifizierten Stamms auf eine frische YEPD-Platte übertragen. Im nächsten Schritt wurde die GFPBibliotheks-Platte auf die zuvor aufgetragenen Kolonien des modifizierten Stamms übertragen und einen Tag bei Raumtemperatur inkubiert.

3. MATa /Adiploide Selektion und Sporulation:

Die resultierenden MATa/ Azygoten wurden zur Selektion auf YEPD-G418-/ clonNAT-Platten übertragen. Die diploiden Selektionsplatten wurden zwei Tage bei 30 ${ }^{\circ} \mathrm{C}$ inkubiert. Im nächsten Schritt wurden die diploiden Zellen auf angereichertes Sporulationsmedium übertragen. Die Platten wurden fünf Tage bei $22^{\circ} \mathrm{C}$ inkubiert.

4. MATa meiotische Nachkommenauswahl (haploide Selektion):

Die Sporen wurden auf SD-His-Arg-Lys+canavanine+S-AEC-Medium übertragen.

Die haploiden Selektionsplatten wurden zwei Tage bei $30^{\circ} \mathrm{C}$ inkubiert.

5. Wiederholung des Schritts vier 
6. Herstellung der finalen modifizierten Selektion der GFP-Bibliothek

Es erfolgte eine Übertragung der Sporen aus den Schritten vier und fünf auf SD(MSG)His-Arg-Lys-ura+canavanine+S-AEC+CloNAT für alle Markierungen beider Quellstämme (modifizierte Stämme (Tabelle 8) und GFP-Bibliothek). Die Selektionsplatten wurden zwei Tage bei $30{ }^{\circ} \mathrm{C}$ inkubiert. 


\section{Ergebnisse}

\subsection{Herstellung eines Knockout-Stammes und einer isogenetischen Kontrolle}

Um die Fragestellung dieser Dissertation zu beantworten, musste ein Knockout-Stamm hergestellt werden, in welchem die $\mu$-Homologie-Domäne von delta-COP deletiert ist. Der Knockout-Stamm Ret2LD2 $\alpha$ wurde nach dem Genabschnitt benannt, welcher der Deletion vorangestellt ist, der Longin-Domäne und der darauffolgenden alpha-Helix $2 \alpha$. Um einen Stamm mit der $\mu$-Homologie-Domäne zu erhalten, der mit dem Ret2LD2 $\alpha$ Stamm vergleichbar ist, wurde eine isogenetische Kontrolle, der Stamm Ret2Clonat, erstellt (Tabelle 8). Beide Stämme enthalten ein Gen, welches Resistenz gegen Clonat vermittelt und als Selektionsmarker dient.

Die Strategie zur Herstellung dieser Stämme beruht auf homologer Rekombination. Hierfür musste zunächst ein Vektor hergestellt werden, der die gewünschten genetischen Informationen enthält. Bei diesem Vorgang wurden Restriktionsenzyme, welche die DNA an bestimmten Positionen erkennen und schneiden können, eingesetzt. Bevor die benötigten Schnittsequenzen mittels Plasmids in den Zielorganismus transferiert werden konnten, mussten sie durch Ligasen miteinander verknüpft werden.

Tabelle 17: Die verwendeten Restriktionsenzyme und ihre jeweilige Erkennungssequenz

\begin{tabular}{|c|c|}
\hline Restriktionsenzym & Erkennungssequenz \\
\hline \multirow{2}{*}{ BamHI (Bacillus amyloliquefaciens) } & 5'-GGATCC-3' \\
\hline & 3'-CCTAGG-5' \\
\hline \multirow{2}{*}{ EcoRI (Escherichia coli) } & 5'-GAATTC-3' \\
\hline & 3'-CTTAAG-5' \\
\hline \multirow{2}{*}{ XhoI (Xanthomonas holcicola) } & 5'-CTCGAG-3' \\
\hline & 3'-GAGCTC-5' \\
\hline
\end{tabular}

(Official REBASE Homepage | The Restriction Enzyme Database | NEB)

Die zur Rekombination zu verwendende Kassette wurde unter Verwendung von BamH1EcoR1 und EcoR1-Xho1 in P416 kloniert. 


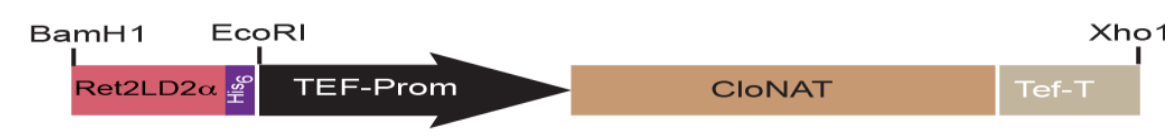

a

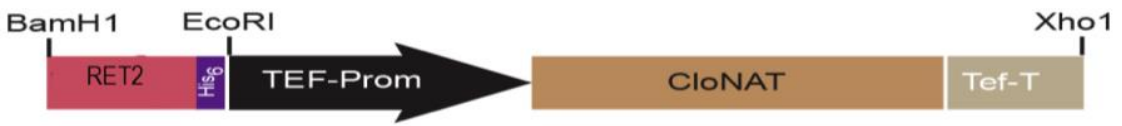

b

Abbildung 4: Schematische Darstellung der Herstellung eines Knockout-Stammes (a) und einer isogenetischen Kontrolle (b)

Nachdem ein geeigneter Plasmid-Vektor (p416 Ret2LD2a-His6-Tefp-Clonat) mit den erforderlichen genetischen Informationen hergestellt worden war, musste dieser zum Zwecke der homologen Rekombination in den Zielorganismus S. cerevisiae transferiert werden. Das innerhalb der Untersuchungen erzeugte und verwendete Plasmid wies eine Antibiotikaresistenz gegen Clonat auf. Durch das Wachstum auf Clonat-haltigem Selektivagar kam es zur Selektion der Hefezellen, in denen der Austausch stattgefunden hatte.

\subsection{Auswahl eines Knockout-Stammes und einer isogenetischen Kontrolle}

Die Auswahl eines geeigneten Knockout Stammes und einer isogenetischen Kontrolle wurde anhand von mehreren Faktoren - den Western Blots, der Wachstums-Analyse, der DNA-Analyse der genomischen DNA sowie der DNA-Sequenzierung - getroffen. Es wurden insgesamt vier Knockout-Stämme (1A-1D) und drei isogenetische Kontrollen (2A2C) ausgewertet. Mit Hilfe von PCR aus genomischer DNA, gefolgt von einer DNA Sequenzierung, konnte nachgewiesen werden, dass es sich bei den Stämmen 1A-1D um Stämme handelte, bei denen die $\mu$-Homologie Domäne (Ret2) nicht vorhanden war. Dies wurde zusätzlich durch einen Western-Blot untermauert, in dem das delta-COP-Protein (Ret2) mit einem spezifischen Antiserum nachgewiesen wurde (siehe Abbildung 5). 


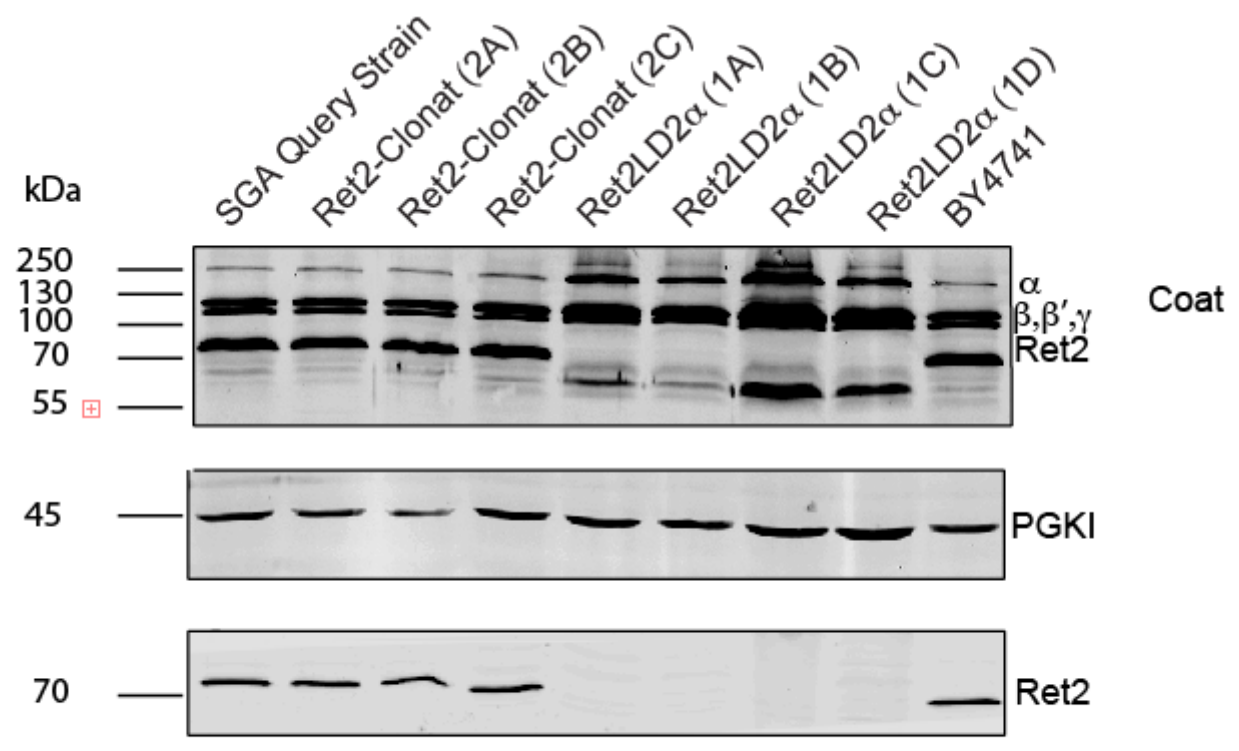

Abbildung 5: Western Blot der Knockout Stämme (1A-1D) und der isogenetischen Kontrollen (2A-2C);

Das anti-COPI-Coat-Antiserum diente dabei der Detektion aller COPI-Untereinheiten. Der antiRet2-Antikörper detektiert hingegen die $\mu$-Homologie Domäne. Zur Ladekontrolle wurden die Membranen im Anschluss mit anti-PGK1 inkubiert und detektiert. Der hier nicht genetisch modifizierte SGA-Query Strain und BY4741 dienen als Kontrollstämme.

Bei der Untersuchung des Western Blots (siehe Abbildung 5) war - im Vergleich zu den isogenetischen Kontrollen - eine Zunahme von $\alpha$-COP in den Knockout-Stämmen zu erkennen. Es lag der Verdacht einer Kompensationsreaktion nahe, mit der die Zellen möglicherweise versuchen, die Funktionalität des COPI-Komplexes zu steigern. Der Stamm 1B zeigte die größte Konformität zu den Vergleichsstämmen. Die isogenetischen Kontrollen wirkten im Western Blot kongruent.

Die Analyse der genomischen DNA lieferte bei den Knockout-Stämmen 1B und 1C die besten Ergebnisse. Für die isogenetischen Kontrollen zeigte hingegen die genomische DNA von 2A den optimalsten Wert.

Um Aussagen zum Wachstum der einzelnen Stämme machen zu können, wurde je ein Wachstumstest für die Knockout Stämme (1A-1D) und die isogenetischen Kontrollen (2A2C) bei 30,37 und $39{ }^{\circ} \mathrm{C}$ durchgeführt. Temperaturen über $30^{\circ} \mathrm{C}$ setzen Hefezellen unter Hitzestress und ermöglichen einen Test auf den robusten Ablauf aller zellulären Prozesse. Hitze-Empfindlichkeit ist häufig ein Anzeichen für eine molekulare Fehlfunktion in einem genetisch manipulierten Stoffwechselweg oder zellbiologischen Prozess. Eine Visualisierung der bei diesem Test erzielten Ergebnisse zeigt Abbildung 6. 


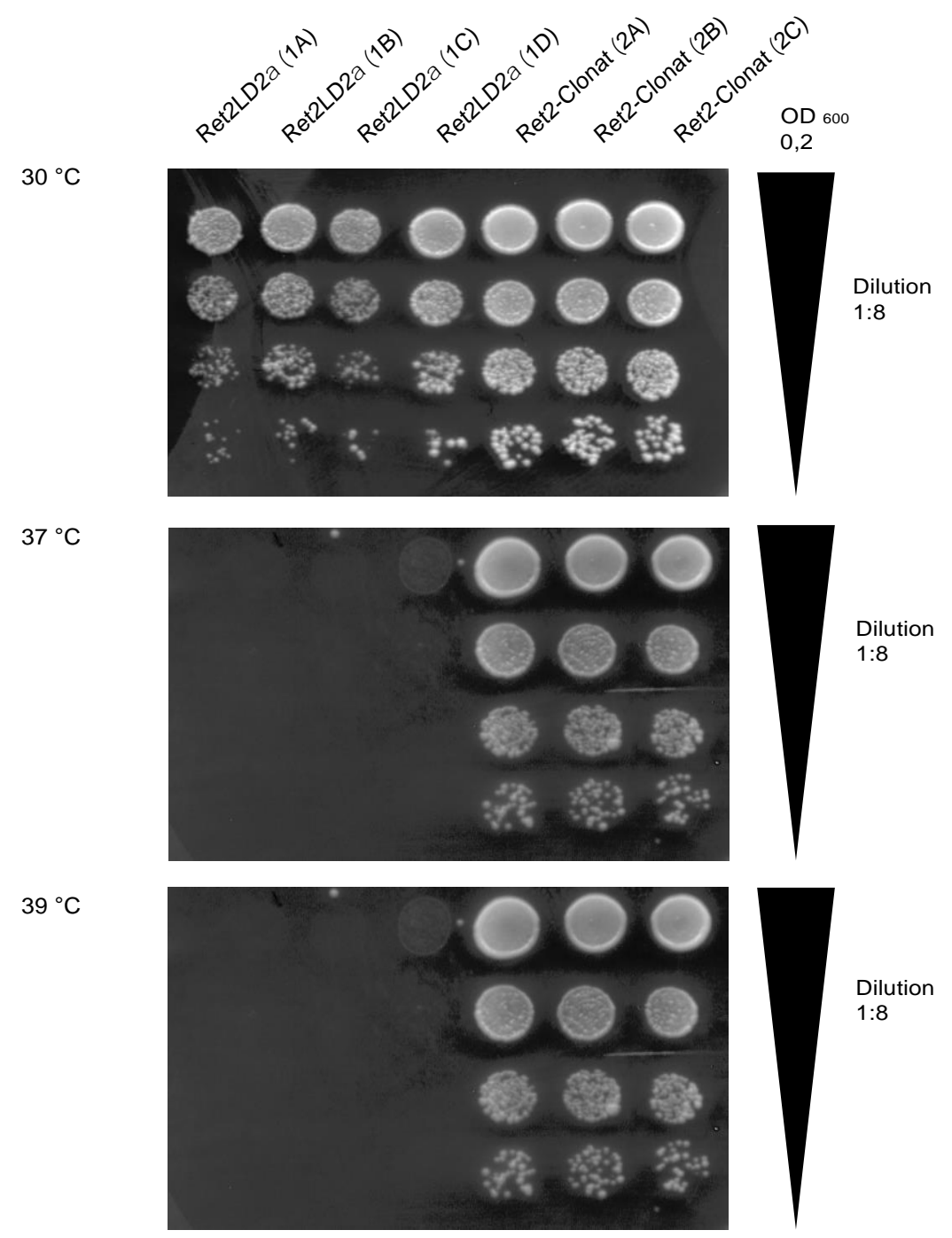

Abbildung 6: Wachstumstest verschiedener Knockout Stämme und isogenetischer Kontrollen

Wachstums-Analyse der Knockout Stämme (1A-1D) und der isogenetischen Kontrollen (2A-2C); Verwendetes Selektivmedium Medium: SC-URA, drei Platten mit jeweils vier Verdünnungsstufen ( jede Stufe enthielt nur noch 1/8 der Menge der vorhergehenden); anschließende Inkubation für 48 Stunden $\left(30^{\circ} \mathrm{C}, 37^{\circ} \mathrm{C}\right.$ und $\left.39^{\circ} \mathrm{C}\right)$

Es wurden drei Platten mit jeweils vier Verdünnungsstufen angefertigt. Jede dieser Stufen enthielt nur noch ein Achtel der Konzentration der vorherigen Stufe. Anschließend wurden die Platten für 48 Stunden in Inkubatoren mit den bereits erwähnten, unterschiedlichen Temperaturen $\left(30^{\circ} \mathrm{C}, 37^{\circ} \mathrm{C}\right.$ und $\left.39^{\circ} \mathrm{C}\right)$, gelegt.

Bei der Auswertung der Resultate zeigte sich, dass die Knockout-Stämme hitzeempfindlich, die isogenetischen Kontrollen hingegen hitzestabil, waren. Bei $30{ }^{\circ} \mathrm{C}$ waren alle Stämme lebensfähig. Durch zunehmende Verdünnung zeigte sich jedoch eine erhöhte 
Wachstumsrate der isogenetischen Kontrollen im Vergleich zu den Knockout Stämmen. Innerhalb der Knockout-Stämme schien das Wachstum von 1B und 1D leicht überlegen zu sein. Unter den isogenetischen Kontrollen waren in der Wachstums-Analyse keine signifikanten Unterschiede erkennbar.

Unter Beachtung aller bisherigen Versuche zur grundlegenden Charakterisierung der Stämme lag die Wahl von 1B als Knockout-Stamm und 2A als isogenetische Kontrolle nahe.

\subsection{Untersuchung der Hitzesensibilität}

Die Ergebnisse der Wachstums-Analyse warfen neue Fragen auf, da bisher publizierte Studien eine Hitzeresistenz bis $39{ }^{\circ} \mathrm{C}$, auch nach einer Deletion der $\mu$-Homologie-Domäne, belegen (siehe Diskussion) und somit im Widerspruch zu den innerhalb dieser Dissertation erarbeiteten Ergebnissen stehen. Allerdings wurde dieses Ergebnis in einem anderen genetischen Hintergrund als dem hier verwendeten des SGA-Query-Stammes erzielt (REF Arakel 2016).

Um eine genauere Auswertung der Wachstumshemmung unter Hitzeeinwirkung zu ermöglichen, wurden weitere Wachstums-Analysen durchgeführt, welche in Abbildung 7 zu sehen sind. Zunächst wurde mit Hilfe einer Überexpression von Ret2LD2 $\alpha$ versucht, das Wachstum des Knockout-Stammes zu retten. Hierzu wurden die isogenetische Kontrolle und der Knockout-Stamm jeweils mit den Plasmiden Ret2 und Ret2LD2 $\alpha$ sowie - zur Vergleichskontrolle - mit p416MET25. Bei p416MET25 handelt es sich um das leere Empfängerplasmid, in das Ret2 und Ret2LD2 $\alpha$ transformiert wurden. Weiterhin wurden die Versuche sowohl unter Verwendung eines SC-URA-Mediums (Selektion auf das Plasmid) als auch eines YPAD-Vollmediums (keine Selektion) durchgeführt. 


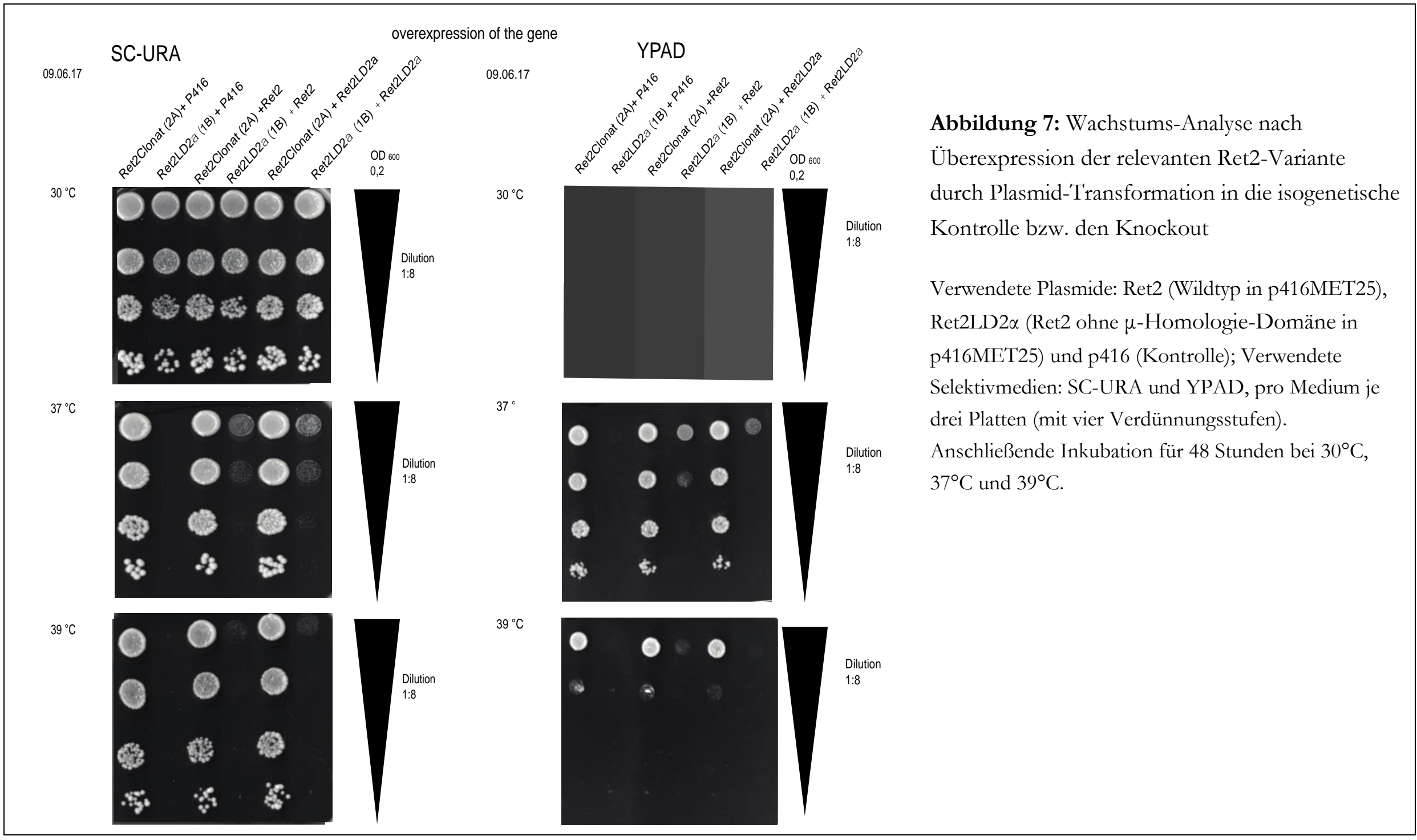


Die Assays wurden dabei parallel auf SC-URA- und YPAD-Platten mit unter den gleichen Bedingungen durchgeführt. Es wurden demnach auch hier pro Medium drei Platten mit jeweils vier Verdünnungsstufen angefertigt. Das bereits beschriebene Vorgehen hinsichtlich der Verdünnung wurde beibehalten (siehe Gliederungspunkt 3.2). Anschließend wurden die Platten ebenfalls für 48 Stunden in Inkubatoren mit Temperaturen in Höhe von 30, 37 und $39^{\circ} \mathrm{C}$ gelegt.

Zur Verifizierung der Wachstums-Versuche wurde die Proteinexpression in den transformierten Stämmen im Anschluss mit Hilfe von Western-Blots analysiert. Das Resultat ist Abbildung 8 zu entnehmen.

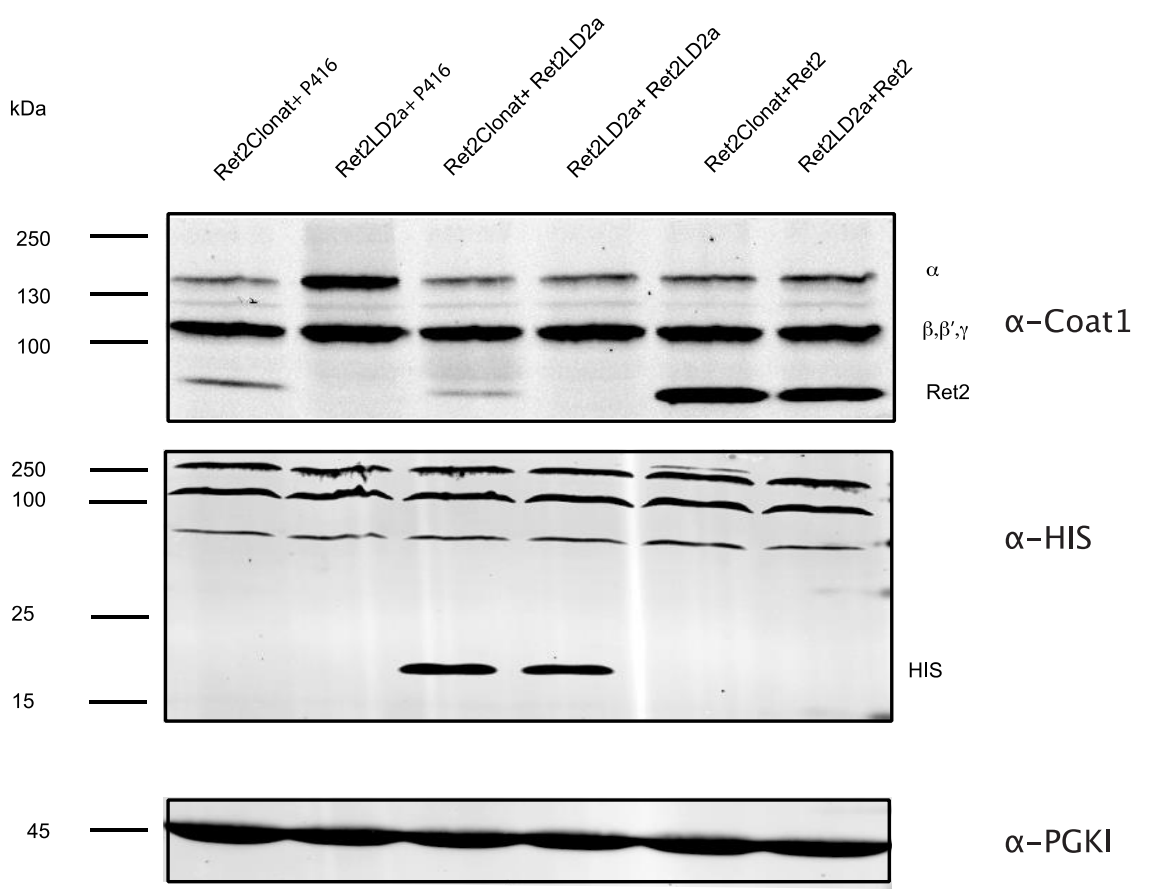

Abbildung 8: Western Blots nach Überexpression der relevanten Ret2-Variante durch Plasmid-Transformation in die isogenetische Kontrolle bzw. den Knockout;

Verwendete Plasmide: Ret2 (Wildtyp in p416MET25), Ret2LD2 $\alpha$ (Ret2 ohne $\mu$-HomologieDomäne in p416MET25) und p416MET25 (Kontrolle); Verwendete Antikörper: Anti-COPICoat-Antiserum zur Detektion der COPI-Untereinheiten; HIS-Antikörper zur Darstellung der HIS Markierung des Ret2LD2 $\alpha$ Stamms; anti-PGK1als Ladekontrolle

In der vorangegangenen Abbildung 8 diente das anti-COPI-Coat-Antiserum der Detektion der COPI-Untereinheiten. Der anti-HIStag-Antikörper zeigt hingegen die HIStag- 
Markierung des überexprimierten Ret2LD2 $\alpha$-Proteins auf. Zur Ladekontrolle wurden die Membranen im Anschluss mit anti-PGK1 inkubiert und auf diese Weise detektiert.

Bei der Auswertung des Western Blots (siehe Abbildung 8) sollte die Analogie von Knockout-Stamm und isogenetischer Kontrolle nach der Transformation mit Ret2 erwähnt werden, da die beiden Stämme im Spotting Assay ein unterschiedliches Wachstumsverhalten aufwiesen. Deutlich erkennbar wird die Überexpression von Ret2LD2 $\alpha$ durch Nachweis des HIStags sowohl im Knockout-Stamm als auch in der isogenetischen Kontrolle.

\subsection{SGA der SWAT-GFP Bibliothek mit dem Knockout-Stamm und der isogenetischen Kontrolle}

Für das geplante SGA (Herstellung einer neuen Hefe-Bibliothek mit Hilfe Synthetischer Genetischer Arraytechnik) wurde eine Teilkollektion der SWAT-GFP-Bibliothek gewählt. Insgesamt besteht die Bibliothek aus vier Platten mit jeweils 1536 unterschiedlichen Proteinen. Minimiert man die Anzahl der Proteine pro Platte auf 384 Stück, so erhält man 16 Platten für die gesamte Bibliothek. Um einen angemessenen Zeitrahmen für diese Arbeit einhalten zu können, wurde der Fokus innerhalb des geplanten SGAs auf fünf ausgewählte Platten mit je 384 Kolonien gelegt. Es handelte sich hierbei um die Platten eins bis vier, sowie Platte 16. Der gesamte SGA-Ansatz erfolgte parallel für Ret2LD2 $\alpha$ und Ret2-Clonat. In Abbildung 9 wird der detaillierte Ablaufplan für den SGA-Ansatz visualisiert: 


\begin{tabular}{|c|c|c|c|c|}
\hline Step & Plates & Recipe & Growth & Temperature \\
\hline \multirow[t]{2}{*}{$\begin{array}{l}\text { Query strain } \\
\text { liquid starter }\end{array}$} & $\begin{array}{l}\text { Liquid media } \\
\text { (Innoculation) }\end{array}$ & $\begin{array}{c}\text { YPAD }+1 \times \text { CloNAT } \\
5 \mathrm{ml}\end{array}$ & 1 day & $30^{\circ} \mathrm{C}$ \\
\hline & $\begin{array}{l}\text { Liquid media } \\
\text { (Dilution) }\end{array}$ & $\begin{array}{c}\text { YPAD }+1 \times \text { CloNAT } \\
50 \mathrm{ml}\end{array}$ & 1 day & $30^{\circ} \mathrm{C}$ \\
\hline $\begin{array}{c}\text { Query strain } \\
\text { array }\end{array}$ & Agar plates & YPAD + 1x Clonat & 2 days & $30^{\circ} \mathrm{C}$ \\
\hline $\begin{array}{l}\text { Library array } \\
\text { (SWAT) }\end{array}$ & Agar plates & SC -Ura & 1 day & $30^{\circ} \mathrm{C}$ \\
\hline Mating & YPAD plates & YPAD & 1 day & RT \\
\hline $\begin{array}{l}\text { Diploid } \\
\text { selection }\end{array}$ & $\begin{array}{c}\text { Plates that contain specific selection to both } \\
\text { the query strain markers and the library } \\
\text { markers. }\end{array}$ & SD(MSG) -URA + 1x CloNAT & 2 days & $30^{\circ} \mathrm{C}$ \\
\hline $\begin{array}{l}\text { 2. Diploid } \\
\text { selection }\end{array}$ & & SD(MSG) - URA + 1x CloNAT & 2 days & $30^{\circ} \mathrm{C}$ \\
\hline Sporulation & Nitrogen starvation plates & $\begin{array}{c}(1 \% \text { K acetate }+ \text { met }+ \text { lys }+ \text { his }+ \text { leu, } \\
25 \% \text { of standard SC ie } 2.5 \mathrm{ml} / / \text { of } 100 \mathrm{x} \\
\text { stock })\end{array}$ & 5- 6 days & $\begin{array}{l}22^{\circ} \mathrm{C} / \mathrm{RT} \\
\text { in a wet box }\end{array}$ \\
\hline $\begin{array}{l}\text { Haploid } \\
\text { selection }\end{array}$ & $\begin{array}{c}\text { SD-His-Arg-Lys+canavanine+S-AEC for } \\
\text { MAIa }\end{array}$ & $\begin{array}{c}\text { SD-His-Arg-Lys+canavanine+ } \\
\text { Thialysine (S-AEC) }\end{array}$ & 2 days & RT \\
\hline $\begin{array}{l}\text { Repeat print } \\
\text { from } \\
\text { sporulation to } \\
\text { haploid }\end{array}$ & $\begin{array}{c}\text { SD-His-Arg-Lys+canavanine+S-AEC for MAT } \\
\text { a. }\end{array}$ & SD-His-Arg-Lys+canavanine+thialysine & 2 days & RT \\
\hline $\begin{array}{l}\text { Final mutant } \\
\text { selection }\end{array}$ & $\begin{array}{l}\text { SD(MSG)-His -Arg-Lys-ura+canavanine+S- } \\
\mathrm{AEC}+\text { CloNAT for all markers from both the } \\
\text { query strain and the library }\end{array}$ & $\begin{array}{c}\text { SD(MSG)-His -Arg-Lys- } \\
\text { ura+canavanine+S-AEC + 1x CloNAT }\end{array}$ & 2days & RT \\
\hline
\end{tabular}

Abbildung 9: SGA-Ablaufplan für Ret2LD2 $\alpha$ und Ret2Clonat zur Kreuzung mit der SWAT GFPBibliothek

Bei den einzelnen Zwischenschritten erschien die Wachstumsgeschwindigkeit der Kontrolle geringfügig höher.

Nach der vollständigen Durchführung des SGA-Protokolls wurden einzelne Stämme stichprobenartig mit Hilfe von Western Blots verifiziert, um den Erfolg der automatisierten Kreuzung zu überprüfen.

\subsection{Mikroskopie des SGAs}

Die fünf Platten der neu hergestellten Bibliothek wurden mit Hilfe von „High Throughput“- Fluoreszenz-Mikroskopie untersucht. Hierzu wurden die 384er-Platten mit den frisch gewachsenen Hefezellen über Nacht in SC-URA-HIS+NAT inokuliert und am nächsten Tag in einem „Low-Fluo“-Medium mit niedriger Eigenfluoreszenz verdünnt. Jeweils 30 Minuten nach der Verdünnung erfolgte die Mikroskopie. Anschließend verweilten die Kulturen zudem für weitere vier Stunden bei $30{ }^{\circ} \mathrm{C}$ im Inkubator und wurden im Anschluss erneut mikroskopiert. Somit erhielt man Bilder der exponentiellen und der stationären Wachstums-Phase.

Zur Auswertung der Mikroskopie-Bilder wurde nach einer möglicherweise veränderten Lokalisation eines Proteins in dem Mutanten-Stamm ohne $\mu$-Homologie-Domäne gesucht und das Ergebnis mit der Lokalisation in der isogenetischen Kontrolle verglichen. 
Als vorläufige Treffer wurden jene Proteine definiert, die nach der Kreuzung mit Ret2LD2 $\alpha$ einen anderen Lokalisations-Phänotyp aufwiesen als nach der Kreuzung mit Ret2-Clonat. Nach dem ersten Mikroskopie-Durchlauf ergab sich so eine Treffermenge von 54 Proteinen.

\subsection{Untersuchung der Treffer}

Da sichergestellt werden musste, dass es sich bei den Ergebnissen um reproduzierbare phänotypische Veränderungen handelt und dass nicht kurzfristig entstandene Mutationen oder Methodik-Fehler die Ursache sind, wurde zur weiteren Auswertung erneut ein automatisierter Fluoreszenz-Mikroskopie-Durchlauf ausgeführt. In diese Untersuchung wurden die zuvor ermittelten 54 Treffer zur Verifikation erneut untersucht. Nach der Auswertung der Bilder verringerte sich die Anzahl der vorläufigen Treffer auf zehn Proteine. 

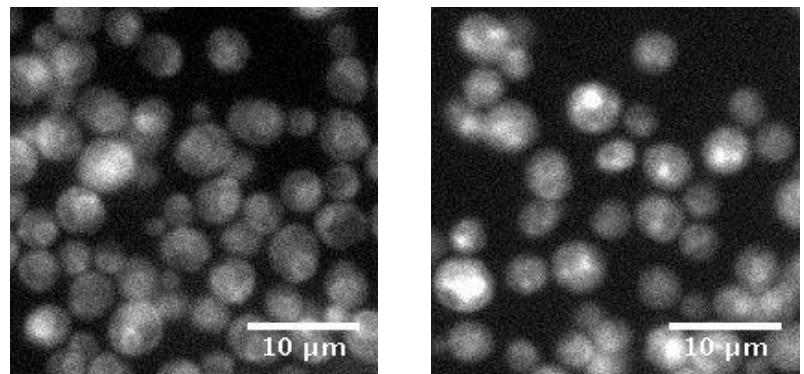

Ret2Clonat $x$ Swat GFP FUN14 Ret2LD2a x Swat GFP FUN14

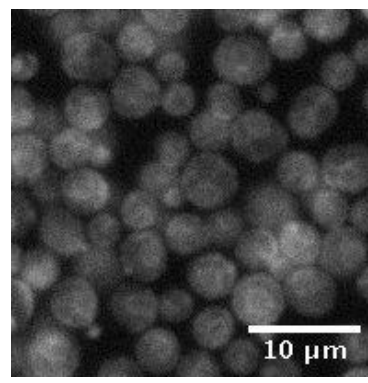

Ret2Clonat x Swat GFP UBX3

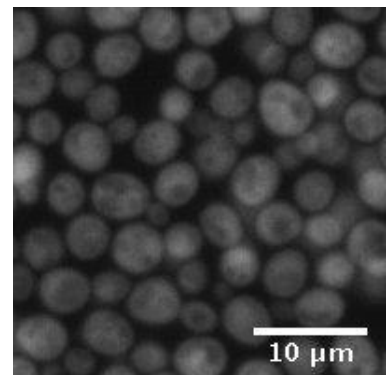

Ret2Clonat x Swat GFP GET3

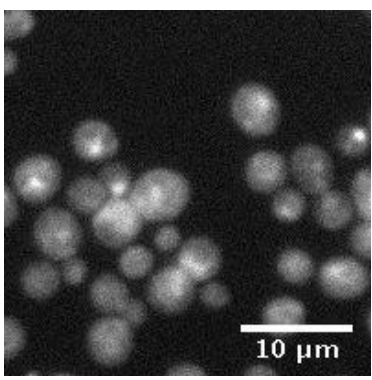

Ret2LD2a x Swat GFP UBX3

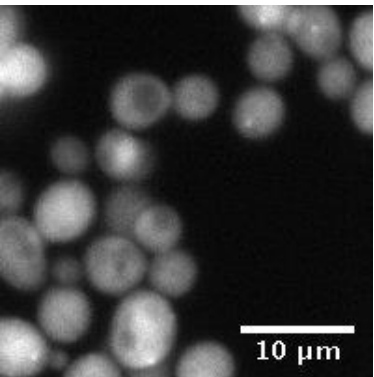

Ret2LD2a x Swat GFP GET3

Abbildung 10: Mikroskopie-Bilder der Proteine Fun14, Ubx3 und Get3.

Die in Abbildung 10, Abbildung 11 und Abbildung 12 gezeigten Ausschnitte aus dem Gesamtbild sind jeweils unter derselben Belichtungseinstellung aufgenommen und ausgewertet worden. Die abgebildete Maßstabsangabe ermöglicht einen Größenvergleich. Auf diese Weise wird erkennbar, dass sich bei einem Vergleich zwischen isogenetischer Kontrolle (linke Spalte der Abbildungen) und Stamm mit Ret2 ohne $\mu$-HomologieDomäne (rechte Spalte der Abbildungen) nicht nur die Lokalisation z. T. verändert, sondern dass sich die Proteine in manchen Fällen ebenso hinsichtlich ihrer Größe und Helligkeit unterscheiden. So erscheinen die Zellen des Ret2LD2 $\alpha$, gekreuzt mit GFP-Get3, heller und größer als bei Ret2-Clonat, welches mit GFP-Get3 gekreuzt wurde. 


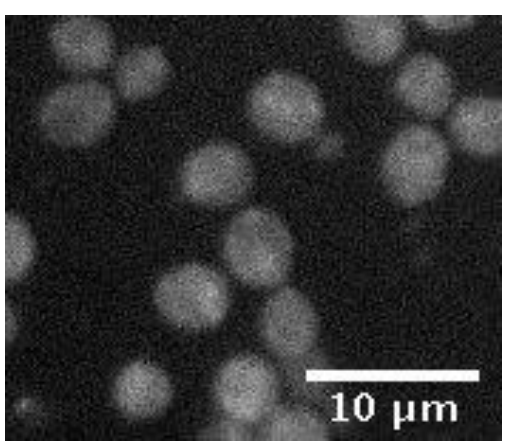

Ret2Clonat x Swat GFP APM3

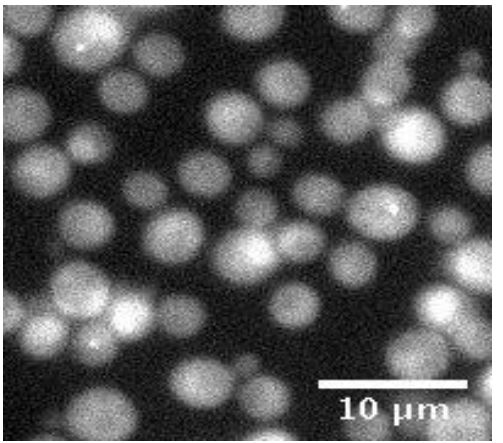

Ret2Clonat x Swat GFP ATG8

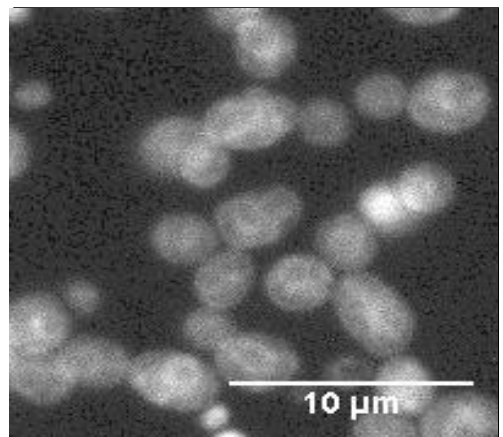

Ret2Clonat x Swat GFP EMP24

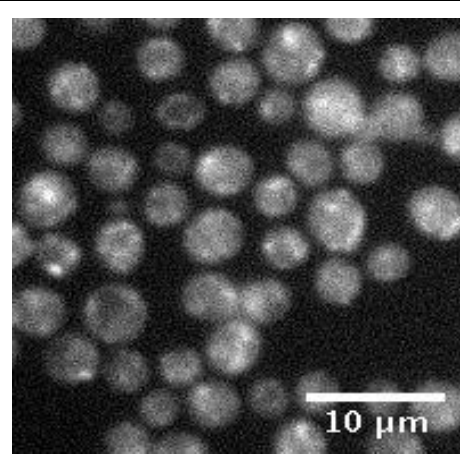

Ret2LD2a x Swat GFP APM3

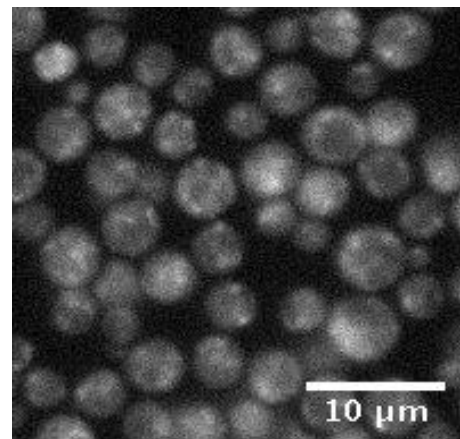

Ret2LD2a x Swat GFP ATG8

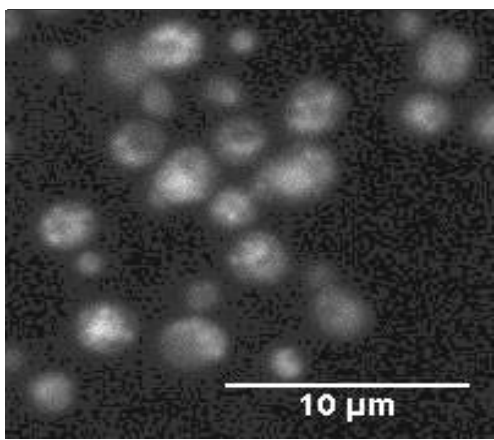

Ret2LD2a x Swat GFP EMP24

Abbildung 11: Mikroskopie-Bilder der Proteine Apm3, Atg8 und Emp 24.

Auch in Abbildung 11 lassen sich Lokalisationsunterschiede erkennen. Beim Protein ATG8 erscheint die isogenetische Kontrolle deutlich heller als der Knockout-Stamm. 

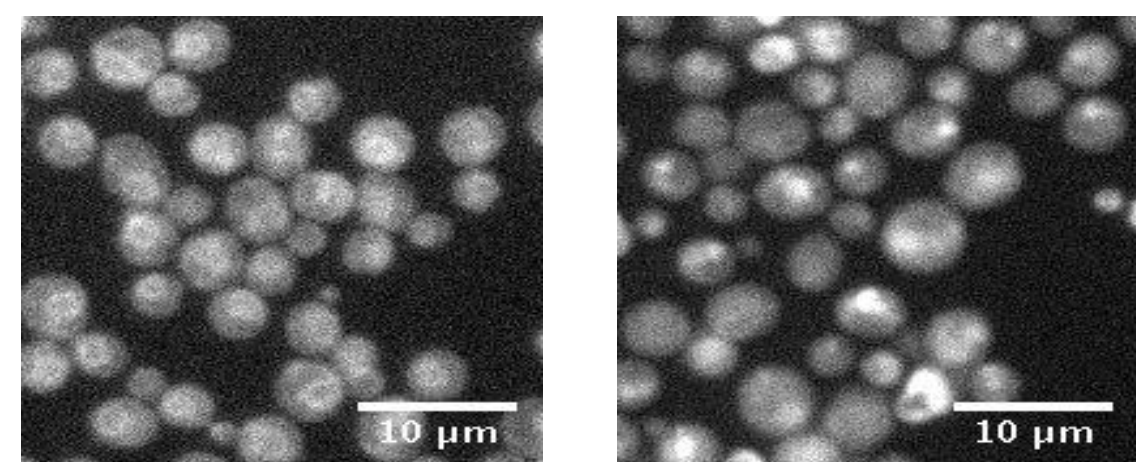

Ret2Clonat x Swat GFP YGR016W

Ret2LD2a x Swat GFP YGR016W

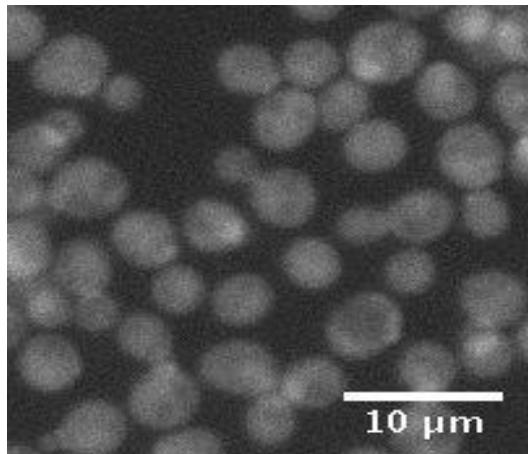

Ret2Clonat x Swat GFP HRR25

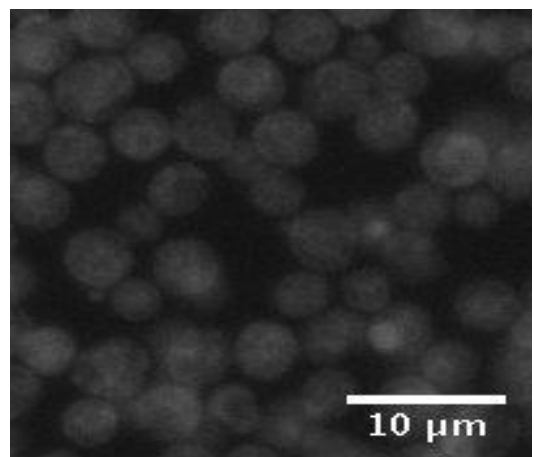

Ret2Clonat x Swat GFP MPD1

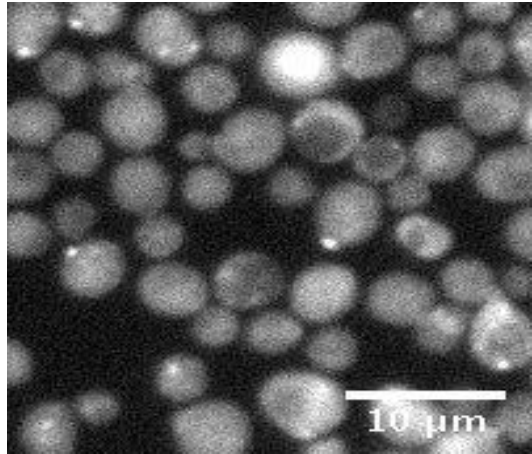

Ret2LD2a x Swat GFP HRR25

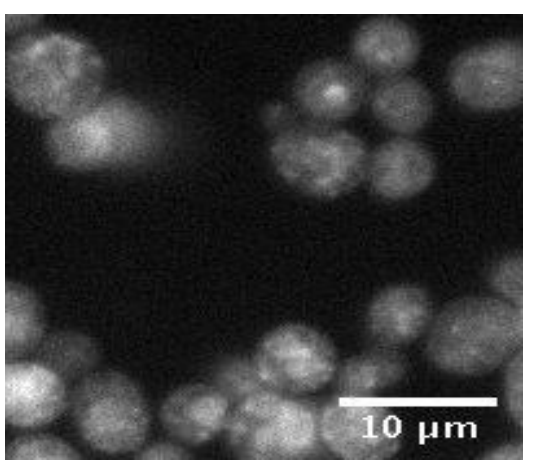

Ret2LD2a x Swat GFP MPD1

Abbildung 12: Mikroskopie-Bilder der Proteine Ygr016w, Hrr25 und Mpd1.

In Abbildung 12 zeigt sich ein deutlicher Helligkeitsunterschied zwischen dem mit GFPHrr25 gekreuzten Ret2LD2 $\alpha$-Stamm und dem, wesentlich dunkleren, mit GFP-Hrr25 gekreuzten Ret2-Stamm. Bei einer Betrachtung des Proteins GFP-Mpd1 erscheinen die Zellen des Knockout-Stammes hingegen größer als die der isogenetischen Kontrolle.

Die Kenntnis über das Molekulargewicht des jeweiligen Fusionsproteins ist, in Anbetracht der weiteren Auswertung mittels Western Blots, äußerst relevant. Sollten die molaren Größen von isogenetischer Kontrolle und Knockoutstamm im anti-GFP-Antikörper Blot nicht übereinstimmen, so muss von einer ungewollten zusätzlichen Mutation oder einer Kontamination während des SGA-Prozesses ausgegangen werden. 
Aus diesem Grund sind in Tabelle 18 alle vorläufigen Treffer und die jeweiligen Lokalisationen der isogenetischen Kontrolle und des Knockout-Stammes sowie ihre aus der Primärsequenz berechneten Molekulargewichte angegeben.

Tabelle 18: Vorläufige Trefferliste der High-Throughput-Fluoreszenz-Mikroskopie

\begin{tabular}{|c|c|c|c|}
\hline Name & $\begin{array}{l}\text { Lokalisation log. } \\
\text { Phase Ret2Clonat }\end{array}$ & $\begin{array}{l}\text { Lokalisation log. Phase } \\
\text { Ret2LD } 2 \alpha\end{array}$ & $\begin{array}{l}\text { Größe ohne } \\
\text { GFP (kDa) }\end{array}$ \\
\hline FUN14 & ER & Punktförmige Anordnung & 22 \\
\hline UBX3 & ER & Punktförmige Anordnung & 53 \\
\hline GET3 & zytosolisch & Punktförmige Anordnung & 39 \\
\hline YGR016W & ER & Punktförmige Anordnung & 22 \\
\hline JEM1 & ER & $\begin{array}{c}\text { ER und punktförmige } \\
\text { Anordnung }\end{array}$ & 75 \\
\hline APM3 & $\begin{array}{l}\text { Zytosolisch mit vereinzelter } \\
\text { punktförmiger Verteilung }\end{array}$ & $\begin{array}{c}\text { Ausgeprägte punktförmige } \\
\text { Anordnung }\end{array}$ & 55 \\
\hline ATG8 & $\begin{array}{l}\text { Zytosolisch mit vereinzelter } \\
\text { punktförmiger Verteilung }\end{array}$ & Punktförmige Anordnung & 14 \\
\hline EMP24 & ER & Punktförmige Anordnung & 23 \\
\hline HRR25 & zytosolisch & $\begin{array}{c}\text { Vereinzelte punktförmige } \\
\text { Anordnung }\end{array}$ & 57 \\
\hline MPD1 & ER & $\begin{array}{c}\text { Ausgeprägte punktförmige } \\
\text { Verteilung }\end{array}$ & 92 \\
\hline
\end{tabular}

Bei der weiteren Untersuchung der vorläufigen Treffer-Proteine mit Hilfe von WesternBlots kam ein anti-COPI-Coat-Antiserum zur Detektion der COPI-Untereinheiten zur Anwendung. Ein anti-Ret2-Antikörper sollte die Deletion der $\mu$-Homologie-Domäne belegen und ein anti-GFP-Antikörper wurde zur Identifikation des jeweiligen GFPFusionsproteins aus der Bibliothek verwendet. Die Ergebnisse der Proteinanalyse in den untersuchten Stämmen können der nachfolgenden Abbildung entnommen werden: 


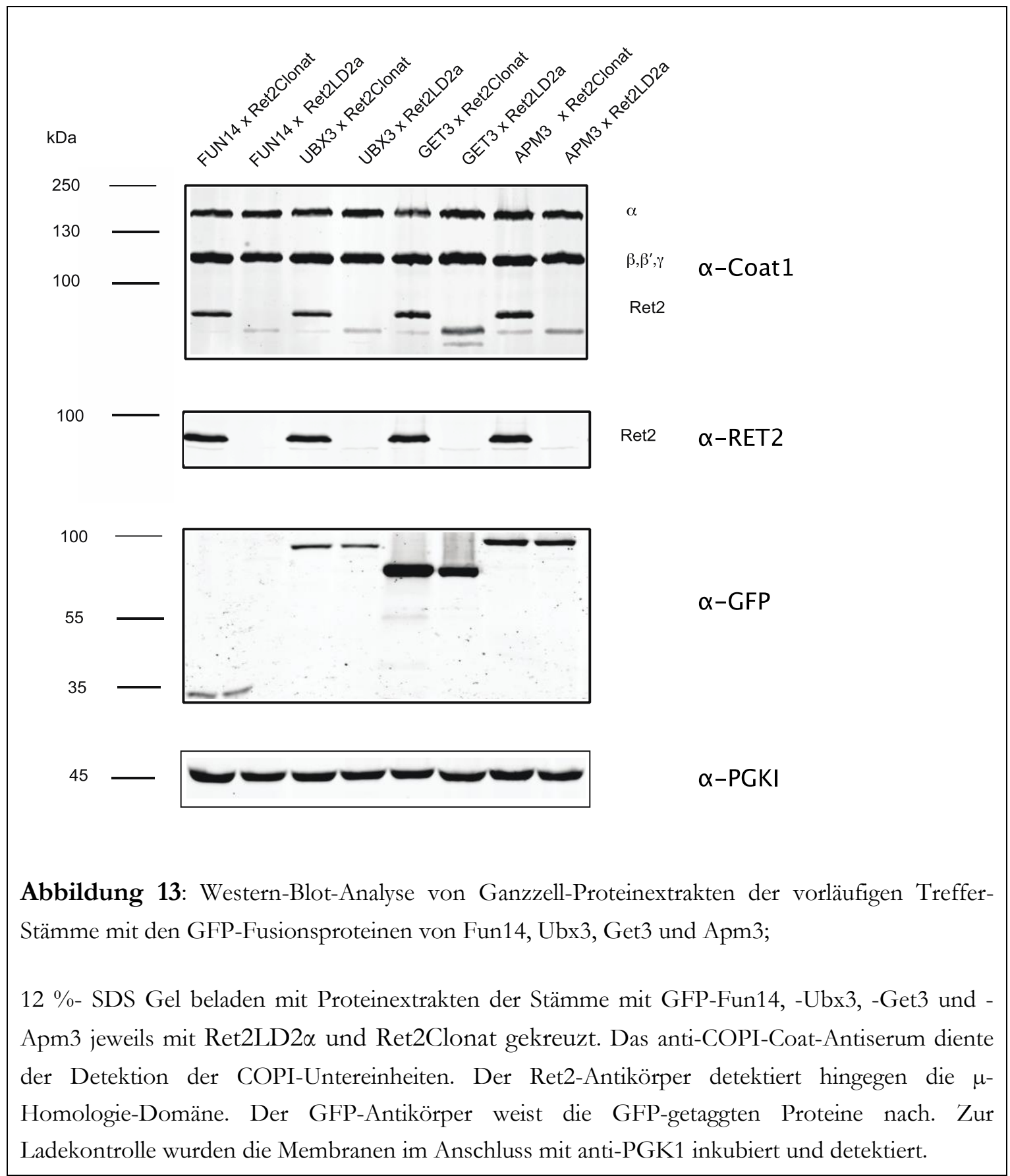

Die Auswertung der angefertigten Western-Blots von Fun14, Ubx3, Get3 und Apm3 zeigt zum einen, dass bei den angegebenen Knockout-Stämmen weiterhin eine Deletion der $\mu$ Homologie-Domäne vorliegt (siehe anti-Ret2-Antikörper). Zum anderen konnte mit Hilfe des anti-GFP-Antikörpers gezeigt werden, dass es sich bei den jeweiligen KnockoutStämmen und ihrer isogenetischen Kontrolle um Stämme handelt, deren GFP-Proteine das gleiche Laufverhalten und damit die gleiche Größe besitzen (siehe anti-GFP-Antikörper). Der Antikörper anti-PGK1 zeigt eine gleichmäßige Beladung des Gels.

Dasselbe Vorgehen (wie bei Fun14, Ubx3, Get3 und Apm3) fand ebenfalls für die Proteine Atg8 und Emp24 Anwendung. Das bedeutet, hier wurden auf ein zwölf-prozentiges SDS- 
Gel Proteinextrakte der isogenetischen Kontrolle und des Stamms ohne $\mu$-HomologieDomäne und jeweils mit der GFP-Fusion von Atg8 und Emp24 aufgetragen. Zur Ladekontrolle wurden die Membranen im Anschluss mit anti-PGK1 inkubiert und detektiert, sodass sich folgende Blots ergaben:

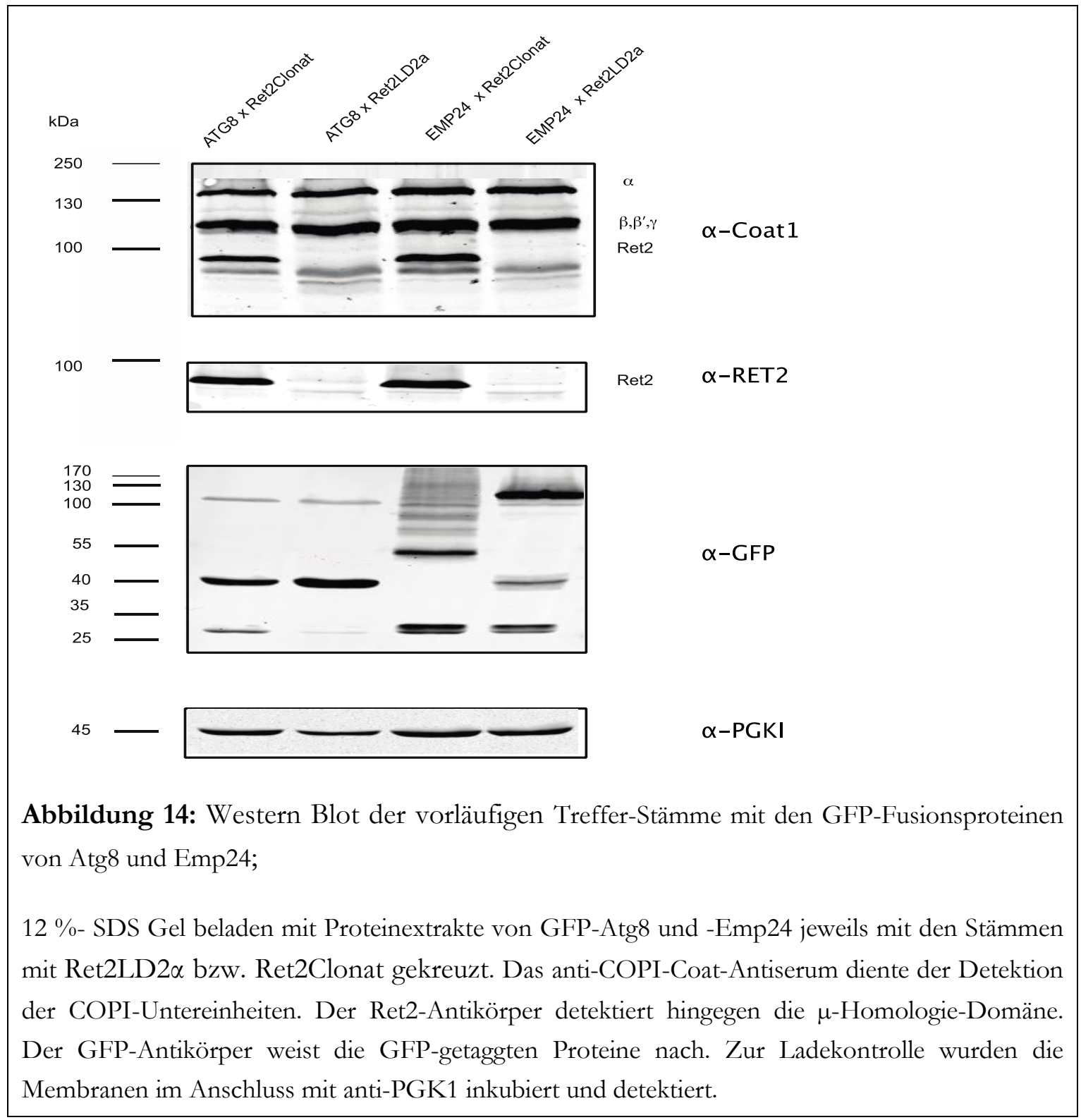

Bei Betrachtung der Abbildung 14 lässt sich ebenfalls die deletierte $\mu$-Homologie-Domäne der Knockout-Stämme mit Hilfe des anti-Ret2-Antikörper nachweisen. Die Darstellung der Emp24-Kreuzungen mit dem anti-GFP-Antikörper zeigen jedoch eine Degradation von GFP-Emp24 beim Vergleich von Knockout-Stamm und isogenetischer Kontrolle. Betrachtet man die GFP-Atg8-Kreuzungen nach der Verwendung des anti-GFPAntikörper, so erscheint die unterste Bande im Western Blot ( $\approx 28$ Kilodalton) beim Knockout-Stamm deutlich verblasst im Vergleich zur isogenetischen Kontrolle. Ohne $\mu$ - 
Homologie-Domäne zeigt sich Emp24 - im Vergleich zu seiner isogenetischen Kontrolle nach Nachweis mit dem anti-GFP-Antikörper deutlich verändert. Betrachtet man die unterste Bande ( $\approx 28$ Kilodalton), so erscheint sie im Knockout-Stamm etwas schwächer. Auf der Höhe der zweiten Bande des Knockout-Stammes ( $\approx 40$ Kilodalton) weist die isogenetische Kontrolle gar keine Bande auf. Ihre zweite Bande liegt etwas höher $(\approx 50$ Kilodalton). Sie erscheint, ausgehend von mehreren verschwommenen Banden oberhalb, degradiert zu sein. Der Knockout-Stamm zeigt eine dritte Bande ( $\approx 130$ Kilodalton). Diese stellt zugleich die am stärksten ausgeprägte Bande des GFP-Emp24-Proteins im Stamm ohne $\mu$-Homologie-Domäne dar.

Auch in folgender Darstellung (Abbildung 15) zeigt sich mit Hilfe des anti-Ret2Antikörpers die erfolgreiche Deletion der $\mu$-Homologie-Domäne in Stämmen mit GFPYgr016w, -Hrr25, -Mpd1 und -Jem1.

Um die nachfolgenden Bilder zu generieren, wurden ebenfalls auf ein $12 \%$-iges SDS-Gel Proteinextrakte der isogenetischen Kontrolle und des Stamms ohne $\mu$-Homologie-Domäne mit GFP-Ygr016w, -Hrr25, -Mpd1 und -Jem1 aufgetragen. Zur Ladekontrolle wurden die Membranen im Anschluss erneut mit anti-Pgk1 inkubiert und detektiert. 


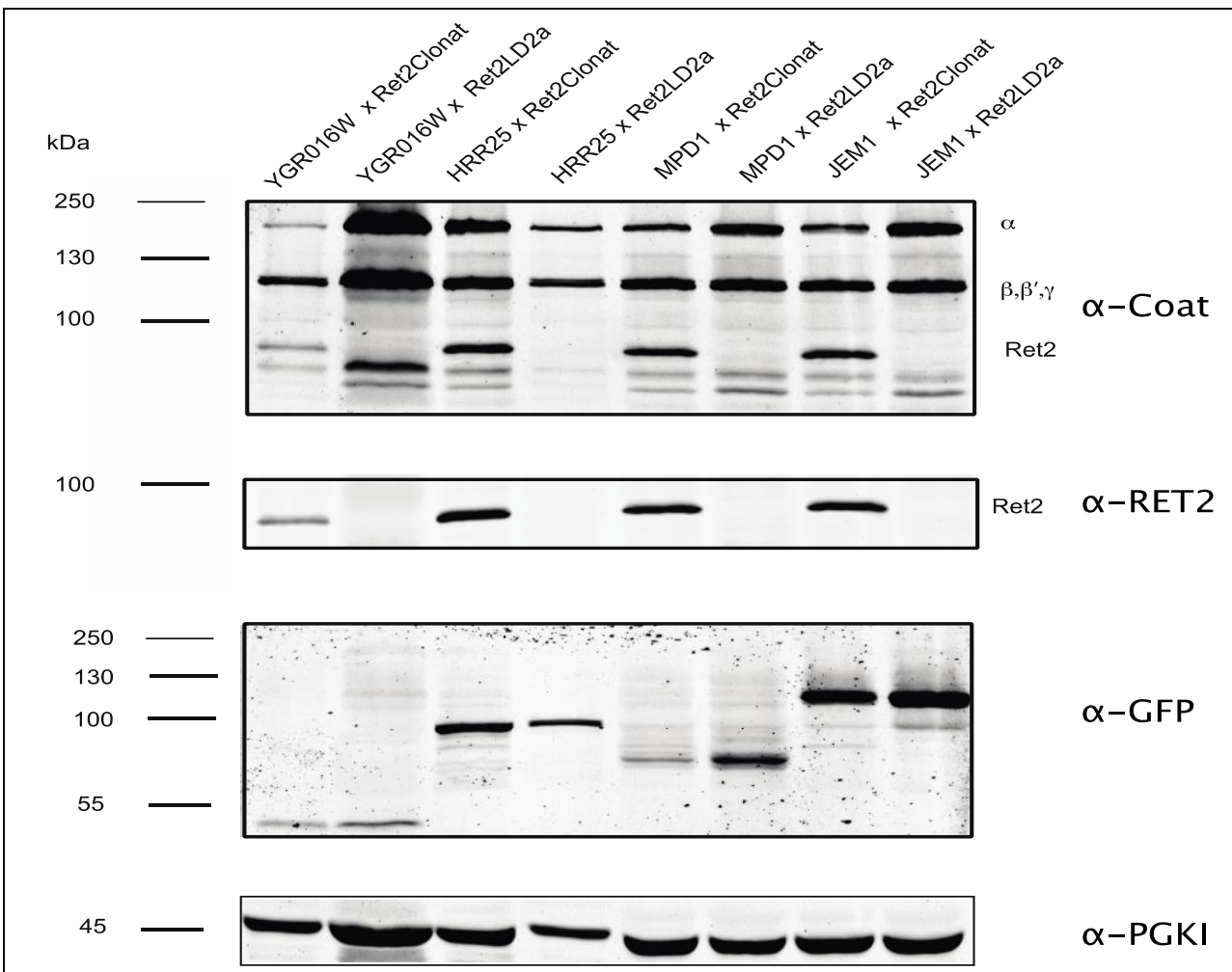

Abbildung 15: Western Blot der vorläufigen Treffer-Stämme mit den GFP-Fusionsproteinen von Ygr016w, Hrr25, Mpd1 und Jem1;

auf ein $12 \%$ - SDS Gel wurden Proteinextrakte der isogenetischen Kontrolle und des Knockouts der Stämme YGR016W, HRR25, MPD1 und JEM1 aufgetragen. Das anti-COPI-Coat-Antiserum diente der Detektion der COPI-Untereinheiten. Der anti-Ret2-Antikörper detektiert hingegen die $\mu$-Homologie-Domäne. Der anti-GFP-Antikörper weist die GFP-getaggten Proteine nach. Als Ladekontrolle wurden die Membranen im Anschluss mit anti-PGK1 inkubiert und detektiert.

In der Abbildung 15 zeigt sich, neben der erfolgreichen Deletion der $\mu$-HomologieDomäne, mit Hilfe des anti-GFP-Antikörpers bei allen vier untersuchten Stämmen, dass es sich bei den jeweiligen Knockout-Stämmen und ihrer isogenetischen Kontrolle um Stämme handelt, deren GFP-Proteine jeweils die gleiche Größe in den beiden Ret2-manipulierten Stämmen besitzen. 


\section{Diskussion}

Betrachtet man die vier erstellten Knockout-Stämme im Vergleich zu den isogenetischen Kontrollen, die unter Gliederungspunkt 3.2 vorgestellt und in einem Western-Blot dargestellt wurden, fällt eine Zunahme von $\alpha$-COP auf. Es liegt der Verdacht einer Kompensationsreaktion nahe, die COPI als Reaktion auf die Deletion der $\mu$-HomologieDomäne durchführt.

Bei der Anfertigung der ersten Wachstums-Analyse (siehe Abbildung 6) traten, wie im Ergebnissteil bereits erwähnt, Widersprüche zu bestehenden Veröffentlichungen auf. Auch der Versuch, die Temperaturempfindlichkeit durch Überexpression zu kompensieren, misslang. Dies ist vor allem deswegen verwunderlich, da u.a. eine Transformation der Stämme Ret2-Clonat und Ret2LD2 $\alpha$ mit Ret2 durchgeführt wurde. Somit standen dem konstruierten Stamm alle COPI-Untereinheiten zur Verfügung. Dies belegen auch die Ergebnisse des in Abbildung 8 gezeigten Western-Blots.

In der nachfolgenden Abbildung ist eine komprimierte Wachstums-Analyse zu sehen, welche noch einmal verdeutlicht, dass die Deletion der Ret2- $\mu$-Homologie-Domäne vor einem anderen genetischen Hintergrund bis zu $39{ }^{\circ} \mathrm{C}$ keine Temperaturempfindlichkeit verursacht (diese Abbildung wurde freundlicherweise von Dr. Eric Arakel zur Verfügung gestellt). 


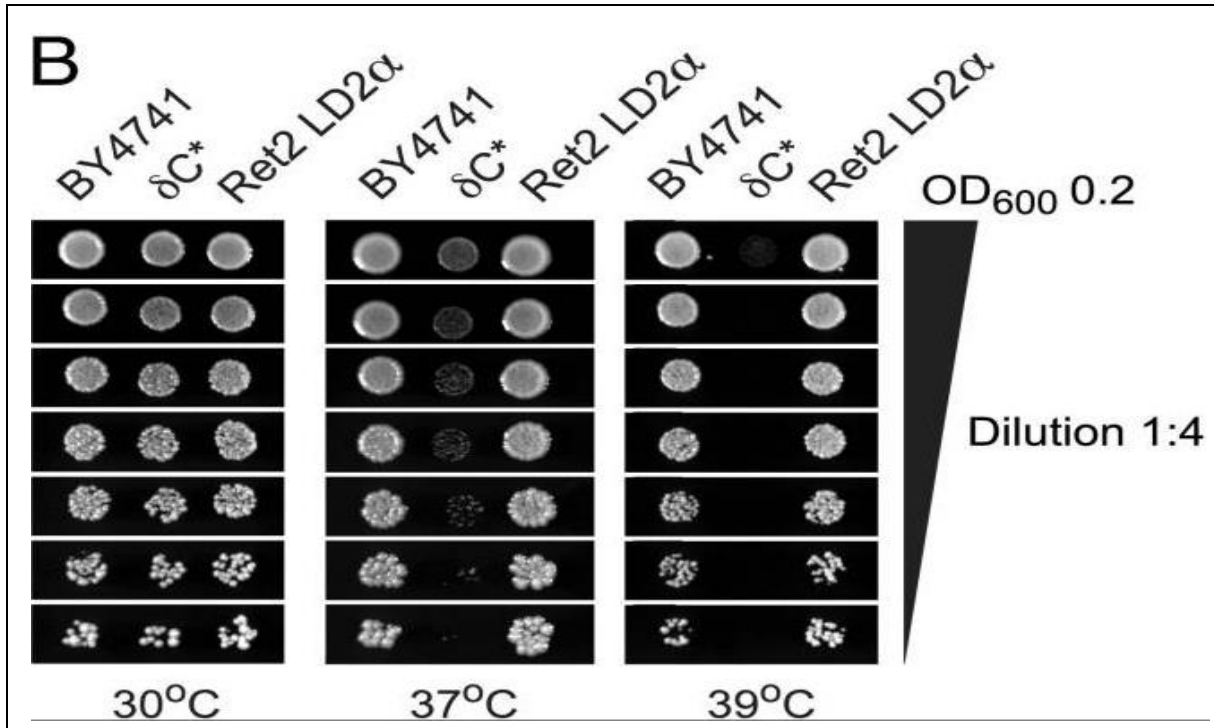

Abbildung 16: Spotting-Assays der Stämme BY4741, $\delta c^{*}$ und Ret2LD2 $\alpha$ (mit Genehmigung von Arakel et al., 2016);

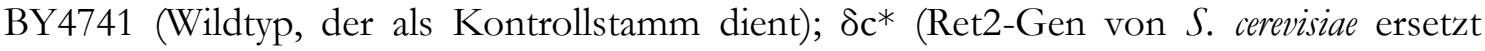
durch ARCN1 vom Bos taurus); Ret2LD2 $\alpha$ (Deletion der $\mu$-Homologie-Domäne)

Bei BY4741 handelt es sich um einen Wildtyp, welcher als Kontrollstamm dient. Im ebenfalls dargestellten Stamm $\delta C^{*}$ ersetzte ARCN1 vom Bos taurus (Hausrind) das RET2Gen in S. cerevisiae.

Bei RET2 handelt es sich hingegen um ein essenzielles Gen. Aus diesem Grund war bei der Manipulation des Ret2-Hefegens mit einem hohen Selektionsdruck zu rechnen. Zwar gelang es, die Expression der entsprechenden Proteine mit spezifischen Antikörpern nachzuweisen und auch die DNA-Sequenzierung der genomischen DNA bewies die korrekte Deletion der $\mu$-Homologie-Domäne; allerdings zeigen die Unterschiede zwischen der Wachstums-Analyse des Stammes, der im Jahr 2016 von Eric Arakel erstellt wurde, sowie der Wachstums-Analyse des Stammes, der im Rahmen dieser Arbeit konstruiert wurde, ebenfalls, dass eine Veränderung des Phänotyps der Stämme besteht.

Wie bereits erwähnt, wurde für die Publikationen von Dr. Eric Arakel ein anderer Ausgangsstamm (BY4743) verwendet als für die innerhalb der Dissertation durchgeführten Experimente (BY4741). Weiterhin erfolgte die Konstruktion der Stämme nicht auf dieselbe Art und Weise. Insofern weisen beide Stämme genomische Unterschiede auf.

Im Stamm, der für die Studien von Dr. Eric Arakel konstruiert wurde, ersetzte eine Kanamycin-Resistenz-Kassette mit temperatursensitiver RET2-Variante (p416 ret2-1) und URA3-Marker-Gen das ursprüngliche RET2-Gen des ausgehenden Wildtypstammes 
BY4743. Mit Hilfe dieses Stammes wurde das veränderte delta-COP(RET2)-Gen in das Genom der Hefe integriert. Im Anschluss wurde eine Gegen-Selektion des Plasmids mit der Hefeversion des delta-COP-Gens ret2-1 durch die Verwendung von 5-Fluorouracil herbeigeführt. Die Anwesenheit von URA3 führt zu einer Transformation des 5Fluorouracils in ein toxisches Produkt. Folglich konnten ausschließlich Zellen überleben, die das URA3-markierte Plasmid verloren haben. Die Herstellung des in dieser Dissertation betrachteten Stammes erfolgte wie unter Gliederungspunkt 3.1 beschrieben. Durch die Unterschiede zwischen dem Ursprungsstamm und dem aus einer Herstellung resultierenden Stamm sind die beiden Ret2LD2 $\alpha$-Varianten trotz gleicher Benennung nicht vollständig vergleichbar.

Es liegt der Verdacht nahe, dass eine Mutation außerhalb des im Fokus stehenden RET2Gens entstanden ist, da sowohl die Sequenzierung der DNA als auch die Western Blots belegen, dass im Bereich der gezielt vorgenommenen DNA-Modifikation mittels PlasmidVektor keine zusätzlichen ungewollten Mutationen vorliegen. Begünstigt wurde die genetische Veränderung vermutlich durch den erhöhten Selektionsdruck, dem die modifizierten Stämme ausgeliefert waren.

Die „High Throughput“-Fluoreszenz-Mikroskopie unter Gliederungspunkt 3.5 lieferte im ersten Durchlauf 54 Treffer. Die erneute Mikroskopie eben dieser Stämme ergab zehn verifizierte Treffer. Der Verlust von ungefähr 85 Prozent der Treffer im Verlauf der Verifikation innerhalb eines Hochdurchsatz-Screenings ist als normal zu bewerten. Eine mögliche Ursache sind z. B. Fehler während der Mikroskopieplatten-Vorbereitung. Da die „High Throughput“-Fluoreszenz-Mikroskopie mit mehreren, sowohl manuellen als auch maschinellen Teilschritten, eine Reihe potentieller Fehlerquellen birgt, liegt die Vermutung nahe, dass es innerhalb der Vorbereitungen zu Verunreinigungen einzelner „Wells“ kam. Daher sollten so gewonnene experimentelle Ergebnisse grundsätzlich mehrfach mit den entsprechenden Experimenten getestet werden, bevor man ihre Ergebnisse weiterverfolgt.

Bei der Anfertigung der Western-Blots der zehn vorläufigen, aus dem Screening erhaltenen Treffer fielen insbesondere die isogenetischen Kontrollen und die Stämme ohne $\mu$ Homologie-Domäne der Proteine Atg8 und Emp24 auf (siehe Abbildung 14). Die Inkubation und Detektion mit anti-GFP zeigte Unterschiede im Laufverhalten des jeweiligen GFP-Fusionsproteins. Bei Atg8 handelte es sich um einen eher geringfügigen Unterschied, welcher vernachlässigbar ist. Die Abweichungen bei Emp24 sind hingegen deutlich wahrnehmbar und lassen darauf schließen, dass GFP-Emp24 im Stamm ohne $\mu$ Homologie-Domäne möglicherweise stark degradiert wird. Tabelle 19 können die finalen Treffer und die dazugehörigen Funktionen bzw. Aufgaben der einzelnen Proteine entnommen

werden. 
Tabelle 19: Finale Trefferliste der High-Throughput- Fluoreszenz-Mikroskopie

\begin{tabular}{|c|c|c|c|c|}
\hline Name & $\begin{array}{l}\text { Charakteristika und Aufgaben } \\
\text { (Saccharomyces Genome Database | SGD) }\end{array}$ & Beziehung zur Autophagie & Beziehung zu COPI & $\begin{array}{l}\text { Subzelluläre } \\
\text { Lokalisation }\end{array}$ \\
\hline FUN14 & $\begin{array}{l}\text { Mitochondrial-integrales Protein der äußeren } \\
\text { Membran; mitochondriale Organisation; } \\
\text { Aufgabe: Phospholipid-Homöostase }\end{array}$ & $\begin{array}{l}\text { Autophagie der Mitochondrien; } \\
\text { interagiert genetisch mit: RPD3 }\end{array}$ & & $\begin{array}{l}\text { Äußere } \\
\text { Mitochondrien- } \\
\text { membran }\end{array}$ \\
\hline UBX3 & $\begin{array}{l}\text { Clathrin-beschichtete Vesikelkomponente; } \\
\text { Aufgabe: Endozytose } \\
(\rightarrow \text { effiziente Clathrin-vermittelte Endozytose })\end{array}$ & $\begin{array}{l}\text { Interagiert genetisch mit ATG17, MON1 und RPD3; } \\
\text { interagiert physikalisch mit CDC48 }\end{array}$ & $\begin{array}{l}\text { Interagiert genetisch mit SEC28 und } \\
\text { physikalisch mit RSP5 }\end{array}$ & $\begin{array}{l}\text { Endoplasmatisches } \\
\text { Retikulum }\end{array}$ \\
\hline GET3 & $\begin{array}{c}\text { Teil des Get-Komplexes; Aufgaben: Beteiligung } \\
\text { am ATP- abhängigen Golgi } \rightarrow \text { ER-Transport; } \\
\text { Insertion von Tail-Anker-Proteinen in die ER- } \\
\text { Membran }\end{array}$ & $\begin{array}{l}\text { Interagiert genetisch mit ARL1, ATG32, BET3, } \\
\text { BET5, ESA1, RPD3, SEC18, TRS23, TRS85, VMA1, } \\
\text { VMA21, VPH2, YPT1, YPT6 }\end{array}$ & $\begin{array}{l}\text { Interagiert genetisch mit MTC1, RET2, } \\
\text { RET3, SEC26 und SEC27 }\end{array}$ & $\begin{array}{l}\text { Cytosol; } \\
\text { endoplasmatisches } \\
\text { Retikulum }\end{array}$ \\
\hline YGR016W & & & $\begin{array}{l}\text { Protein mit vier vorhergesagten } \\
\text { Transmembran-Segmenten und einem } \\
\text { putativen KXKXX-COOH, COPI- } \\
\text { abhängiges Retrieval-Signal; } \\
\text { interagiert genetisch mit COP1, RET2, } \\
\text { RET3 und SEC26 }\end{array}$ & $\begin{array}{l}\text { Endoplasmatisches } \\
\text { Retikulum }\end{array}$ \\
\hline ATG8 & $\begin{array}{c}\text { Aufgabe: Regulator von Atg1p } \\
\rightarrow \text { bindet den Atg1p-Atg13p-Komplex und löst } \\
\text { dessen vakuolären Abbau aus }\end{array}$ & $\begin{array}{l}\text { Bestandteil von Autophagosomen und Cvt-Vesikeln; } \\
\text { interagiert genetisch mit APE1, ATG1, ATG13, } \\
\text { ATG15, ATG4, ATG7, KSP1, SIR2, VMA1, } \\
\text { VMA21, VPS21 und YPT6; } \\
\text { interagiert physikalisch mit APM3 und EMP24, }\end{array}$ & $\begin{array}{l}\text { Interagiert genetisch mit COP1 und } \\
\text { MTC1; interagiert physikalisch mit RSP5, } \\
\text { SEC21 und SEC26 }\end{array}$ & $\begin{array}{l}\text { Vakuole vom } \\
\text { Pilztyp, Zytoplasma }\end{array}$ \\
\hline
\end{tabular}




\begin{tabular}{|c|c|c|c|c|}
\hline Name & $\begin{array}{l}\text { Charakteristika und Aufgaben } \\
\text { (Saccharomyces Genome Database | SGD) }\end{array}$ & Beziehung zur Autophagie & Beziehung zu COPI & $\begin{array}{l}\text { Subzelluläre } \\
\text { Lokalisation }\end{array}$ \\
\hline & & $\begin{array}{l}\text { APE1, ATG1, ATG12, ATG21, ATG3, ATG32, } \\
\text { ATG34, ATG39, ATG4, ATG40, phys. Interaktion: } \\
\text { ATG5, ATG7, ATG9, CCZ1, CDC48, CUE5, KSP1, } \\
\text { SEC17, SEC4, VPS21 und YPT1 }\end{array}$ & & \\
\hline EMP24 & & $\begin{array}{c}\text { Interagiert genetisch mit BET3, BET5, ROT1, } \\
\text { TRS20, TRS23, TRS85, YPT1 und YPT6; interagiert } \\
\text { physikalisch mit ATG23, ATG27, ATG8, ATG9 und } \\
\text { VPS30 }\end{array}$ & $\begin{array}{c}\text { Interagiert genetisch mit RET2, SEC21 } \\
\text { und SEC27; interagiert physikalisch mit } \\
\text { MST27 }\end{array}$ & $\begin{array}{l}\text { Membran des } \\
\text { endoplasmatischen } \\
\text { Retikulums; Golgi- } \\
\text { Membran }\end{array}$ \\
\hline JEM1 & $\begin{array}{c}\text { Chaperon-Bindung; } \\
\text { Aufgaben: Proteinfaltung im endoplasmatischen } \\
\text { Retikulum; Beteiligung an der Karyogamie }\end{array}$ & $\begin{array}{l}\text { Interagiert genetisch mit MON1; } \\
\text { interagiert genetisch mit MPD1 }\end{array}$ & & $\begin{array}{l}\text { Membran des } \\
\text { endoplasmatischen } \\
\text { Retikulums }\end{array}$ \\
\hline APM3 & $\begin{array}{c}\text { Bestandteil des AP3-Komplexes; } \\
\text { Aufgabe: Protein-Targeting, d.h. Transport des } \\
\text { Proteins von Golgi zur Vakuole }\end{array}$ & $\begin{array}{l}\text { Interagiert genetisch mit ARL1, TRS20, TRS23, } \\
\text { VMA21, VPS21, YPT52 und YPT6; } \\
\text { interagiert physikalisch mit ATG8 }\end{array}$ & Interagiert genetisch mit RSP5 und SEC27 & Golgi-Apparat \\
\hline HRR25 & $\begin{array}{c}\text { Aufgaben: ATP-Bindung; Proteinkinase- } \\
\text { Aktivität; DNA-Reparatur; Regulation der } \\
\text { Clathrin-abhängigen Endozytose; Regulierung } \\
\text { des ER } \rightarrow \text { Golgi-Vesikel-vermittelten Transports } \\
\text { (vermittelnder Transport?) }\end{array}$ & $\begin{array}{l}\text { Autophagie des Peroxisoms; interagiert genetisch mit, } \\
\text { ATG13, BET5, CDC48, LTV1, PPM1, RPD3, } \\
\text { SEC17, SEC2, TRS20, TRS23, VMA21 und XRN1; } \\
\text { interagiert physikalisch mit APE1, ATG32, ATG34, } \\
\text { DNM1, LTV1, SEC2 und YPT1 }\end{array}$ & $\begin{array}{l}\text { Interagiert genetisch mit COP1; } \\
\text { interagiert und physikalisch mit SGM1 }\end{array}$ & $\begin{array}{l}\text { Plasma-Membran; } \\
\text { Golgi-Apparat; } \\
\text { Nukleus }\end{array}$ \\
\hline MPD1 & $\begin{array}{l}\text { Mitglied der Proteindisulfidisomerase-Familie; } \\
\text { Aktivität der Protein-Disulfid-Reduktase } \\
\text { (Glutathion); Aufgaben: Zellredox-Homöostase; } \\
\text { Proteinfaltung }\end{array}$ & Interagiert genetisch mit JEM1 & & $\begin{array}{c}\text { Lumen des } \\
\text { endoplasmatischen } \\
\text { Retikulums, Vakuole } \\
\text { vom Pilztyp }\end{array}$ \\
\hline
\end{tabular}


Bei Fun14 handelt es sich um ein mitochondriales, integrales Protein der äußeren Membran. Es kann sowohl Änderungen in der Mitochondrienmorphologie als auch innerhalb der Proteinkomplexanordnung und Phospholipid-Homöostase bewirken.

Fundc1 (Fun14-Analoga im H. sapiens) trägt zur Hypoxie-induzierten Mitophagie bei. Es kann die Autophagiemaschinerie rekrutieren und den Mitophagieprozess starten (Liu et al., 2012).

Ubx3 stellt einen Cofaktor von Cdc48 für die Ubiquitylierung der Histon-Untereinheit H2B dar (Bonizec et al., 2014). Bei diesem Vorgang wird das Protein Ubiquitin reversibel an $\mathrm{H} 2 \mathrm{~B}$ gebunden. Infolgedessen führen weitere Reaktionen schließlich dazu, dass das Enzym Argininosuccinat-Synthase (ASS) nicht mehr hergestellt wird. ASS ist für die Katalisierung von Aspartat und Citrullin zu Argininosuccinat zuständig. Diese Reaktion findet bei der Biosynthese der Aminosäure Arginin statt (Sun und Allis, 2002). Somit ist Ubx3 maßgeblich an der Regulation des Arginin-Stoffwechsels beteiligt.

Get3 spielt eine wesentliche Rolle im Get-Komplex. Dieser spielt - wie COPI - eine wesentliche Rolle für die Integrität des sekretorischen Wegs, da er bestimmte C-terminal verankerte Membranproteine, z. B. SNAREs, die bei der Vesikelfusion eine Rolle spielen, ins ER einschleust. Get3 transportiert die sogenannten Tail-Anchored (TA)Membranproteine zur ER-Membran, wobei Get1 und Get2 einen Rezeptorkomplex bilden, der den Get3-TA-Proteinkomplex erkennt und die Freisetzung der TA-Proteine ermöglicht. TA-Proteine spielen während des gesamten sekretorischen Wegs eine entscheidende Rolle (Schuldiner et al. 2008).

Beim Protein YGR016W handelt es sich um ein putatives Protein unbekannter Funktion (YGR016W | SGD).

Jem1 (YJL073) kodiert für ein DnaJ-ähnliches Protein, welches in der ER-Membran lokalisiert ist. DnaJ-Proteine sind molekulare Chaperonproteine. Die Funktion von Jem1 besteht in der Faltung von Proteinen. Weiterhin ist es für die Kernmembranfusion während des Matings erforderlich. Auch genetische Wechselwirkungen mit Kar2 konnten bewiesen werden (Nishikawa und Endo, 1997; JEM1 | SGD). Bei Kar2 handelt es sich um eine ATPase, die ebenfalls am Proteinimport in das ER beteiligt ist und als Chaperon wirkt, um die Proteinfaltung im ER zu vermitteln (Romisch, 1999, S. 61; Okamura et al., 2000, S. 2; KAR2 | SGD, S. 2; Tokunaga M, et al., 1992 | SGD).

Apm3 ist am Protein-Targeting zur Vakuole beteiligt. Es ist demnach für die Zielsteuerung der Proteine nach der Synthese bedeutend, deren Zielkompartiment die Vakuole ist. Insbesondere zum Protein-Transport vom Golgi-Apparat zur Vakuole trägt Apm3 bei, da es Bestandteil des Adaptorproteins Komplex-3 ist (APM3 | SGD, S. 3).

HRR25 gehört zur Familie der Caseinkinase 1 (CK1). Diese stellen eine Gruppe von den Serin-/Threonin-Proteinkinasen dar, deren Regulation und Rolle im Membranverkehr weitgehend unbekannt sind (Knippschild et al., 2005). Innerhalb des COPII-Transports 
spielt die Phosphorylierung von COPII durch Hrr25 eine entscheidende Rolle für den gerichteten Transport vom ER zum Golgi-Apparat (Lord et al., 2011). Hrr25 wird durch Ypt1 direkt zu COPII-Vesikeln rekrutiert, um den Vesikeltransport vom ER zum GolgiApparat zu aktivieren. Aktuelle Studien zeigten auch, dass die Kinase Hrr25 durch Phosphorylierung von Rezeptorproteinen zwei unterschiedliche, selektive Autophagie bezogene Pfade in S. cerevisiae reguliert: Zum einen Atg19, welches die Assemblierung von vakuolären Enzymen im CVT-Weg erkennt; zum anderen Atg36, welches überflüssige Peroxisomen identifiziert. Die Hrr25-vermittelte Phosphorylierung verstärkt die Wechselwirkungen dieser Rezeptoren mit dem gemeinsamen Adapter Atg11, welcher die autophagosomalen Kernproteine rekrutiert, die die Bildung der autophagosomalen Membran vermitteln (Tanaka et al. 2014).

MPD1 ist ein Mitglied der Proteindisulfidisomerase-Familie. Es interagiert mit der Chaperon-Aktivität der Cne-Proteindisulfid-Isomerase und hemmt diese. Weiterhin ist es an der Zellredox-Homöostase und der Proteinfaltung beteiligt.

Die Unterschiede zwischen den Phänotypen der jeweiligen Knockout-Stämme und den isogenetischen Kontrollen lassen vermuten, dass durch eine Deletion der $\mu$-HomologieDomäne (verkürztes Ret2) eine Änderung der Lokalisation innerhalb der Zelle bewirkt wird. Die finalen Trefferproteine treten ihrerseits mit anderen Proteinen in Interaktion. Da die Funktionsweise eines Proteins im direkten Zusammenhang mit seiner Lokalisation stehen kann, besteht die Möglichkeit, dass das Fehlen der $\mu$-Homologie-Domäne zu einer Art Kettenreaktion führt. Es wird deutlich, dass die $\mu$-Homologie-Domäne auf nachfolgende Prozesse in der Zelle Einfluss besitzt.

Zur weiteren Analyse der erzielten Treffer wurde im Folgenden näher auf die Interaktionen eingegangen. Die Informationen hierzu wurden mit Hilfe der Genome Database SGD ermittelt. Generell lässt sich zwischen genetischer und physikalischer Interaktion differenzieren: Die genetische Interaktion wurde bspw. durch Knockout-Screens nachgewiesen. So kam es bei einem Knockout eines einzelnen Proteins zu keiner Veränderung; ein Knockout beider Interakteure führte jedoch $\mathrm{zu}$ einer Wachstumsänderung. Die physikalische Beziehung ist eine physische Bindung, die z. B. durch ein Bindungsexperiment („Pull-Down“) ermittelt wurde.

Aus Tabelle 19 geht bereits hervor, dass die finalen Treffer teilweise eine genetische oder physikalische Beziehung zueinander aufweisen. Diese werden in der nachfolgenden Tabelle zusammengefasst dargestellt. 
Tabelle 20: Liste aller finalen Treffer, die untereinander eine genetische/physikalische Beziehung aufweisen

\begin{tabular}{|c|c|c|}
\hline Finaler Treffer 1 & Finaler Treffer 2 & Genetisch/Physikalische Beziehung \\
\hline APM3 & ATG8 & $\begin{array}{c}\text { Phys. Interaktion } \\
\text { (Affinitätserfassungs-Massenspektrometrie) }\end{array}$ \\
\hline MPD1 & JEM1 & $\begin{array}{c}\text { Gen. Interaktion } \\
\text { (phänotypische Suppression) }\end{array}$ \\
\hline EMP24 & ATG8 & $\begin{array}{c}\text { Phys. Interaktion } \\
\end{array}$ \\
\hline
\end{tabular}


Interessant ist hierbei, dass sich in Tabelle 20 einige interagierenden Proteine aus Tabelle 19 wiederholen. Somit stehen die finalen Treffer teilweise mit den gleichen Proteinen in einer genetischen oder physikalischen Beziehung. Die folgenden zwei Tabellen sollen dazu dienen diese Zusammenhänge der Interakteure übersichtlicher darzustellen. Es wurden jene Proteine in die Auflistung aufgenommen, welche mit zwei oder mehr finalen Treffern interagieren. Weiterhin liefern die Tabellen Informationen zur Art der Beziehung (genetisch oder physikalisch) und zur jeweiligen Funktion. Tabelle 21 bezieht sich dabei auf die Beziehungen $\mathrm{zu}$ COPI und Tabelle 22 auf die zur Autophagie. 
Tabelle 21: Liste der Proteine, die mit mehreren Treffern aus Tabelle 19 interagieren und in einer Beziehung zu COPI stehen

\begin{tabular}{|c|c|c|c|}
\hline Interakteur & Phys. Beziehung zu Treffer & Gen. Beziehung zu Treffer & Beschreibung des Interakteurs \\
\hline RET2 & & GET3, YGR016W, EMP24 & Delta-Untereinheit des Coatomers (COPI) \\
\hline RET3 & & GET3, YGR016W & Zeta-Untereinheit des Coatomers (COPI) \\
\hline SEC21 & ATG8 & EMP24 & Gamma-Untereinheit des Coatomers (COPI) \\
\hline SEC26 & ATG8 & GET3, YGR016W & Beta-Untereinheit des Coatomers (COPI) \\
\hline SEC27 & & GET3, EMP24, APM3 & Beta'-Untereinheit des Coatomers (COPI) \\
\hline RSP5 & ATG8, UBX3 & APM3 & $\begin{array}{l}\text { Reguliert u.a. Hitzeschock-Reaktion, Transkription, Endozytose und } \\
\text { Ribosom-Stabilität; erforderlich für effizienten Golgi-ER-Transport in } \\
\text { COPI-Mutanten }\end{array}$ \\
\hline MTC1 & & GET3, ATG 8 & $\begin{array}{l}\text { Interagiert mit Ribosomen; grün-fluoreszierendes Protein (GFP) - } \\
\text { Fusionsprotein ist im Zytoplasma und in COPI-beschichteten Vesikeln } \\
\text { lokalisiert }\end{array}$ \\
\hline COP1 & & YGR016W, HRR25, ATG8 & Alpha-Untereinheit des Coatomers (COPI) \\
\hline
\end{tabular}


Tabelle 22: Liste der Proteine die mit mehreren Treffern aus Tabelle 19 interagieren und in einer Beziehung zur Autophagie stehen

\begin{tabular}{|c|c|c|c|}
\hline Interakteur & Phys. Beziehung zu Treffer & $\begin{array}{l}\text { Gen. Beziehung zu } \\
\text { Treffer }\end{array}$ & Beschreibung des Interakteurs \\
\hline BET3 & & GET3, EMP24 & $\begin{array}{l}\text { Hydrophiles sowie homodimeres Protein, welches in Verbindung mit } \\
\text { SNARE-Proteinen beim Targeting und der Fusion von ER mit Golgi- } \\
\text { Transportvesikeln mitwirkt; reguliert den ER-Golgi-Verkehr, den Intra- } \\
\text { Golgi-Verkehr, den Endosom-Golgi-Verkehr und die Autophagie }\end{array}$ \\
\hline BET5 & & GET3, EMP24, HRR25 & $\begin{array}{l}\text { Reguliert den ER-Golgi-Verkehr, den Intra-Golgi-Verkehr, den Endosom- } \\
\text { Golgi-Verkehr und die Autophagie }\end{array}$ \\
\hline ATG9 & ATG8, EMP24 & & $\begin{array}{l}\text { Transmembranprotein, das an der Bildung von Cvt (Cytoplasm-to- } \\
\text { Vacuole Targeting) und autophagischen Vesikeln beteiligt ist }\end{array}$ \\
\hline ATG13 & & ATG8, HRR25 & $\begin{array}{l}\text { Regulatorische Untereinheit des Atg1p-Signalisierungskomplexes; } \\
\text { stimuliert die Atg1p-Kinase-Aktivität; ist erforderlich für die } \\
\text { Vesikelbildung während der Autophagie und für den Cvt-Signalweg } \\
\text { (Cytoplasm-to-Vacuole Targeting) }\end{array}$ \\
\hline ATG32 & ATG8, HRR25 & GET3 & Mitochondriales Außenmembranprotein zur Einleitung der Mitophagie \\
\hline ATG34 & ATG8, HRR25 & & $\begin{array}{l}\text { Rezeptorprotein, das an der selektiven Autophagie während der Starvation } \\
\text { beteiligt ist }\end{array}$ \\
\hline
\end{tabular}




\begin{tabular}{|c|c|c|c|}
\hline Interakteur & Phys. Beziehung zu Treffer & $\begin{array}{l}\text { Gen. Beziehung zu } \\
\text { Treffer }\end{array}$ & Beschreibung des Interakteurs \\
\hline YPT1 & HRR25 & GET3, ATG8, EMP24, & $\begin{array}{l}\text { Zugehörigkeit zur Rab-Familie GTPase; beteiligt am ER-Golgi Transport } \\
\text { während des Sekretionsweges }\end{array}$ \\
\hline YPT6 & & $\begin{array}{l}\text { GET3, ATG8, EMP24, } \\
\text { APM3 }\end{array}$ & $\begin{array}{l}\text { Zugehörigkeit zur Rab-Familie GTPase; beteiligt am Endosom-Golgi- } \\
\text { Transport, am retrograden internen Golgi-Transport und am retrograden } \\
\text { Golgi-ER-Transport; die Golgi-lokalisierte Form ist GTP-gebunden, } \\
\text { während die cytosolische Form GDP-gebunden ist; Beteiligung an der } \\
\text { „stressbedingten- Autophagie“ }\end{array}$ \\
\hline VMA1 & & GET3, ATG8 & $\begin{array}{l}\text { Beteiligt an der Verlängerung der chronologischen Lebensdauer durch } \\
\text { Methioninrestriktion in autophagienabhängiger Weise }\end{array}$ \\
\hline VMA21 & & $\begin{array}{l}\text { GET3, ATG8, APM3, } \\
\text { HRR25 }\end{array}$ & $\begin{array}{l}\text { Divergiertes Ortholog des humanen XMEA (X-chromosomale Myopathie } \\
\text { mit exzessiver Autophagie) }\end{array}$ \\
\hline TRS20 & & HRR25, EMP24, APM3 & $\begin{array}{l}\text { Reguliert den ER-Golgi-Transport, den Intra-Golgi-Transport, den } \\
\text { Endosom-Golgi-Transport und die Autophagie }\end{array}$ \\
\hline TRS23 & & $\begin{array}{l}\text { GET3, EMP24, APM3, } \\
\text { HRR25 }\end{array}$ & $\begin{array}{l}\text { Reguliert den ER-Golgi-Transport, den Intra-Golgi-Transport, den } \\
\text { Endosom-Golgi-Verkehr und die Autophagie }\end{array}$ \\
\hline TRS85 & & GET3, EMP24 & $\begin{array}{l}\text { Reguliert den Endosom-Golgi-Verkehr und ist für die Membranexpansion } \\
\text { während der Autophagie sowie für den CVT-Weg erforderlich }\end{array}$ \\
\hline
\end{tabular}




\begin{tabular}{|c|c|c|c|}
\hline Interakteur & Phys. Beziehung zu Treffer & $\begin{array}{l}\text { Gen. Beziehung zu } \\
\text { Treffer }\end{array}$ & Beschreibung des Interakteurs \\
\hline RPD3 & & $\begin{array}{l}\text { FUN14, UBX3, GET3, } \\
\text { HRR25 }\end{array}$ & $\begin{array}{l}\text { Reguliert Transkription, Stummschaltung, Autophagie und andere } \\
\text { Prozesse durch eine Beeinflussung des Chromatin-Remodellings }\end{array}$ \\
\hline MON1 & & JEM1, UBX3 & $\begin{array}{l}\text { Untereinheit eines heterodimeren Guaninnukleotidaustauschfaktors } \\
\text { (GEF); die GEF-Aktivität wird durch Membranassoziationen und } \\
\text { anionische Phospholipide stimuliert; spielt eine Rolle bei der Lokalisierung } \\
\text { von Ypt7p auf der Vakuolarmembran; ist erforderlich für Autophagie, für } \\
\text { den CVT-Weg sowie für die Mitophagie }\end{array}$ \\
\hline CDC48 & $U B X 3, A T G 8$ & HRR25 & AAA ATPase; Beteiligung an der Makroautophagie \\
\hline ARL1 & & APM3, GET3 & $\begin{array}{l}\text { Beteiligt an der „stress“ induzierten Autophagie (z. B. hohe Temp.); } \\
\text { lösliche GTPase mit Beteiligung an der Regulation des Membrantransports }\end{array}$ \\
\hline VPS21 & ATG8, & ATG8, APM3 & $\begin{array}{l}\text { Endosomale Rab-Familie GTPase; erforderlich für den endozytischen } \\
\text { Transport und die Sortierung von vakuolären Hydrolasen; beteiligt an } \\
\text { Autophagie- und Ionenstresstoleranz }\end{array}$ \\
\hline SEC17 & ATG8 & HRR25 & $\begin{array}{l}\text { Alpha-SNAP-Cochaperon; peripheres Membranprotein, das für den } \\
\text { vesikulären Transport zwischen ER und Golgi, den "Priming"-Schritt bei } \\
\text { der homotypischen Vakuolenfusion und der Autophagie erforderlich ist }\end{array}$ \\
\hline
\end{tabular}


Anhand der vorangegangenen Tabellen wird deutlich, dass eine Vielzahl an komplexen Verknüpfungen und Parallelen zwischen einigen Treffern existieren.

Die Tabelle 21 zeigt, dass fünf Untereinheiten des Coatomers mehr als einmal eine Rolle als Interakteure der Trefferproteine spielen. Es handelt sich dabei um Untereinheiten des delta-, zeta-, gamma-, beta- und beta'-COP.

Aus Tabelle 22 geht hervor, dass die Interakteure, die eine Beziehung der finalen Treffer zur Autophagie herstellen, teilweise aus den gleichen Proteinfamilien stammen. Es kommen bspw. mehrere Vertreter der Bet-Gruppe, der Bromodomänen und extraterminalen Domänen vor. Dies ist durch das Vorhandensein von zwei TandemBromodomänen und einer extra-terminalen Domäne gekennzeichnet (Taniguchi 2016). Auch die Gruppen der Autophagie-verwandten-Proteine (Atg) sowie die der GTPbindenden-Proteine sind mehrfach vertreten. Zwei weitere Interakteure sind Mitglieder der vakuolären ATPase-Assemblierung (Vma). Außerdem konnten drei Vertreter des sogenannten „Transport-Protein-Partikel-Komplexes“ (Trs) ermittelt werden.

Vor allem der Bezug zur Autophagie ist deutlich erkennbar. Es lässt sich daher annehmen, dass eine Delation der $\mu$-Homologie-Domäne auch Auswirkungen auf die autophagischen Prozesse innerhalb der eukaryontischen Zelle besitzt.

Eine mögliche Hypothese wäre z. B., dass ER-Proteine oder zirkulierende Proteine, welche bedingt durch die Delation im Knockout-Stamm nicht mehr korrekt gefaltet werden, abgeschnürt werden und der Prozess der Autophagie induziert wird.

Betrachtet man bspw. Atg8, so ist es in der Auswertung der Mikroskopiebilder im Knockout-Stamm punktförmiger verteilt als in der isogenetischen Kontrolle. Eine mögliche Interpretation dieser Veränderung wäre, dass die neue Lokalisation Strukturen im Zytosol zeigen, welche nun Autophagie betreiben.

Möchte man diese These weiterverfolgen, so ließe sich die Vermutung aufstellen, dass Proteine, welche eher luminal bzw. im Bereich der Membran lokalisiert sind (wie z. B. Jem1 und Mpd1) durch die Delation der $\mu$-Homologie-Domäne stabilisiert werden und somit weniger der Autophagie zugeführt werden. In Folge dessen käme es zu einer Akkumulation der betroffenen Proteine. Dies würde die stärker ausgeprägte Bande der Knockout-Stämme mit Jem1 und Mpd1 in dem Western Blot mit anti-GFP-Antikörper erklären (siehe Abbildung 15).

Eine weitere Annahme wäre, dass Proteine, welche auf zytoplasmatischer Seite lokalisiert (z. B. Ubx3 und Get3) und Ubiquitin-regulations-abhängig sind, autophagisch abgebaut werden. 
Nachfolgend werden die Interaktionen der finalen Treffer untereinander noch einmal anschaulich visualisiert. Weiterhin werden die korrespondieren Koregulatoren mit in die Abbildung aufgenommen. Teilweise kommt es bei diesen zu Übereinstimmungen; es gilt dabei allerdings zu beachten, dass es sich um recht generelle Transkriptionsregulatoren handelt. 


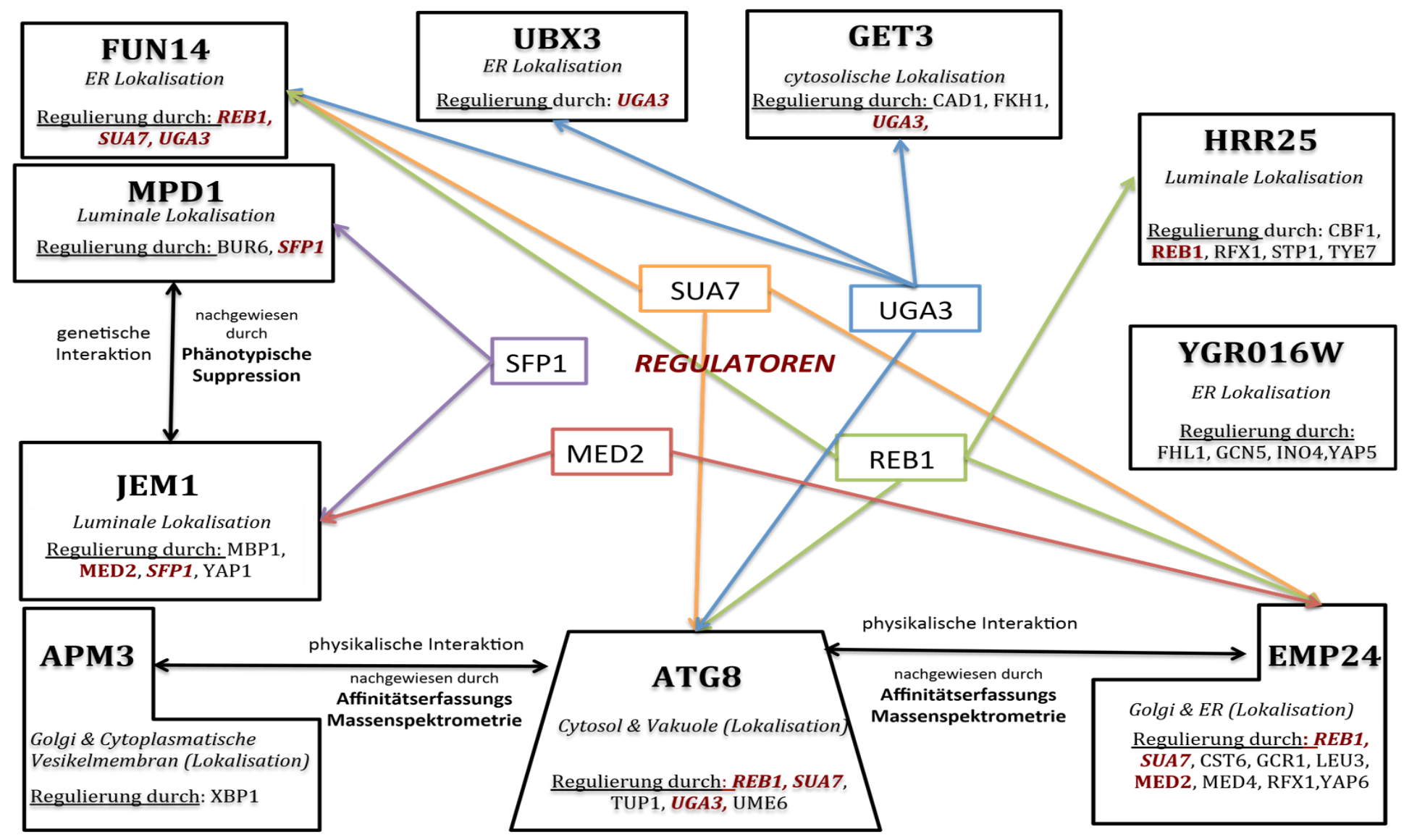

Abbildung 17: Finale Treffer und die Koregulation durch Transkriptionsregulatoren; 


\section{$5 \quad$ Zusammenfassung}

Im Rahmen dieser Arbeit konnte die Rolle des essentiellen COPI-Hüllvesikelproteins näher betrachtet werden. Seine Funktion besteht primär im retrograden Transport innerhalb der eukaryontischen Zelle vom Golgi-Apparat zum ER. Das Hüllvesikelprotein besteht aus sieben Untereinheiten: alpha-, beta-, beta'-, gamma-, delta-, epsilon- und zeta-COP.

Bestehende Studien zeigten die Entbehrlichkeit der $\mu$-Homologie-Domäne, welche Bestandteil von delta-COP ist. Die erzielten Ergebnisse im Modellorganismus S. cerevisiae stützen diese Annahme ebenfalls und liefern erste Einblicke in die Folgen der Delation der $\mu$-Homologie-Domäne.

Als Grundlage für die Forschungsarbeiten im Rahmen dieser Dissertation wurden durch Transformation zunächst zwei vergleichbare Hefestämme erzeugt. Die entwickelten Stämme Ret2Clonat und Ret2LD2 $\alpha$ glichen sich in Bezug auf die Resistenz gegen Clonat und den HIS-Tag. Einzig die Länge von RET2 variierte bei den beiden Stämmen. Bei RET2 handelt es sich um das delta-COP-Analoga im Hefezellorganismus. Bei Ret2LD2 $\alpha-$ dem Knockout-Stamm - liegt aufgrund der Delation der $\mu$-Homologie-Domäne ein verkürztes RET2-Gen vor. Ret2Clonat - d.h. die isogenetische Kontrolle - besitzt hingegen die vollständige RET2-Sequenz.

Bei der Konstruktion der Stämme wurden mehrere Transformationen parallel realisiert (vier Knockout-Stämme 1A-1D und drei isogenetische Kontrollen 2A-2C). Die jeweils korrekte Nukleotid-Abfolge des delta-COPs wurde mit Hilfe einer DNA-Sequenzierung belegt. Die Auswahl der Ausgangsstämme für das geplante SGA aus den konstruierten Stämmen erfolgte anhand von Western Blots, Wachstums-Analysen und der DNASequenzierung der genomischen DNA.

Die Auswertung der angefertigten Wachstums-Analysen warf Fragen bezüglich der Hitzeresistenz der Knockout-Stämme auf. In bereits bestehenden Studien konnte ein Überleben von Ret2LD2 $\alpha$ auch bei Temperaturen bis $39{ }^{\circ} \mathrm{C}$ Celsius gezeigt werden. Im Rahmen dieser Arbeit gelang es allerdings nicht, ein Wachstum der Knockout-Stämme 1A$1 \mathrm{D}$ bei Temperaturen über $30^{\circ} \mathrm{C}$ zu realisieren. Selbst die Überexpression des RET2-Gens und eine Veränderung des Wachstumsmediums führten zu keiner Verbesserung der Hitzeresistenz. Folglich muss von einer, während der Stamm-Konstruktion entstandenen, irreversiblen Modifikation im Genom dieses Stammes ausgegangen werden.

Für das geplante SGA wurde eine Teilkollektion von fünf Platten der Bibliothek, die insgesamt 16 Platten mit 384 Proteinen umfasst, gewählt. So umfassten die folgenden Versuche Platte eins bis vier, sowie Platte 16. Das gesamte SGA erfolgte für Ret2LD2 $\alpha$ und die Kontrolle Ret2Clonat parallel. 
Die fünf fertigen Platten wurden mit Hilfe von „High Throughput“-FluoreszenzMikroskopie untersucht. Nach dem ersten Mikroskopie-Durchlauf ergab sich eine Treffermenge von 54 Proteinen. Nach einem erneuten „High Throughput“-FluoreszenzMikroskopie-Durchlauf verringerte sich die Anzahl der vorläufigen Treffer auf zehn Proteine. Es handelt sich um phänotypische Veränderungen der log-Phase zwischen den folgenden mit Ret2LD2 $\alpha$ und Ret2Clonat gekreuzten Proteinen: Fun14, Ubx3, Get3, Ygr016w, Jem1, Apm3, Atg8, Eem24, Hrr25 und Mpd1.

Die erzielten Trefferproteine wurden hinsichtlich ihrer Funktion und Verknüpfungen zueinander untersucht. Auffällig war die bei nahezu allen Treffern auftretende indirekte oder sogar direkte Beteiligung an autophagischen Prozessen. Um die indirekte Beziehung näher zu erläutern, wurden die Interakteure der Trefferproteine, welche in Verbindung zur Autophagie standen, tabellarisch zusammengefasst. Bei der Betrachtung der Gesamtheit dieser Interakteure traten einige mehr als nur einmal auf - sie standen demzufolge mit mehreren Trefferproteinen in einer Beziehung. Aufgrund dessen wurden jene AutophagieInterakteure, die mindestens zweimal genannt wurden, in einer weiteren Tabelle aufgelistet. Dabei handelte es sich um Atg9, Atg13, Atg32, Atg4, Ypt1, Ypt6, Bet3, Bet5, Vma1, Vma21, Trs20, Trs23, Trs85, Rpd3, Mon1, Cdc48, Arl1, Vps21 sowie Sec17. Die Gruppen der Autophagie-verwandten-Proteine (Atg), die der GTP-bindenden-Proteine sowie die Proteinfamilie der Bromodomänen und extra-terminalen Domänen (Bet) sind somit mehrfach unter den Autophagie-Interakteuren anzutreffen. Zwei weitere Interakteure sind Mitglieder der vakuolären ATPase-Assemblierung (Vma). Zudem konnten drei Vertreter des „Transport-Protein-Partikel-Komplexes“ (Trs) ermittelt werden.

Die finalen Treffer wurden weiterhin bezüglich ihrer Verbindung zu COPI genauer untersucht. Hierbei wurden erneut alle mehrfach auftretenden Interakteure tabellarisch dargestellt; dieses Mal jene, die in Verbindung zu COPI stehen: Ret2, Ret3, Sec1, Sec26, Sec27, Rsp5, Mtc1 und Cop1. Es wurde gezeigt, dass fünf Untereinheiten des Coatomers mehr als einmal eine Rolle als Interakteure der Trefferproteine spielen. Es handelt sich hier um die Untereinheiten delta-, zeta-, gamma-, beta- und beta'-COP (Ret2, Ret3, Sec21, Sec26, Sec27). 


\section{$6 \quad$ Literaturverzeichnis}

\subsection{Beiträge in Sammelwerken, Handbüchern, Lehrbüchern, Monographien und Zeitschriftenbeiträgen}

Annaert W, De Strooper B (2002): A Cell Biological Perspective on Alzheimer's Disease. Annu Rev Cell Dev Biol 18, 25-51

Arakel EC, Richter KP, Clancy A, Schwappach B (2016): $\delta$-COP contains a helix C-terminal to its longin domain key to COPI dynamics and function. Proc Natl Acad Sci 113, 6916-6921

Bonizec M, Hérissant L, Pokrzywa W, Geng F, Wenzel S, Howard GC, Rodriguez P, Krause S, Tansey WP, Hoppe T, Dargemont C (2014): The ubiquitin-selective chaperone Cdc48/p97 associates with Ubx3 to modulate monoubiquitylation of histone H2B. Nucleic Acids Res $\underline{42}, 10975-10986$

Botstein D, Fink GR (2011): Yeast: An Experimental Organism for 21st Century Biology. Genetics $\underline{189}, 695-704$

Boujard D, Anselme B, Cullin C, Raguénès-Nicol C: Zell- und Molekularbiologie im Überblick. Springer Spektrum 2014

Buselmaier W: Zelluläre Strukturelemente; in: Biologie für Mediziner; hrsg. v. Buselmaier W; Springer Berlin Heidelberg, Berlin, Heidelberg 2012, 9-48

Chardin P, Paris S, Antonny B, Robineau S, Béraud-Dufour S, Jackson CL, Chabre M (1996): A human exchange factor for ARF contains Sec7- and pleckstrin-homology domains. Nature $\underline{384}, 481-484$

Cooper AA, Gitler AD, Cashikar A, Haynes CM, Hill KJ, Bhullar B, Liu K, Xu K, Strathearn KE, Liu F, et al. (2006): $\alpha$-Synuclein Blocks ER-Golgi Traffic and Rab1 Rescues Neuron Loss in Parkinson's Models. Science $\underline{313}, 324-328$

Deretic V, Levine B (2009): Autophagy, immunity, and microbial adaptations. Cell Host Microbe $\underline{5}$, $527-549$

Dodonova SO, Diestelkoetter-Bachert P, von Appen A, Hagen WJH, Beck R, Beck M, Wieland F, Briggs J a. G (2015): VESICULAR TRANSPORT. A structure of the COPI coat and the role of coat proteins in membrane vesicle assembly. Science $\underline{349}, 195-198$

Donaldson JG, Cassel D, Kahn RA, Klausner RD (1992): ADP-ribosylation factor, a small GTPbinding protein, is required for binding of the coatomer protein beta-COP to Golgi

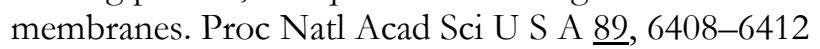

Franco M, Chardin P, Chabre M, Paris S (1996): Myristoylation-facilitated Binding of the G Protein ARF1 to Membrane Phospholipids Is Required for Its Activation by a Soluble Nucleotide Exchange Factor. J Biol Chem 271, 1573-1578

Gaynor EC, Graham TR, Emr SD (1998): COPI in ER/Golgi and intra-Golgi transport: do yeast COPI mutants point the way? Biochim Biophys Acta BBA - Mol Cell Res 1404, 33-51 
Giaever G, Chu AM, Ni L, Connelly C, Riles L, Véronneau S, Dow S, Lucau-Danila A, Anderson $\mathrm{K}$, André B, et al. (2002): Functional profiling of the Saccharomyces cerevisiae genome. Nature 418, 387-391

Gillingham AK, Munro S (2007): The small G proteins of the Arf family and their regulators. Annu Rev Cell Dev Biol 23, 579-611

Gozuacik D, Kimchi A (2004): Autophagy as a cell death and tumor suppressor mechanism. Oncogene 23, 2891-2906

Hara-Kuge S, Kuge O, Orci L, Amherdt M, Ravazzola M, Wieland FT, Rothman JE (1994): En bloc incorporation of coatomer subunits during the assembly of COP-coated vesicles. J Cell Biol $\underline{124}, 883-892$

Huh W-K, Falvo JV, Gerke LC, Carroll AS, Howson RW, Weissman JS, O'Shea EK (2003): Global analysis of protein localization in budding yeast. Nature $\underline{425}, 686-691$

Izumi K, Brett M, Nishi E, Drunat S, Tan E-S, Fujiki K, Lebon S, Cham B, Masuda K, Arakawa M, et al. (2016): ARCN1 Mutations Cause a Recognizable Craniofacial Syndrome Due to COPI-Mediated Transport Defects. Am J Hum Genet $\underline{99}$, 451-459

Johansen T, Lamark T (2011): Selective autophagy mediated by autophagic adapter proteins. Autophagy $\underline{7}, 279-296$

Khmelinskii A, Meurer M, Duishoev N, Delhomme N, Knop M (2011): Seamless Gene Tagging by Endonuclease-Driven Homologous Recombination. PLoS ONE $\underline{6}$

Kim J, Scott SV, Oda MN, Klionsky DJ (1997): Transport of a large oligomeric protein by the cytoplasm to vacuole protein targeting pathway. J Cell Biol $\underline{137}$, 609-618

Kirchhausen T (2000): Three ways to make a vesicle. Nat Rev Mol Cell Biol 1, 187-198

Knippschild U, Gocht A, Wolff S, Huber N, Löhler J, Stöter M (2005): The casein kinase 1 family: participation in multiple cellular processes in eukaryotes. Cell Signal 17, 675-689

Krauss M, Jia J-Y, Roux A, Beck R, Wieland FT, De Camilli P, Haucke V (2008): Arf1-GTPinduced Tubule Formation Suggests a Function of Arf Family Proteins in Curvature Acquisition at Sites of Vesicle Budding*. J Biol Chem 283, 27717-27723

Lechowski S: Zell- und Molekularbiologie im Überblick. Springer Spektrum, Berlin [u.a.] 2014

Levine B, Klionsky DJ (2004): Development by Self-Digestion: Molecular Mechanisms and Biological Functions of Autophagy. Dev Cell $\underline{6}, 463-477$

Liu Y, Kahn RA, Prestegard JH (2009): Structure and Membrane Interaction of Myristoylated ARF1. Struct Lond Engl 1993 17, 79-87

Lord C, Bhandari D, Menon S, Ghassemian M, Nycz D, Hay J, Ghosh P, Ferro-Novick S (2011): Sequential interactions with Sec23 control the direction of vesicle traffic. Nature $\underline{473}, 181$ 186

Lynch-Day MA, Klionsky DJ (2010): The Cvt pathway as a model for selective autophagy. FEBS Lett $\underline{584}, 1359-1366$

Malhotra V, Serafini T, Orci L, Shepherd JC, Rothman JE (1989): Purification of a novel class of coated vesicles mediating biosynthetic protein transport through the Golgi stack. Cell $\underline{58}$, $329-336$ 
Meurer M, Duan Y, Sass E, Kats I, Herbst K, Buchmuller BC, Dederer V, Huber F, Kirrmaier D, Stefl M, et al. (2017): A genome-wide resource for high-throughput genomic tagging of yeast ORFs. bioRxiv 226811

Mizushima N, Komatsu M (2011): Autophagy: renovation of cells and tissues. Cell 147, 728-741

Nakagawa I, Amano A, Mizushima N, Yamamoto A, Yamaguchi H, Kamimoto T, Nara A, Funao J, Nakata M, Tsuda K, et al. (2004): Autophagy defends cells against invading group A Streptococcus. Science 306, 1037-1040

Nishikawa S, Endo T (1997): The Yeast JEM1p Is a DnaJ-like Protein of the Endoplasmic Reticulum Membrane Required for Nuclear Fusion. J Biol Chem 272, 12889-12892

Okamura K, Kimata Y, Higashio H, Tsuru A, Kohno K (2000): Dissociation of Kar2p/BiP from an ER Sensory Molecule, Ire1p, Triggers the Unfolded Protein Response in Yeast. Biochem Biophys Res Commun $\underline{279}$, 445-450

Palade G (1975): Intracellular aspects of the process of protein synthesis. Science $\underline{189}$, 347-358

Palmer DJ, Helms JB, Beckers CJ, Orci L, Rothman JE (1993): Binding of coatomer to Golgi membranes requires ADP-ribosylation factor. J Biol Chem 268, 12083-12089

Robinson MS (2004): Adaptable adaptors for coated vesicles. Trends Cell Biol 14, 167-174

Romisch K (1999): Surfing the Sec61 channel: bidirectional protein translocation across the ER membrane. J Cell Sci 112, 4185-4191

Schuldiner M, Metz J, Schmid V, Denic V, Rakwalska M, Schmitt HD, Schwappach B, Weissman JS (2008): The GET Complex Mediates Insertion of Tail-Anchored Proteins into the ER Membrane. Cell $\underline{134}$, 634-645

Scott SV, Guan J, Hutchins MU, Kim J, Klionsky DJ (2001): Cvt19 is a receptor for the cytoplasmto-vacuole targeting pathway. Mol Cell , 1131-1141

Sherman F: Getting started with yeast; in: Methods in Enzymology, Band 350; hrsg. v. Guthrie C, Fink GR; Academic Press 2002, 3-41

Shintani T, Huang W-P, Stromhaug PE, Klionsky DJ (2002): Mechanism of Cargo Selection in the Cytoplasm to Vacuole Targeting Pathway. Dev Cell $\underline{3}, 825-837$

Springer S, Spang A, Schekman R (1999): A Primer on Vesicle Budding. Cell 7ㅜ, 145-148

Sun Z-W, Allis CD (2002): Ubiquitination of histone H2B regulates H3 methylation and gene silencing in yeast. Nature $\underline{418}, 104-108$

Tanaka C, Tan L-J, Mochida K, Kirisako H, Koizumi M, Asai E, Sakoh-Nakatogawa M, Ohsumi Y, Nakatogawa H (2014): Hrr25 triggers selective autophagy-related pathways by phosphorylating receptor proteins. J Cell Biol 207, 91-105

Taniguchi Y (2016): The Bromodomain and Extra-Terminal Domain (BET) Family: Functional Anatomy of BET Paralogous Proteins. Int J Mol Sci $\underline{17}$

Tarassov K, Messier V, Landry CR, Radinovic S, Serna Molina MM, Shames I, Malitskaya Y, Vogel J, Bussey H, Michnick SW (2008): An in vivo map of the yeast protein interactome. Science $\underline{320}, 1465-1470$

Waters MG, Serafini T, Rothman JE (1991): „Coatomer“: a cytosolic protein complex containing subunits of non-clathrin-coated Golgi transport vesicles. Nature $\underline{349}, 248$ 
Watkin LB, Jessen B, Wiszniewski W, Vece T, Jan M, Sha Y, Thamsen M, Santos-Cortez RLP, Lee K, Gambin T, et al. (2015): COPA mutations impair ER-Golgi transport causing hereditary autoimmune-mediated lung disease and arthritis. Nat Genet $\underline{47}$, 654-660

Weidberg H, Shvets E, Elazar Z (2011): Biogenesis and cargo selectivity of autophagosomes. Annu Rev Biochem 으, 125-156

Wickner W, Schekman R (2005): Protein Translocation Across Biological Membranes. Science $\underline{310}$, 1452-1456

Xu X, Kedlaya R, Higuchi H, Ikeda S, Justice MJ, Setaluri V, Ikeda A (2010): Mutation in Archain 1, a Subunit of COPI Coatomer Complex, Causes Diluted Coat Color and Purkinje Cell Degeneration. PLOS Genet $\underline{6}$, e1000956

Yofe I, Weill U, Meurer M, Chuartzman S, Zalckvar E, Goldman O, Ben-Dor S, Schütze C, Wiedemann N, Knop M, et al. (2016): One library to make them all: Streamlining yeast library creation by a SWAp-Tag (SWAT) strategy. Nat Methods $\underline{13}$, 371-378

Yuga M, Gomi K, Klionsky DJ, Shintani T (2011): Aspartyl aminopeptidase is imported from the cytoplasm to the vacuole by selective autophagy in Saccharomyces cerevisiae. J Biol Chem 286, 13704-13713

\subsection{Internetquellen}

APM3 | SGD. https://www.yeastgenome.org/locus/S000000492; Zugriff am 06.03.2019

JEM1 | SGD. https://www.yeastgenome.org/locus/S000003609\#reference; Zugriff am 06.03.2019

KAR2 | SGD. https://www.yeastgenome.org/locus/S000003571; Zugriff am 06.03.2019

Molekularbiologische Methoden 2.0 - 9783838587424. https://www-1utb-2studi-2e-2book-1de18dwondw9b9ff.han.sub.unigoettingen.de $/$ Viewer2.0/pdfviewer $/$ index $/$ viewer?isbn $=9783838587424 \&$ access $=24 \mathrm{e} 10 \mathrm{ba}$ 3147 cbe43eb7b16ee5d09acff\&code $=$ cf857da2a8b6723b496fd4176c3b09e7\&q=\&lang $=$ de \&key $=$ \&page $=\&$ label $=$ A\&prodId $=2460 \&$ hash $=$ a29e95900351e0a076fe3b2e8e68f3b0\&tok en $=$ a29e95900351e0a076fe3b2e8e68f3b0\&timestamp $=$ cf857da2a8b6723b496fd4176c3b09 e7; Zugriff am 03.06.2019

Official REBASE Homepage | The Restriction Enzyme Database | NEB. http://rebase.neb.com/rebase/; Zugriff am 14.02.2019

Saccharomyces Genome Database | SGD. https://www.yeastgenome.org/; Zugriff am 06.03.2019

Tokunaga M, et al. (1992) | SGD. https://www.yeastgenome.org/reference/S000055090; Zugriff am 06.03.2019

YGR016W | SGD. https://www.yeastgenome.org/locus/S000003248; Zugriff am 06.03.2019 


\section{Danksagung}

An erster Stelle möchte ich gerne Prof. Dr. Blanche Schwappach und Dr. Eric Arakel von ganzem Herzen danken. Gemeinsam sind Sie ein echtes „Betreuungs-Dream-Team“, sie ergänzten sich perfekt und arbeiteten stets in dieselbe Richtung. Daraus resultierte eine Rundum-Sorglos Betreuung für mich.

Blanche unterstütze mich stets, von der Themenfindung über die Planung und Durchführung der Experimente bis hin zur Niederschrift und Korrektur dieser Dissertation. Sie ist eine großartige Doktormutter, die stets ein offenes Ohr hatte und sich jedem meiner Probleme angenommen hat. Durch ihre sympathische und einfühlsame Art hat Sie es geschafft ein durchweg motiviertes und engagiertes Team aufzubauen. Als Teil ihrer Arbeitsgruppe kann man sich somit nur wohl fühlen.

Einen Betreuer wie Eric würde ich jedem Promovierenden wünschen. Er hat immer ein freundliches Wort auf den Lippen, erklärt mit engelsgleicher Geduld jeden Versuchsaufbau bis ins kleinste Detail, ist jederzeit für Fragen offen und beantwortet diese äußerst ausführlich und leicht verständlich.

Weiterhin möchte ich gerne Arkos, Anne, Ariane und der gesamten Arbeitsgruppe danken. Sie begleiteten mich im täglichen Prozess der Experimente, halfen und unterstützen mich wo sie nur konnten. Ihre Zuarbeit, Betreuung und Unterstützung trugen in großem Maße zum Gelingen dieser Arbeit bei. 